\title{
The Relative Effects of Institutions on Ownership in Acquisitions
}

BY

\section{Camille Cochrane}

Supervisor: Prof. Siah Hwee Ang

\begin{abstract}
A thesis
submitted to the Victoria University of Wellington in fulfillment of the requirements for the degree of Master of Commerce.
\end{abstract}

Victoria University of Wellington

School of Marketing and International Business

October 2017 


\begin{abstract}
Purpose - Globalization has increased competition to an international level. However, limited market experience causes uncertainty, affecting how firms strategize their entry. Institutional distance can be a dominant cause of such environmental uncertainty. The institutional environment incorporates three institutional pillars; the regulatory pillar, the normative pillar and the cognitive pillar. Institutions are shaped by culture and desires to protect domestic business, meaning institutions differ between countries. This is known as institutional distance. There is, however, a research gap concerning the relative influence of institutional pillars on cross-border acquisition ownership, when institutional distance is present. This thesis seeks to research the influential effect of all three institutional pillars on acquisition ownership, when firms are faced with institutional distance.
\end{abstract}

Theory - Institutional theory was the fundamental theory used in this research, applying the sociology perspective of Scott (1995). Firstly, investigations were conducted on individual pillars to see how each pillar influenced acquisition ownership. Secondly, individual pillar findings were then combined and compared, to illustrate their relative influence on acquisition ownership. Such simultaneous acknowledgement of all three institutional pillars, provided new insight on the relative effects of institutions on acquisition ownership.

Methodology - This study implemented a single method approach, using quantitative analysis. Archival data was gathered focusing on firms from three industries in eleven selected countries who conduct cross-border acquisitions (CBAs). CBAs were chosen due to their popular use as a research construct in imitation research. Cognitive distance, normative distance and regulatory distance were then used to measure institutional distance. Cognitive distance effects were measured using frequency based imitation. Normative distance was measured using two of Hofstede's (1980) cultural value dimensions: uncertainty avoidance and collectivism. Regulatory distance was measured using World Bank Governance Indicators. Thus, it was important to strategically choose home countries to ensure a variety of dimension and indicator values with which to conduct a reliable study. Logistic regression, conducted with STATA, was then used to analyze relationships between institutions and acquisition ownership. 
Key Findings - The findings illustrate that all three institutional pillars have an influential effect on acquisition ownership decisions. This reinforces the emerging belief, that studies must include all three institutional pillars in research. This finding adds to this scant research. Analyzing the comprehensive institutional environment produces more reliable results.

The findings suggest that institutional pillars form an institutional hierarchy when institutional distance exists between the home and host countries. Regulatory distance have the strongest influence on acquisition ownership. Severe regulatory sanctions threaten illegitimate behaviours, forcing foreign entrants to prioritize compliance to regulatory institutions. Normative distance has the second strongest impact on acquisition ownership. Its tacit nature camouflages dysfunctional cultural complexities that disrupt strategy implementation, which can cause a firm to relocate. Lastly, cognitive distance has the third strongest influence on acquisition ownership. Its lack of severe repercussions facilitates the prioritization of the previous two pillars. However, cognitive distance acknowledgement is important as it illustrates how host participants interpret stimuli from their environment, which informs foreign entrants of appropriate cross-national responsive behaviour.

Contributions - This study contributes to international business research by illustrating the hierarchical formation of the influence of institutional pillars on cross-border acquisition ownership, where institutional distance is present. This contribution has managerial implications. Managers are strongly encouraged to consider all of regulatory pillar, normative pillar and cognitive pillar when venturing abroad. Further, managers must acknowledge the institutional pillar hierarchy and prioritize responses accordingly, to avoid crippling outcomes that could lead to poor acquisition outcomes. Lastly, this thesis contributes to literature by highlighting the need to include collectivism as a research construct in ownership studies. Prior studies have narrowly focused on uncertainty avoidance and power distance. However, collectivism has been observed to influence ownership, likely due to the recent rise of Asia in international business.

Keywords: Institutional distance, Ownership, Cross-border Acquisitions. 


\section{Dedication}

I dedicate this thesis to my mother, Sabine, my father, Steve, and my brother Tom. Thank you for your unconditional love and support throughout my master's journey.

I also dedicate this thesis to the family I lost during my university journey.

Grandad, Grandma and Grand-mère I promised to forever make you proud.

Lastly, I dedicate my thesis to those who have faced distressing circumstances and managed to regain strength, use their wings and continue to fly high, reaching for the stars in whatever they do. 


\section{Acknowledgements}

I would like to thank Professor Siah Hwee Ang for his incredible support, patience and encouragement. Thank you for facilitating my master's journey and believing in me.

Moreover, I would like to thank Katrina Walsh for being the copy editor for my thesis. Thank you so much for taking the time to help me perfect my work.

I would also like to acknowledge the staff at the School of Marketing and International Business who helped make my master's journey attainable. Thank you for providing a supportive environment full of enthusiasm that gave me the self-confidence to proceed with such an endeavor. 


\section{Table of Contents}

Chapter 1. Introduction ................................................................................................................8

1.1 Background and Rationale for the Study .............................................................................. 8

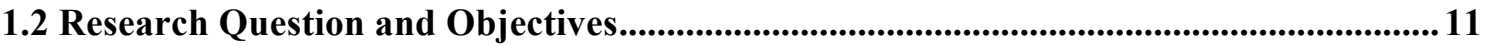

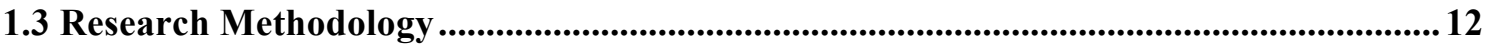

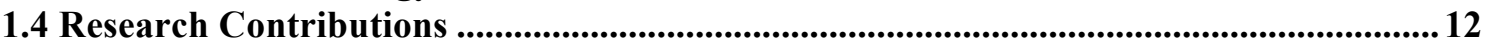

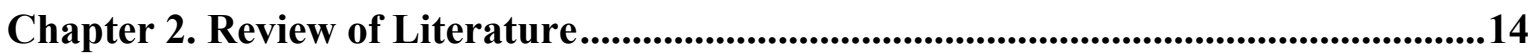

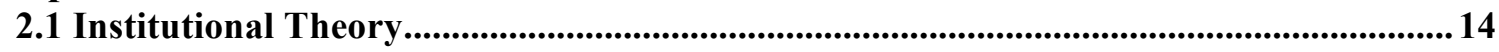

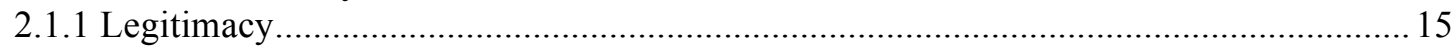

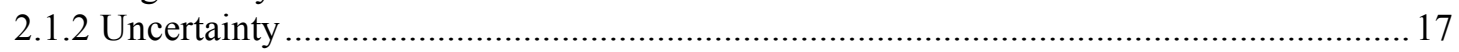

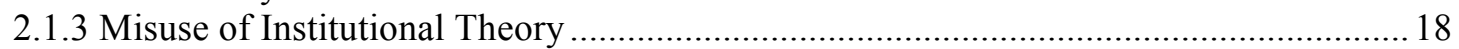

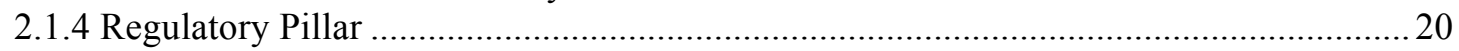

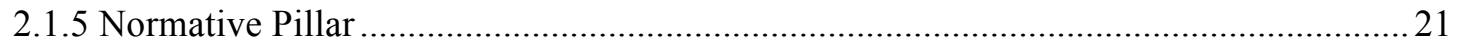

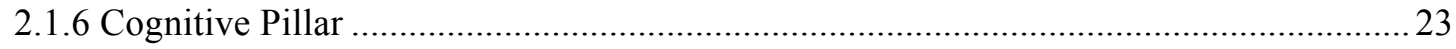

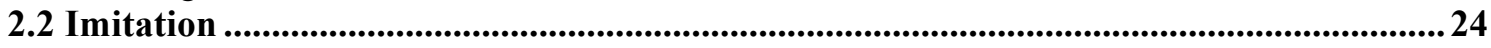

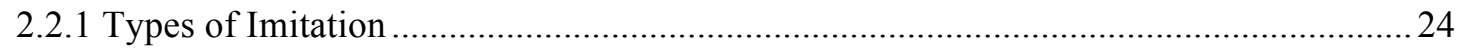

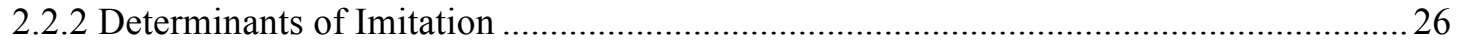

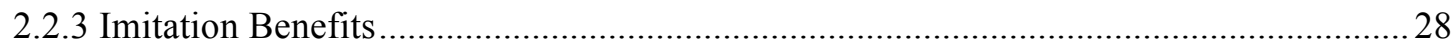

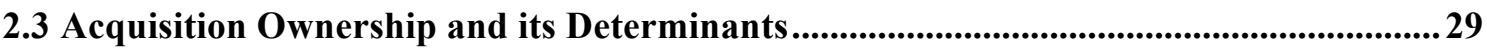

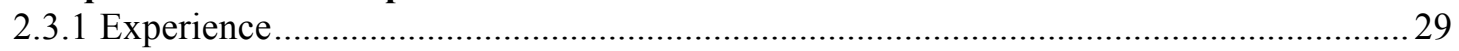

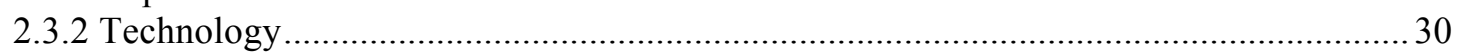

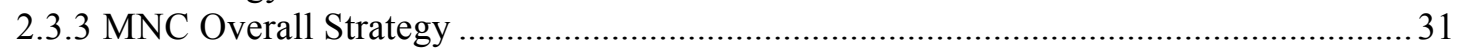

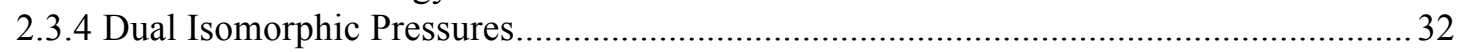

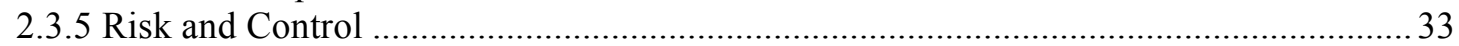

Chapter 3. Hypotheses Development ......................................................................36

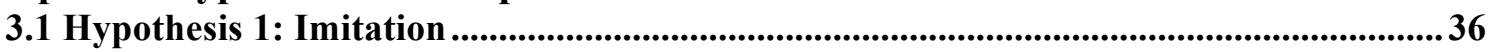

3.2 Hypothesis 2: Uncertainty Avoidance .................................................................................37

3.3 Hypothesis 3: Collectivism .................................................................................................39

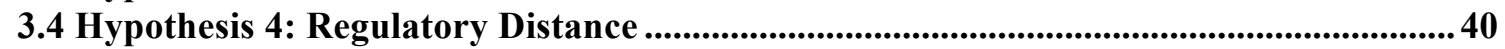

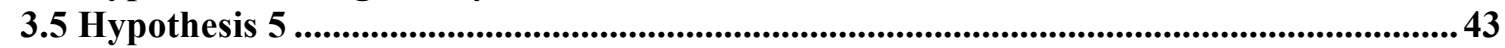

Chapter 4. Data and Methodology ….............................................................................................45

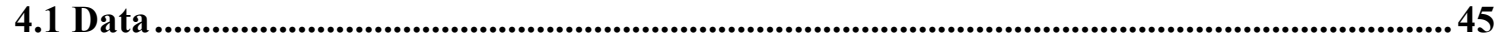

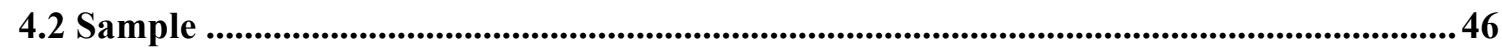

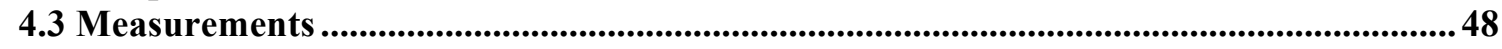

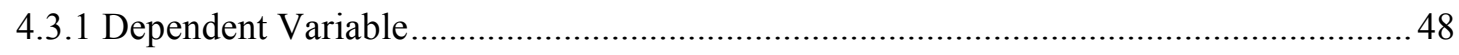

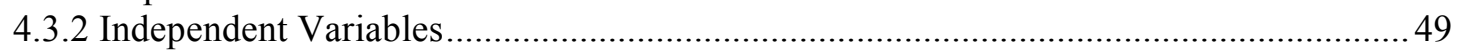

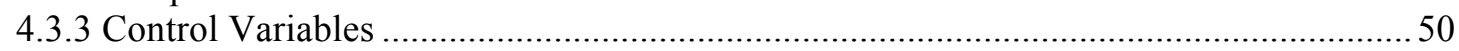

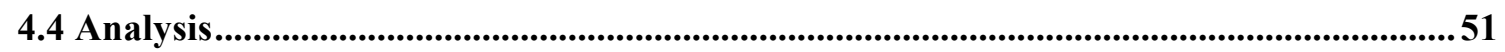

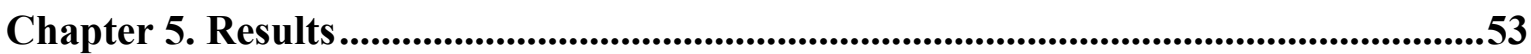

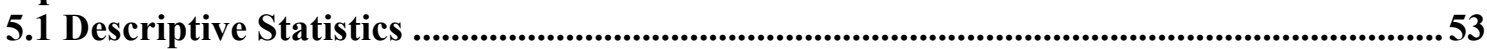

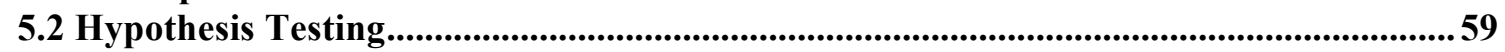

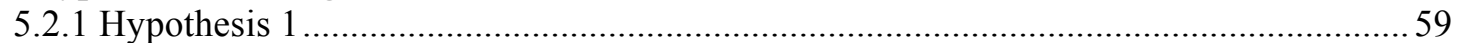

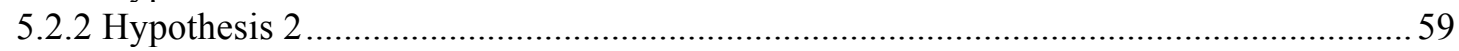

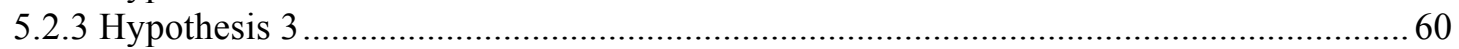

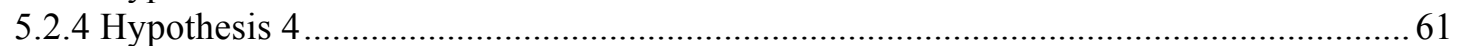

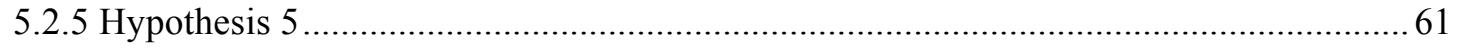

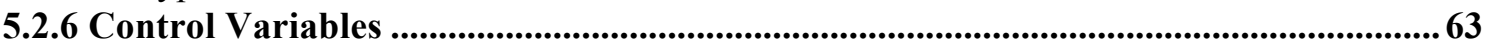

Chapter 6. Discussions and Conclusions................................................................65

6.1 Discussion of Results of Hypothesis Testing .................................................................................65

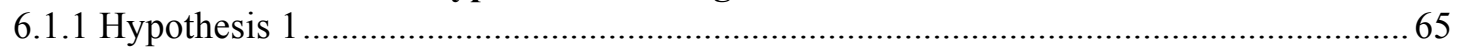

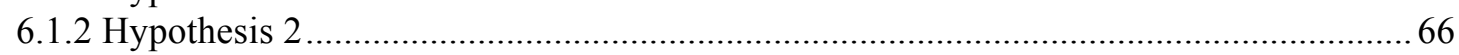




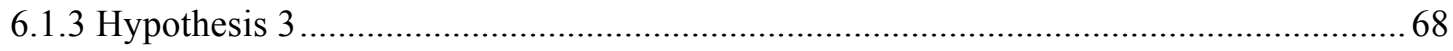

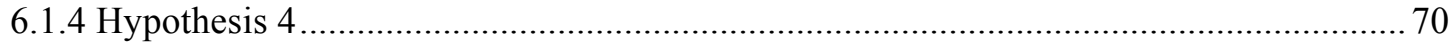

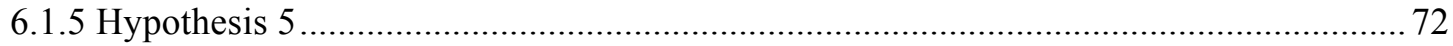

6.2 Conclusions ........................................................................................................................... 74

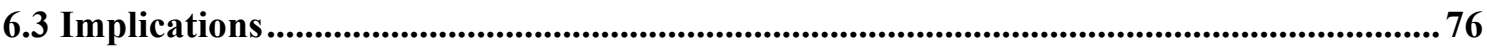

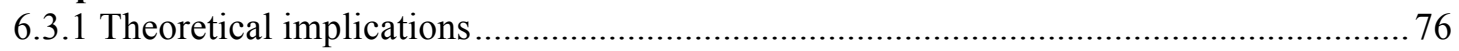

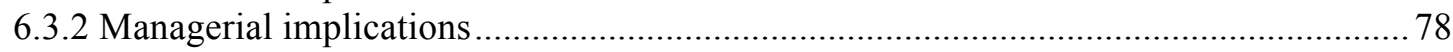

6.4 Limitations and Suggestions for Future Research ................................................................. 79

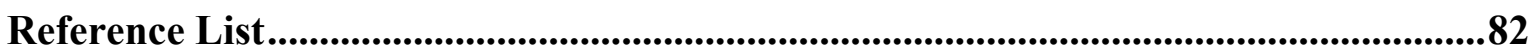




\section{Chapter 1. Introduction}

\subsection{Background and Rationale for the Study}

Globalization has increased competition to an international level. However, limited experience causes international environment uncertainty, affecting how firms strategize their market entry. This thesis is primarily concerned with the imitation of cross-border acquisition ownership.

This study investigates the relative influence of institutional pillars on acquisition ownership. Institutional theory consists of three pillars; the cognitive pillar, the normative pillar and the regulatory pillar. Each pillar consists of uniquely formed institutions that coerce foreign entrants to adjust host market behaviours. In return, foreign entrants gain host market acceptance, in the form of legitimacy. The pillars have both separate and interactive effects. However, a large portion of literature states that institutional theory has been misused when it comes to explaining imitation. This may have occurred due to the relatively recent introduction of institutional theory to the strategy tripod (Peng, 2003). However, a great deal of strategy research focuses solely on one pillar - the cognitive pillar. This limits the value and applicability of such research (Chuang, Church, \& Ophir, 2011). It has also caused imitators to become stereotyped, portrayed as firms simply following each other. Ang, Benishke, and Doh (2015) identified the importance of including all three pillars in imitation research because cognitive, regulative and normative pillars interact with each other. Therefore, it is possible that firms do indeed acknowledge all three institutional pillars and do not simply follow each other. Consequently, current research fails to acknowledge the comprehensive institutional environment, limiting our knowledge of imitation behaviour. Further research is required to investigate the interplay and relative influence of all three institutional pillars on imitation behaviour. Cross-border acquisitions (CBAs) are commonly used in imitation research. The suitability of this entry-mode is based on its prevalence as an international entry mode and its increasing use as an imitation model (Moatti, 2009). Importantly, CBAs are not conceived in isolation, their surroundings also play a role (Lin, Peng, Yang, \& Sun, 2009). Therefore, CBAs are the focus form of entry mode for this research. 
This study assesses the relative influence of institutional theory's cognitive, normative and regulatory pillars on CBA ownership to understand imitation behavior around CBA.

The cognitive pillar will be used as the base model. This pillar will represent the common ownership practice in the host environment, and foreign entrant followership will be identified as imitation. The normative pillar will depict cultural distance to identify whether firms acknowledge cultural differences or simply follow each other. This pillar is embodied in national culture and is commonly interpreted as cultural difference (Gollnhofer \& Turkina, 2015). Furthermore, previous studies have indicated cultural distance affects acquisition formulation in new markets (Collins, Holcomb, Certo, Hitt, \& Lester, 2009). Two of Hofstede's (1980) national culture value dimensions are chosen for this study. The inclusion of only two national culture value dimensions allowed a large coverage of different home and host countries, due to data collection efficiency. It also kept the quantity of data to a manageable size. Uncertainty avoidance illustrates how cultures cope with the unknown future (Hofstede, 2001). Imitation overcomes international expansion uncertainty in two ways; by signaling local institution obedience for local legitimacy attainment (Ang et al., 2015; DiMaggio \& Powell, 1983), and by achieving better outcome certainty. Moreover, collectivism involves strong in-groups founded on loyalty (Hofstede \& Bond, 1984). Literature states that networks facilitate imitation, as they provide trustworthy knowledge sources for insufficient experience. Lastly, regulatory distance can cause severe consequences for firms who fail to meet diverse expectations. Differences in regulatory institutions require foreign entrants to make strategy adaptations. This, in turn, encourages firms to be aware of regulatory institutions in the host country in order to avoid unwanted consequences. In this case, firms do not simply follow each other, they proactively acknowledge government imposed rules.

Previous literature has failed to recognize the importance of institutional context (Lin et al., 2009). This has been detrimental to earlier imitation research, as acquisitions are not conceived in isolation (Lin et al., 2009). Also, inexperienced firms lack the ability to conduct assessments when embarking on international expansion, so understanding imitation contexts is important (Lu, 2002). Evidently, context influences entry-mode decision making and must be acknowledged. This gap is driven by the traditional economic-focused imitation literature. Economic perspectives were originally applied to entry mode imitation (Xia, Tan, \& Tan, 2008; Yang \& Hyland, 2012; Yang \& Hyland, 2006). Imitation created cost saving 
benefits and strategically positioned a firm to successfully obtain host market legitimacy and survive long term, based on transaction cost theory (Brouthers, 2013). However, some researchers now see this narrow economic view as limiting international business research and acknowledge the importance of sociology (Shenkar, 2012). Consequently, research is progressing from traditional perspectives, to specifically resolve gaps in international entry mode strategy, national culture and institutional theory (Davis, Desia, \& Francis, 2000; Ferreira, Santos, de Almeida, \& Reis, 2014; Li, Yang \& Yue, 2007). Yet, gaps remain present in recent attempts to improve such research areas. Specifically, acquisition ownership literature incorporates institutional theory by using one or two institutional pillars as research constructs. Evidently, the lack of comprehensive pillar inclusion reduces research reliability. This thesis seeks to contribute to an overlooked academic area, to specifically identify the relative importance of institutions when firms formulate CBA ownership strategies in new markets.

International expansion poses significant risks for new entrants. The pressure on MNEs to efficiently enter and ensure long term survival, is immense (Tan, 2009). Therefore, it is critical to understand how institutions influence ownership strategies, as institutions are ever present and can cause significant risk in foreign markets. Institutional interplay will offer comprehensive insights into how firms can successfully enter institutionally distant markets. Such insight will permit strategies to be uniquely crafted in order to adequately respond to forecasted institutional differences. This will facilitate comprehension about how to enter institutionally distant markets and ensure long term survival.

Furthermore, the recent popularity of the institution-based view in international business strategy cannot be overlooked (Brouthers, 2013). Institutional theory portrays distinguishable differences between home and host countries, identifying context as influencer of entry mode decisions (Ferreira et al., 2014; Hoffman, 1999). This new-found capacity portrays that more entry mode studies are needed (Hennart \& Slangen, 2015). A criticism of both the industry and resource-based views in international strategy is that they fail to incorporate context (Peng, Wang, \& Jiang, 2008; Peng, Sun, Pinkham, \& Chen, 2009). Moreover, acknowledgement of specific national cultural value dimensions that influence entry mode imitation is also a literature gap. $\mathrm{Lu}$ (2002) stated that national culture could have influenced imitation practice in their study, but was not analyzed. Current research fails to identify the home and host national culture context in which isomorphism is used 
(Salomon \& Wu, 2012). This gap is important, as imitation is ingrained in certain cultures (Lai \& Zaichkowsky, 1999; Xie \& White, 2006). Therefore, cultural value dimensions may indeed influence imitation attitudes, and shape global competitive environments.

Moreover, the use of institutional theory to explain imitation has often been misleading. The cognitive pillar is commonly employed in strategy research to label imitation (Chuang, Church, \& Ophir, 2011). However, excluding the effects of institution interplay on CBA ownership is deceiving (Mizruchi \& Fein, 1999). Previous literature has failed to explain acquisition ownership within the complexity of institutional contexts. Ownership literature focuses heavily on regulatory distance, institutional distance or simplistically formal and informal institutions, without specifically recognizing the integrated relationship and variation of relative importance between all three institutional pillars (Liou, Chao, \& Ellstrand, 2017; Liou, Chao, \& Yang, 2016). Such a perspective weakens the application of institutional theory (Hirsch, 1997). Gaur, Delios and Singh (2007) state that when pillars are simultaneously analysed, institutional distance depictions are more comprehensive. Also, MNCs are unlikely to acknowledge only one institutional pillar when venturing abroad (Ang et al., 2015). Therefore, a research gap surrounds the application of all three institutional pillars and their relative influence on acquisition ownership.

In conclusion, the focal research components of this study will be institutional theory, CBA ownership, cultural distance and regulatory distance. Neglect of the complex pillar interplay in acquisition ownership studies, limits current research. Consequently, the cognitive pillar, regulatory pillar and normative pillar will be under joint investigation. This will offer insight into comprehensive entry mode imitation and foster understanding about CBA ownership decisions.

\subsection{Research Question and Objectives}

The key question of this study is: How do cognitive, normative and regulatory institutions relatively influence cross-border acquisition ownership levels?

The following research objectives are used to answer this research question.

H1. There is a positive relationship between full acquisitions conducted by other firms in a host country and a focal firm's adoption of full acquisitions in the host country. 
H2. There is a positive relationship between uncertainty avoidance distance between host and home country and a focal firm's adoption of full acquisitions in the host country.

H3. There is a negative relationship between collectivism distance between host and home country and a focal firm's adoption of full acquisitions in the host country.

H4. There is a positive relationship between regulatory distance between host and home country and a focal firm's adoption of full acquisitions in the host country.

H5. The effect of regulatory and normative distance on a focal firm's adoption of full acquisitions in a host country is stronger than the effect of full acquisitions conducted by other firms in the host country, on a focal firm's adoption of full acquisitions in the host country.

\subsection{Research Methodology}

This study uses a single method approach, quantitative analysis. Archival data is sourced from the databases COMPUSTAT and SDC Platinum, commonly used for acquisition research, and Worldwide Governance Indicators (WGI) commonly used in regulatory distance research (Ang et al., 2015; Beckman \& Haunschild, 2002; Collins et al., 2009 Haunschild \& Miner, 1997; Westphal, Seidel, \& Stewart, 2001). Archival data permits efficient data collection, possession of cross-cultural data facilitating country comparisons, longitudinal data to identify imitation, and ease of data storage (Schultz, Hoffman, \& ReiterPalmon, 2005). Analysis was done at the firm level. The choices of industries and countries acknowledged institutional variations, to ensure the sample was representative of the population. Logistic regression, conducted on STATA, was used to analyze hypotheses.

\subsection{Research Contributions}

This study seeks to contribute to theory by acknowledging the importance of interplay between all three institutional pillars on acquisition ownership. I hope to highlight the importance of including cognitive, normative and regulative institutional pillars in ownership research, as previous research focuses on either the normative pillar, the 
regulatory pillar or any two pillars of institutions. Such approaches overlook the complexity of the combined influence that all three institutional pillars have on acquisition ownership. The pillars are connected and overlapped, so an understanding of their profound interplay offers greater clarity on how acquisition ownership is influenced by the institutional environment. This is reiterated by Hoffman (1999) who stated “... to capture the full scope of institutional dynamics, researchers must analyse both the specific institutions that lie at the centre of an issue-based field and the competing institutions that may lie within the individual populations (or constituencies) that inhabit the field" (p. 365). Therefore, the simultaneous inclusion of three institutional pillars is an identified need in acquisition ownership research. As such, this research aims to demonstrate a more valuable understanding of how the institutional environment comprehensively influences CBA ownership.

Moreover, I seek to identify a hierarchal formation of the institutional pillars influence on CBA ownership. By incorporating all three pillars in this research, institutional interplay will portray the influence strength of each pillar on CBA ownership. This contribution is highly valuable as it will inform managerial practitioners of how to prioritize their strategic ownership response to institutional distance. Managerial understanding of the complete influence institutional pillars and their unique hierarchy of influence, will protect their CBAs from detrimental harm.

Such contributions will be highly valuable to acquisition ownership research. Currently, the incorporation of institutional theory in acquisition ownership research is misleading, as the influence of all three pillars' is not analysed. This has led to prior research offering misleading insight into how institutional pillars influence CBA ownership. Therefore, this study will contribute an accurate and complete analysis of all the institutional pillars influence on CBA ownership.

Lastly, I would like to contribute to CBA ownership literature by acknowledging the importance of collectivism as a research construct in studies. Previous CBA ownership research has focused on uncertainty avoidance and power distance, which limits cultural explanations for ownership strategies. 


\section{Chapter 2. Review of Literature}

\subsection{Institutional Theory}

Institutional theory is the most recent addition to the strategy tripod in international business (Peng et al., 2009). Historically, Meyer and Rowan (1977) stated that institutional rules were indeed myths by which organizations abide, to gain legitimacy and increase their chance of survival. More recently, North (1990) described institutions as "humanly devised constraints that shape human interaction" (p. 3), and distinguished between formal and informal institutions. Strategic management research has identified the importance of institutions, calling them the 'rules of the game'. This complements both the industry and resource-based views (Peng et al., 2008; Peng et al., 2009). Based on North's (1990) foundation, Scott (1995) configured three institutional pillars; cognitive, normative and regulatory, to refine institution focus. These pillars are not mutually exclusive and differ in tacitness and formalization (Kostova \& Zaheer, 1999). Such pillars are explicitly defined as “... multifaceted systems incorporating symbolic systems - cognitive constructions and normative rules - and regulative processes carried out through shaping social behaviour" (Scott, 1995, p.33). This shaping of behaviour is known as isomorphism. Isomorphism involves a firm adopting structures, practices and policies that are deemed legitimate in their new organizational field (DiMaggio \& Powell, 1983).

Institutional theory states that in different institutional environments firms desire legitimacy to ensure survival, to obtain legitimacy they practice isomorphism (DiMaggio \& Powell, 1983). The organizational field in an institutional environment develops criteria for legitimacy. An organizational field is defined as "a community of organizations that partakes of a common meaning system and whose participants interact more frequently and fatefully with one another than actors outside the field" (Scott, 1995, p. 56). Within a field, communication and discussion channels exist and identify what behaviour is legitimate. Hence, institutional theory allows firms to comprehend bureaucracy in modern commercial environments (DiMaggio \& Powell, 1983). As a result, institutional theory cements the importance of institutional rules in strategy research. 


\subsubsection{Legitimacy}

As stated previously, legitimacy is the primary motivation for participation in isomorphic practices. Organizational legitimacy is defined as "the acceptance of the organization by its environment..." (Kostova \& Zaheer, 1999, p. 64). It exists as behaviours become institutionalized by organizational fields (Kostova \& Roth, 2002). Hence, legitimacy is “... dictated by external audiences that assess its conformity to a set of social codes ..." ( $\mathrm{Li}$, Jiang, \& Shen, 2007 p.175). An important issue for MNCs is attaining legitimacy to enhance their opportunities for positive interactions and survival.

However, MNCs are multifaceted structures, being both geographically dispersed and function differentiated (Kostova \& Zaheer, 1999). Therefore, MNCs face greater complexities than uni-national firms (Cantwell, Dunning, \& Lundan, 2010). MNCs are expected to adjust appropriately to each host market, which can cause difficulty when various expectations of legitimacy are involved. They face numerous different institutional environments, each with varied cognitive, normative and regulatory institutional domains. Some believe subsidiaries have the most difficult position, as they must maintain internal and external legitimacy, with the two being diverse (Kostova \& Zaheer, 1999). Internal legitimacy ensures MNC HQ and other subsidiary dependence remains feasible, whereas external legitimacy ensures that the presence of the subsidiary in a foreign host market is subject to survival opportunities. This 'dual integration' is complicated when high distance exists between the MNC's internal and host market's external institutions (Estrin et al., 2009). How an MNC reacts to the trade-off can be influenced by whether the MNC carries a geocentric, ethnocentric or polycentric mindset (Kostova \& Zaheer, 1999). Geocentric firms manage and allow differences with greater ease, whereas conflict can more easily arise with ethnocentric firms. In addition, this trade-off is also influenced by the dependency of a subsidiary on transfers from its HQ. This dependency is determined by the underlying strategy an MNC is using. The implementation of a global strategy prioritizes internal institutions, as a subsidiary relies heavily on resource transfers within an MNC to implement its standardized strategy in the global market (Harzing, 2002). In contrast, MNCs that partake in multi-domestic strategies have less reliance on the MNC HQ and prioritize external institutions, due to such a strategy being adaptable to individual host requirements (Harzing, 2002; Xu \& Shenkar, 2002). 
Foreign MNCs are also burdened by liability of foreignness (LOF) (Guillén, 2002; Kostova \& Zaheer, 1999, Li et al., 2007; Salomon \& Wu, 2012). This liability occurs when routines and knowledge a firm develops in its home country have limited application in a host country. These firms then encounter additional costs to operate in a new organizational field. Consequently, foreign MNCs may not obtain legitimacy until they functionally conform to the organizational field's expectations. However, overcoming LOF is not a simple task. Detrimental confrontations include: the host country's lack of foreign MNC knowledge to judge their legitimacy, stereotypes, criteria differentiations for foreign MNC legitimacy evaluation relative to domestic firms, and MNCs being political targets for interest groups (Kostova \& Zaheer, 1999). Such confrontations are augmented when MNCs also face liability of size and visibility, making them vulnerable to attention (Kostova \& Zaheer, 1999). Therefore, LOF and size can delay or even sabotage an MNC's ability to attain legitimacy.

However, not all MNCs enter a new institutional environment with zero legitimacy. The extent of legitimacy required varies depending on the power possessed by the foreign entrant. When MNCs have relatively higher power, they appear legitimate and the institutional pressures of isomorphic behaviour are reduced (Kostova \& Roth, 2002). Some MNCs are perceived to be of equal power as local institution actors (Cantwell et al., 2010). In such a context, MNCs can manage their legitimacy through negotiations, and drawing on their bargaining power (Kostova \& Zaheer, 1999). Moreover, in markets where local firms have been stripped of legitimacy due to corruption, legitimacy is readily attainable for MNCs (Kostova \& Zaheer, 1999).

Furthermore, determinants of attaining legitimacy vary between organizational fields. Three common determinants are; the institutional environment of the host country, characteristics of the organization, and the process of legitimization in the environment (Kostova \& Zaheer, 1999). FDI communities and host country societal opinion also impact on legitimacy offers (Guillén, 2003; Li et al., 2007; Yang \& Hyland, 2012). Additional complexity occurs as legitimacy attainment is based on bounded rationality, due to both the MNC and the host market having insufficient information about one another, impeding decision making (Kostova \& Zaheer, 1999). Moreover, legitimacy donors vary with time. The status of a legitimacy donor is reduced once a firm has conducted its first entry (Guillén, 2002). Hence, the role of the organizational field differs according to whether a firm is making its first 
entry, or subsequent entries. Therefore, the social and cognitive construction of legitimacy hinders receivership (Kostova \& Zaheer, 1999). With various influencers and limited information, the legitimization process is complex. In addition, 'taken for granted' behaviours are also time dependent. When new entry modes emerge and become institutionalized, they are subject to imitation (Xia et al., 2008). Hence, internationalizing firms must remain up-to-date with institutionalized behaviours, to ensure that they attain legitimacy. This reflects Meyer and Rowan's statement (1977) that organizational language is imperative for institutional isomorphism to bloom.

\subsubsection{Uncertainty}

Levels of uncertainty vary depending on a variety of factors such as the home market situation, firm-level experience, and host market situation. Institutional factors that lead to uncertainty can be labelled as 'institutional hazards', and consist of both formal regulations and informal cultural characteristics (Lin et al., 2009; Slangen \& Beugelsdijk, 2010). These hazards create distance between the institutional expectations of the home and host countries. Distance leads to a firm's inability to comprehend and appropriately adjust to host market institutional expectations. The presence of hazards is positively related to global corporate activity, because different expectations emerge in sociocultural, regulatory, political, and legal environments (Slangen \& Beugelsdijk, 2010).

Two dominant types of institutional hazards are informal institutions and formal institutions (North, 1990). The force of informal institutional hazards is dictated by the amount of cultural distance between the home and host market. When cultural distance increases, uncertainty surrounds expected organizational behaviours, communication and negotiation styles, and customer tastes (Slangen \& Beugelsdijk, 2010). Formal hazards arise from government system quality, which denotes the degree of political stability (Grewal \& Dharwadkar, 2002; Slangen \& Beugelsdijk, 2010). High political instability increases the risk of unfavourable government policies towards foreign MNCs. However, the extent of harm varies depending on a firm's ability to overcome the hazard. Such variation operates on the premise that both formal and informal constraints are stronger for vertical activity rather than horizontal activity, but in general, formal threats have a greater impact (Slangen \& Beugelsdijk, 2010). 
Entry mode strategies are shaped by uncertainty (Hennart \& Slangen, 2015; Kostova \& Zaheer, 1999). The degree of uncertainty is known to determine entry mode, ownership, location choice and the performance of foreign entrants in new markets (Salomon $\& \mathrm{Wu}$, 2012). Therefore, as uncertainty increases operation difficulties increase, encouraging new entrants to pursue isomorphism, in order to improve survival chances. Consequently, entry into a new host environment can be plagued with risk caused by uncertainty in environmental component differences, leading firms to adopt a proactive mimetic isomorphic stance in their behaviour.

Conforming to legitimate practices reduces uncertainty. However, disagreement exists regarding the location of the isomorphic model that best reduces uncertainty. Local isomorphism is practised when host market models are used (Salomon \& Wu, 2012). Specifically, in markets with high regulatory distance local models are perceived to internalize host market regulatory requirements in their strategies to a greater extent than foreign models, reducing entry uncertainty (Ang et al., 2015). In addition, local isomorphism allows earlier attainment of legitimacy (Xia et al., 2008). Consequently, local isomorphism has a direct influence on the reduction of uncertainty. In contrast, home country firms from the same industry are also sources of imitation (Guillén, 2002; Xia et al., 2008). However, institutional duality is at play, as firms are faced with contradictory institutional demands. Pressure from the host country forces firms to adopt local practices, however, MNCs also venture overseas to exploit their competitive advantage abroad. There is evidence that suggests that when internal institutional pressures are strong, local isomorphism may not occur (Davis et al., 2000). However, this can threaten an MNCs ability to remain locally current. Evidently, the selection of an imitable model is complicated, as various factors must be considered.

\subsubsection{Misuse of Institutional Theory}

Institutional theory has been studied in various ways. Traditionally, strategy researchers investigate the cognitive pillar, while international management researchers focus on the normative and regulatory pillars (Ang et al., 2015). Current literature reflects this with the cognitive pillar being highly used in strategy research. This extensive usage is explained by cognitive pillar resemblance to common behavioural practice in American organizational theory, where there is a strong cognitive tendency for perception and action (Mizruchi \& 
Fein, 1999). Consequently, strategy research has adopted a narrow view on institutional influence.

Moreover, when structuring a foreign expansion strategy, it is unlikely that firms acknowledge only one institutional pillar (Ang et al., 2015). This would have damaging consequences and firms would fail to acknowledge vital market factors such as regulatory institutions. This shortcoming is supported by Mizruchi and Fein (1999) who state that when an author excludes pillars, such pillars could illustrate equally plausible behavioural explanations. Consequently, the simultaneous analysis of pillars enhances the comprehensive understanding of pillar effects. Furthermore, argument support is also embodied in the mislabelling of institutional effects. Research practices that fail to acknowledge all three pillars (60\%) often classify observations as mimetic isomorphism (Mizruchi \& Fein, 1999). Failing to acknowledge coercive and normative isomorphism limits research accuracy. According to Mizruchi and Fein (1999) "This may result in a distorted or at least potentially incomplete picture of the phenomenon under investigation" (p. 664). Independent pillar analysis is viewed with scepticism, as it is believed to weaken theory (Hirsch, 1997). When the pillars are analysed simultaneously, depictions of institutional distance are more comprehensive. Consequently, a narrow focus diminishes the value of institutional theory.

Therefore, there is an identified need for the simultaneous inclusion of the three institutional pillars. This approach comprehensively demonstrates how the pillars are intertwined. Pillar interaction describes how pillar dominance can occur, with pillars likely to be supplemented or substituted due to their simultaneous presence (Chuang et al., 2011). This is reiterated by Hoffman who states (1999) pillar dominance is possible, however, the three pillars are connected and coexist, as they interact and overlap. Moreover, conflict can occur between the three types of institutions, when they appear to contradict one another (Chuang et al., 2011). Therefore, the complexities surrounding pillar relationships and how they affect firms needs complete coverage. This was strongly supported by Hoffman (1999) who states “... to capture the full scope of institutional dynamics, researchers must analyse both the specific institutions that lie at the centre of an issue-based field and the competing institutions that may lie within the individual populations (or constituencies) that inhabit the field" (p. 365). 
Holmes, Miller, Hitt and Salmador (2013) find that institutions affect foreign investment differently. In their study, formal institutions out-shone the influence of culture, in terms of inward FDI participation. Similarly, Ang et al. (2015) find that the regulatory and normative pillars have moderating roles. Furthermore, normative institutions can be reflected in regulatory institutions, which may prioritize attention to the regulative pillar due to potential consequences (Ang et al., 2015). This pairing was recognized by Gaur and Lu (2007) who state that normative and regulative pillars can be paired as they share similarities. They find that regulatory and normative distance have an inverted U-shaped relationship with subsidiary survival. Chuang et al.'s (2011) research identified that the cognitive pillar had a dominant influence over the normative and regulatory pillars in a context of institutional contestation. Such findings demonstrate that pillars are not of equal standing in their wider context. Depending on context, institutions have unique combinations of power. Hoffman (1999) further states that the normative and regulatory pillars were developed from human design, so the likelihood of content contestation is high, whereas, the cognitive pillar is developed through the notion of taken-for-granted beliefs, so is less subject to disagreement. Therefore, there is indeed a degree of hierarchy amongst the pillars. The three institutional pillars interact with each other, creating a unique market entry experience for each firm.

\subsubsection{Regulatory Pillar}

Scott introduces the regulatory pillar as "A stable system of rules backed by surveillance and sanctioning power..." (Scott, 1995, pg. 36). This pillar incorporates institutional economics and regulatory institutions, to sustain structure in society (Xu, Pan, \& Beamish, 2004). Specifically, North (1990) states that regulatory institutions are formal, explicit and enforceable laws to safeguard order. Through atmospheric stability, uncertainty and transactional hazards are reduced, as regulations create boundaries that condition appropriate behaviour.

Regulatory environments differ between international settings. This is known as regulatory distance and leads to uncertainty for foreign entrants (Brouthers \& Hennart, 2007; Ang et al., 2015). When regulations differ between national environments, firms are pressured to conform to host regulations. Complexities may arise because of written or tacit regulations. Therefore, it is often not until a firm has a sound comprehension of its new regulatory environment, that it is capable of meeting regulatory expectations (Ang et al., 2015). As a 
result, ambiguity surrounds regulatory expectations. In turn, this threatens the implementation of regulatory sanctions, so firms opt to overcome uncertainty via imitation. Ang et al. (2015) observe that this practice is commonly carried out with MNCs from emerging economies, where regulations are weakly implemented and evolving. In developed markets, globalization and worldwide institutions such as the WTO have resulted in regulations becoming homogenous (Eden \& Miller, 2004). Consequently, MNCs are aware of the strength of regulation and conform to ensure response security. This practise of conformity to legal expectations is known as coercive isomorphism. Coercive isomorphism occurs due to formal and informal pressures forcing, persuading or inviting change, often crafted by government ruling (DiMaggio \& Powell, 1983). Regulatory pressures force firms to behave similarly. Legalities limit flexibility and directly pressure incoming MNCs to conform (DiMaggio \& Powell, 1983). Such conformity can lead to firms employing ritualized controls that reflect host country expectations. Consequently, obeying coercive isomorphic pressures reduces the risk of failure and lets MNCs acquire legitimacy.

\subsubsection{Normative Pillar}

The normative pillar depicts a system of human norms and values that shapes goals, strategies and behaviour (Kostova \& Roth, 2002; Scott, 1995). Social norms and values characterize legitimate ways to carry-out valued behaviour (Scott, 1995). Such characterization occurs through establishing goals and behavioural instructions to ensure accomplishment (Scott, 1995). Hence, the control of social behaviour ensures that valued means are met. However, norms and values are ingrained in culture so complexities arise between the accepted behaviours of different national cultures. National culture is defined by Hofstede (1983a) as "the collective programming of the mind". Hofstede also developed cultural value dimensions; power distance, uncertainty avoidance, masculinity vs femininity, collectivism vs individualism and short-term vs long-term orientation. Following the surge of foreign investment in the late $20^{\text {th }}$ century, such value dimensions were introduced as influencers of business strategy, in particular entry mode decisions (Kogut \& Singh, 1988; Slangen \& Hennart, 2008). Consequently, cultural analysis acknowledges risk to enhance entry-mode selection and performance of foreign entrants (Brouthers, 2002; Shenkar, 2001; Slangen \& Hennart, 2008). Two prominent cultural traits that influence international business are uncertainty avoidance and collectivism. 
Uncertainty avoidance concerns "the extent to which people feel threatened by ambiguous situations" (Hofstede \& Bond, 1984, p. 419). This cultural value dimension has a strong presence in international business, as relatively higher uncertainty is present, compared to domestic transactions (Venaik \& Brewer, 2010). Culture of high uncertainty avoidance combats the threat of ambiguity through strict obedience to regulations, and standardization. Barr and Glynn (2004) maintain that controllable environments provide opportunity whereas uncontrollable environments pose a threat. Therefore, the social norms of firms that avoid uncertainty maximize outcome predictability (Barr \& Glynn, 2004; Duncan, 1972; Kwok \& Tadesse, 2006; Lin, 2013; Nakata \& Sivakumar, 1996; Podoynitsyna, Song, van der Bij, \& Weggeman, 2013; Schneider, 1989; Schneider \& De Meyer, 1991; Straughan \& AlbersMiller, 2001; Venaik \& Brewer, 2010).

Collectivism is defined as "a situation in which people belong to in-groups or collectivities which are supposed to look after them in exchange for loyalty" (Hofstede \& Bond, 1984, p. 419). Collectivists' self-concept is shaped by in-group participation. In-groups are small and based on member similarity due to common threats and fates guiding collective behaviour (Brewer \& Chen, 2007; Triandis, 1989). Members may have similar; values, status, legitimacy and personalities (Chatman, Polzer, Barsade, \& Neale, 1998; Earley, 1993; Fadil, Williams, Limpaphayom, \& Smatt, 2005; Smith, Carroll, \& Ashford, 1995). Furthermore, collectivism prioritizes concern for the effects of actions or decisions on others (Hui \& Triandis, 1986; Triandis, 1989). Hence, collectivist social norms are founded on obliged mutual assistance. Therefore, firms prioritize their in-group to maintain resource opportunities and performance.

However, when firms enter international markets that consist of opposing cultural value dimensions, normative distance results. Rottig (2013) states that national culture integration enhances acquisition success when firms acknowledge and react to disparities early. If ignored, differences in national culture are a common cause of acquisition failure (Barkema \& Vermeulen, 1998; Rottig, 2013). Therefore, it is not national culture but rather managerial neglect that is disruptive. Normative isomorphism responds to normative distance, reducing forecasted uncertainty and catalysing legitimacy attainment. It streamlines professionalism, through a process of filtration, to ensure that consistency facilitates successful performance (DiMaggio \& Powell, 1983). Formal education and professional networks are examples of 
filters used (DiMaggio \& Powell, 1983). Unique employee diversity is not perceived as an opportunity, but a discrepancy to avoid or change.

\subsubsection{Cognitive Pillar}

The cognitive pillar is shaped through sociology. "Meanings arise in interaction, and they are preserved and modified by human behaviour" (Scott, 1995, p. 41). This pillar accounts for social constructions developed during continuous interaction, which become taken-forgranted behaviours immersing culturally similar firms in conformism (Scott, 1995). Yet, the prominence of taken-for-granted behaviour in daily life makes it difficult to identify behaviour as being socially influenced (Scott, 1995). Hence, entities often undertake such behaviour, but remain unaware of its origin. National culture differences contribute to cognitive distance, as cognitive institutions differ between countries and over time. This is evident when assessing Hofstede's cultural value dimensions to uncover the defining characteristics of cultural identities. Western cultures function on socially constructed behaviour of prioritizing the self, whereas, Eastern countries tend to prioritize collective importance. Consequently, when firms venture abroad, they encounter different socially constructed behaviours. This adds complexity to strategy formulation.

Mimetic isomorphism responds to cognitive distance. Cognitive discrepancies create host country environmental uncertainty. Henisz and Delios (2001) state that mimetic isomorphism is provoked by uncertainty surrounding a lack of market experience, not doubt attributed to the structure of market policy construction. Inexperience manifests itself in ambiguous technologies, hazy goals or environmental discrepancies in the host country (DiMaggio \& Powell, 1983; Kostova \& Roth, 2002). Consequently, new entrants seek comfort in imitating the model behaviour of those proven successful in the new host market, to reduce complications of such discrepancies. Mimicking behaviour facilitates comprehension of how such differences work in their unique environment. Imitation also demonstrates a degree of respect of host institutionalized practices, and catalyses legitimacy attainment (Henisz \& Delios, 2001). Therefore, combating uncertainty through mimetic isomorphism enhances survival prospects, permitting resource access and protection from authorities. Consequently, mimetic isomorphism is a cost-efficient solution for combating host environment uncertainty (DiMaggio \& Powell, 1983). 


\subsection{Imitation}

\subsubsection{Types of Imitation}

Pfeffer, Salancik and Leblebici (1976) state that "Social influence ... is inevitable in decision-making situations of great uncertainty" (p. 240). Consequently, in times of uncertainty firms seek insight from peers, and imitation often results. As previously stated, mimetic isomorphism, normative isomorphism and regulatory isomorphism are related to imitation, developed by institutional theory. However, types of imitation focused on in this section were established by learning theories. Three types of imitation exist: frequencybased imitation, trait-based imitation and outcome-based imitation. These types occur independently, yet previous research has adopted purpose groupings (Haunschild \& Miner, 1997). For example, frequency- and trait-based imitation are seen to occur for reasons of legitimacy, both being socially constructed approaches (Haunschild \& Miner, 1997). Hence, interlinked interest can cause complexities when deciphering imitation types.

\section{Frequency-based Imitation}

Frequency-based imitation is based on the number of firms who have adopted a specific strategy (Henisz \& Delios, 2001). This model selection is based on participant volume, not efficiency or outcome. It involves adopting 'taken-for-granted' practices and is implemented when market uncertainty is high (Henisz \& Delios, 2001; Haunschild \& Miner, 1997). Therefore, firms look to their peers for useful responses, observing popular actions. Hence, firms vicariously learn through popularity (Kraatz, 1995). To observe frequency, bandwagon effects are witnessed. This consists of numerous firms adopting the same entry mode in a short time period (Xia et al., 2008). Bandwagons relate to frequency, as pressure to conform is built by the high number of adopters, not by the outcomes (Abrahamson \& Rosenkopf, 1993). Such social pressure builds fear in non-participating firms (Abrahamson \& Rosenkopf, 1993). Therefore, firms succumb to social pressure and follow suit. This concept also works in reverse. When entry mode popularity decreases, negative bandwagons occur (Xia et al., 2008). Consequently, partaking in popular practice offers participants legitimacy and reinforces the acceptability of the practice leading to the activity becoming institutionalized (Burns \& Wholey, 1993; Haunschild \& Miner, 1997; Tseng \& Chou, 2011). 


\section{Trait-based Imitation}

Trait-based imitation occurs based on trait similarities between the imitator and the model firm (Henisz \& Delios, 2001). Unlike frequency-based imitation, trait-based imitation is strategically selective, as imitators seek certain features (Haunschild \& Miner, 1997; Henisz $\&$ Delios, 2001). Again, legitimacy is highly important during market entry, so to proactively partake in accepted behaviours, imitators look for legitimate actors as models. Legitimacy can be inferred from the firm traits; size, success and status (Haunschild \& Miner, 1997). Size is a commonly acknowledged trait, as larger firms have sufficient resources for research and activity, which reflects comprehensive decision making (Tseng \& Chou, 2011). Furthermore, success is a highly identifiable characteristic and a desirable firm state (Lu, 2002). Lastly, status directly reflects legitimacy. Firms seek to imitate models of status to benefit from their established legitimate presence.

Similarly, social processes are important for trait-based imitation, which is implemented when market uncertainty is high (Haunschild \& Miner, 1997; Henisz \& Delios, 2001). Therefore, firms are required to be socially active to develop network acceptance, in which models are made available. Opinion leaders are commonly used models. They encourage followers to replicate their actions, as their image is founded on followership (Haunschild \& Miner, 1997). Nonetheless, if the activity produces negative externalities, imitation will not occur, regardless of attractive firm traits (Haunschild \& Miner, 1997). Therefore, attractive models who partake in any activity that produces negative social consequences are not chosen as imitation models.

\section{Outcome-based Imitation}

Outcome-based imitation observes the result of activity participation. Positive outcomes, such as innovation profitability, are desirable so this imitation type proactively avoids negative results (Haunschild \& Miner, 1997). However, outcomes must be highly salient to be considered. For example, acquisition premiums are commonly used due to their objective nature. Low and high premiums influence imitation likelihood, whereas average premiums have no effect (Haunschild \& Miner, 1997). This reinforces the need for saliency. Furthermore, renowned success can also be a salient outcome. Lu (2002) notes that when outcome-based imitation is applied to entry mode decisions, imitators will seek the mode with the greatest historical success. Success is measured in various ways; however, survival 
and legitimacy are two attractive results. Consequently, outcome-based imitation is a selective process and has high importance during entry mode selection (Lu, 2002).

Similarly, firms learn vicariously through outcome-based imitation (Haunschild \& Miner, 1997). Witnessing behavioural results allows firms to understand how to perform in order to reap similar success. Organizational learning theorists state that vicarious learning can occur both through imitation and outcome avoidance (Haunschild \& Miner, 1997). When firms imitate they learn how to structure and connect their operations with outcomes. In contrast, avoidance teaches firms how not to behave. Therefore, having the capacity to see the results of certain behaviours provides an educational foundation for firms. From an economic perspective, this type of education is interpreted as spill-over learning (Haunschild \& Miner, 1997). Spill-over learning is commonly portrayed as freeriding off the research efforts of imitation models, offering a second mover advantage (Haunschild \& Miner, 1997). This advantage is characterized by risk absorption of first mover market entrant (Haunschild, 1993). Therefore, firms who follow can be advantaged.

\subsubsection{Determinants of Imitation}

Firms are boundedly rational and use their past experiences to respond to new environments (Lin et al., 2009). Diverse experiences expose a firm to distinctive learning contexts, enriching their knowledge (Barkema \& Vermeulen, 1998; Lin et al., 2009). Firms who practice similar acquisitions will not achieve superior acquisition performance (Hayward, 2002). Producing highly similar acquisitions risks competency traps, but producing highly dissimilar acquisitions demonstrates a lack of specialist knowledge (Hayward, 2002). Consequently, imitation permits an experienced firm to explore new options and improve their competitive position. Firms can maximize outcomes by exploiting previous experience and discovering new options (Hayward, 2002). Therefore, experienced firms imitate aspects of modelled behaviour and then personalize imitated practices based on their own experience, to create unique competitive advantage and diversify their strategies (Yang \& Hyland, 2012). Alternatively, experienced firms may also use their knowledge to mimic own past actions. When firms continuously imitate their own actions, it is called repetitive momentum' (Baum, Li \& Usher, 2000; Oehme \& Bort, 2015; Yang \& Hyland, 2006;). However, as previously stated, there is a risk of a competency trap developing and limiting the strategic value of the routinized action. 
In contrast, less experienced firms face increased amounts of uncertainty when venturing abroad. Their lack of experience means outcomes are unpredictable, and they need to draw on failure prevention schemes. Such schemes involve imitating the exact actions of modelled host market behaviour (Yang \& Hyland, 2012). Mimicking exact actions provides performance security, as such activities have proven to be productive. Precise imitation reduces environment uncertainty for firms venturing into a new host market. It helps them to attain legitimacy in the host market, by demonstrating respect of different institutional expectations. Moreover, inexperienced firms are unable to personalize imitated content. Their lack of knowledge impedes on their capacity to formulate competitive bespoke content. Therefore, the only way for imitation to result in desirable outcomes is to precisely mimic other host market behaviour.

Network participation is also a determinant of imitation. Networks facilitate learning to empower firms to venture abroad confidently. Networks provide trusted collaboration opportunities and augment confidence in strategy implementation (Argote, 2013; Lin et al., 2009). For example, board networks provide formal experience of CBA processes and outcomes, offering valuable insight (Beckman \& Haunschild, 2002; Oehme \& Bort, 2015; Westphal et al., 2001). A firm's network position reflects its access to information. Central position holders are experienced firms that are perceived as highly legitimate (Oehme \& Bort, 2015). They obtain prestigious information and due to their experience digress from precise imitation. In contrast, firms located in outer-network positions are relatively inexperienced. They attain general information and imitate full strategic practices (Oehme \& Bort, 2015). As previously stated, inexperienced firms lack knowledge to personalize imitated content. Consequently, networks offer knowledge security by providing participants with models which illustrate successful behaviour.

It is not just firm-level networks that provide resources for imitation. Stimuli at market and industry levels simultaneously influence imitation sources, driven by the importance of remaining competitive (Yang \& Hyland, 2006; 2012). Product market networks are termed appropriate imitation targets, with close competitors referenced as ideal (Yang \& Hyland, 2006). This appropriateness stems from the resemblance of behaviour. However, firms with product relatedness strategies are commonly more influential as a source of imitation (Yang \& Hyland, 2012). But, this depends on the strategic motive behind the firm's imitation 
practice. Having related acquisitions enhances existing capabilities, whereas unrelated acquisitions work as a diversification strategy and come with greater risk (Westphal et al., 2001). Furthermore, imitation sources can be stationed outside the focal product market (Yang \& Hyland, 2006). Informants can provide unique ideas to achieve a competitive advantage. However, firms may refrain from industry level imitation, due to reduced comparability between firms. This increases the risk of such followership.

\subsubsection{Imitation Benefits}

The benefits of imitation are controversial for numerous reasons. Firstly, legitimacy is presented as a dominant benefit; however, this overrides short term financial earnings. From the institutional perspective, "firms require legitimacy on top of economic efficiency to survive and succeed" (Ang \& Michailova, 2008, p. 554). Firms that prioritize legitimacy over finances, can damage short term financial efficiency. Consequently, imitation is negatively perceived in some literature, as it contradicts the firm's raison d'être. Moreover, imitation relies intensely on external assessment criteria to determine strategy structure (Meyer \& Rowan, 1977). Certain literature questions such criteria, as firms are perceived to be going against their own research (Barreto \& Baden-Fuller, 2006). Conforming to external criteria is perceived as a purposeful evasion of sound strategy. This is reinforced by the perspective that when firms conform to the expectations of their institutional environment, they neglect the specific demands of their work activities (Meyer \& Rowan, 1977). Again, this demonstrates significant reliance on external sources, foregoing efficiency in daily operations. In conclusion, those who question imitation benefits perceive firms to be neglecting their financial wellbeing in favour of social acceptance, which contradicts firms' raison d'être.

In contrast, others believe imitation is beneficial for long term success. Seeking legitimacy is termed a rational practice (Lieberman \& Asaba, 2006). DiMaggio and Powell (1983) state that the prioritization of efficiency is counteracted by organizational fields having strong entry barriers. Therefore, as entry barriers are controlled, protectionist measures are indirectly placed on industries, reducing the need to prioritize efficiency. However, such industries have professionally trained labour forces, so the need to compete for prestigious inputs is prioritized, making legitimacy imperative (DiMaggio \& Powell, 1983). Market entry mode success is dependent on obtaining legitimacy and is less reliant on factors 
promoting efficient coordination and control (Meyer \& Rowan, 1977). Moreover, economic efficiency is generally a preconceived motive for early movers, whereas, in the follower position, preservation or improvement of legitimacy is a priority (Ang et al., 2015). Again, this supports imitation benefits as firms have different motivations, hence their raison d'être varies depending on their time of market entry. Evidently, imitation can provide long term survival support prospects (Barreto \& Baden-Fuller, 2006). Therefore, imitation is highly beneficial to internationally expanding firms, particularly from emerging markets, for longer term success (Ang et al., 2015).

\subsection{Acquisition Ownership and its Determinants}

Ownership structure is defined as "the choice concerning degree of ownership taken when a foreign investment is made" (Delios \& Beamish, 1999, p. 915). The importance of ownership structure is highlighted by its direct influence on profits, value and survival (Davis et al., 2000; Gaur \& Lu, 2007; Yang \& Hyland, 2012). The international business environment consists of diverse influences on acquisition ownership configuration; experience, technology, MNC overall strategy, dual isomorphic pressures, and risk and control.

\subsubsection{Experience}

Acquirer experience in foreign markets is a critical factor in ownership decisions. Experience leads to familiarity with a foreign location, which reduces uncertainty in ownership assessments and assists structural decision making (Arslan \& Larimo, 2010; Benito, 1996; Dikova \& van Witteloostuijn, 2007). International experience from a young age develops a bicultural identity for firms, making international expansion feasible with ease (Piaskowska \& Trojanowski, 2014). Consequently, experience is a function of uncertainty (Kogut \& Singh, 1988). It lessens liability of foreignness in market entry, by eradicating knowledge disadvantages and augmenting institutional clarity (Arslan \& Larimo, 2010; Delios \& Beamish, 1999; Peng, 2003). This offers ownership and location advantages for multinationals through experience facilitating strategic decision confidence (Anand \& Delios, 1997; Davidson, 1980; Erramilli, Agarwal, \& Kim, 1997). In contrast, when experience is non-existent, uncertainty increases. The lack of knowledge impedes risk assessment causing faulty ownership decisions (Agarwal \& Ramaswami, 1992). Ownership 
levels vary with the level of market experience. Delios and Beamish (1999) state that experience leads the foreign investor to increase their share of equity ownership. This is supported by Gatignon and Anderson (1988) who state that experienced MNCs often prefer wholly owned subsidiaries. Similarly, Padmanabhan and Cho (1996) note that high experience leads to full ownership, and Arslan and Dikova state (2015) that investment experience leads to full cross-border acquisition ownership. Consequently, full ownership occurs due to the sound assessment capabilities that market experience provides. In contrast, full ownership and inexperience would augment risk and offer a substantial threat of failure.

Furthermore, entry mode experience also has an influence on ownership structure. Joint venture experience establishes the basis of acquisition market entry (Chang \& Rosenzweig, 2001). However, not all experience is beneficial. International joint ventures (IJVs) are positively influenced by domestic JV experience and international wholly owned subsidiary experience, but not IJV experience (Barkema, Shenkar, Vermeulen, \& Bell, 1997). Therefore, it is important to consider entry mode history when assessing ownership decisions.

\subsubsection{Technology}

Technology has an influential role in entry mode decisions. Acquisitions are the preferred mode of entry when technology is of importance, due to the difficulties of attaining tacit knowledge (Elango, Lahiri, \& Kundu, 2013). However, acquisition ownership decisions are influenced by a variety of factors such as; intensity of technology industry and technology sophistication.

Partial ownership is observed when an acquirer is targeting a firm in a high-technology industry (Elango et al., 2013). A partial acquisition is a cooperative mode, which facilitates the procurement of local resources (Estrin et al., 2009). An acquisition in a high-technology industry can be a firm's attempt to ameliorate its resource base, therefore a partial acquisition is the most suitable format. This ownership strategy awards an acquirer the capacity to pool its resources with its target, to gain new technology without encountering high costs and risks (Chang \& Rosenzweig, 2001). 
However, full ownership occurs when technology is highly sophisticated (Elango et al., 2013; Gatignon \& Anderson, 1988). From the MNCs perspective, full ownership is important for protection of highly sophisticated technology which encompasses proprietary knowledge (Gatignon \& Anderson, 1988). Full ownership permits an MNC to exploit its firm specific advantage, by internalizing its strategy. Such control prevents the opportunistic behaviour of host partners which could threaten a firm's technological competitive advantage. From the host market's perspective, FDI inflows are desirable due to the capacity to receive spill over effects from modern technology (Mattoo, Olarreaga, \& Saggi, 2004). Hence, some host governments permit acquirers to practice full ownership when technology is rare (Gatignon \& Anderson, 1988). This fulfils the acquirer's need for technology protection and facilitates the arrival of modern technology in the host country.

Lastly, the influence of technology on ownership strategy is dependent on stages of development of home and host countries. High technology intensity increases ownership in countries that are less developed than the MNC's home country, and reduces ownership in countries that are more developed than the MNC's home country (Erramilli et al., 1997). Developed countries are known for strong formal institutions, whereas, developing countries are informally governed (Eden \& Miller, 2004). Intellectual property standards differ. In less developed nations, the lower standard of formal institutions may threaten the safety of technology. Consequently, this difference results in full ownership due to the relative ease of internal risk control within the MNC (Elango et al., 2013).

\subsubsection{MNC Overall Strategy}

An MNC's overall strategy must be considered as an ownership influencing factor. Ownership structures facilitate the achievement of strategic goals (Dikova \& van Witteloostuijn, 2007; Yang \& Hyland, 2012). The role assigned to a subsidiary is associated with a certain coordination level (Martinez \& Jarillo, 1991). This role is influenced by the strategic rapport that an MNC desires its subsidiary to have with its sibling subsidiaries worldwide (Hill, Hwang, \& Chan, 1990; Kim \& Hwang, 1992). When a subsidiary's level of autonomy increases, integration within the firm decreases, reducing ownership stakes (Martinez \& Jarillo, 1991). This is witnessed in multi-domestic strategies that respond to strong external isomorphic pressures using acquisitions (Harzing, 2002). Less reliance on the parent firm leads to less concern with institutional conflicts within the MNC. 
However, a global strategy is configured around increased integration within the MNC. This strategy does not partake in local environment adaptations, as internal isomorphic pressures fabricate a global standardized ownership strategy (Harzing, 2002). Consequently, MNC sibling subsidiaries located globally have an interdependent relationship. Such interdependency facilitates asset transfers within the $\mathrm{MNC}$ to enable subsidiaries to carryout the same ownership strategy. In turn, this permits MNCs to take advantage of their firmspecific capabilities (Delios \& Beamish, 1999; Erramilli et al., 1997). Hence, global strategies can result from firm-specific advantages that require protection, enabling the exploitation of unique capabilities and reducing the liability of foreignness (Delios \& Beamish, 1999; Zaheer, 2004). Therefore, it is important for the parent to have tight controls to facilitate asset transfers between entities.

Consequently, ownership decisions must not be individually assessed, and the MNC overall strategy must be considered (Hill et al., 1990).

\subsubsection{Dual Isomorphic Pressures}

MNC strategies are influenced by dual isomorphic pressures faced when venturing abroad. Institutional theory states that MNCs are influenced by host market institutions to gain legitimacy (Yiu \& Makino, 2002). Consequently, institutional theory facilitates contextual understanding of differing MNC strategies between countries (Chikhouni, Edwards \& Farashahi, 2017; Eden \& Miller, 2004; Xu \& Shenkar, 2002). Ownership is viewed as a form of response to the institutional environment (Yiu \& Makino, 2002). However, MNC ownership decisions are influenced by the external host environment and the internal institutional environment within the MNC.

Isomorphic response depends on the institutional pressure strength of the parent firm, and that of the new institutional environment. Resource flows are a dominant determinant concerning the orientation of an MNC's response to dual institutional pressures (Davis et al., 2000). Firms respond differently to these institutional pressures depending on their strategic structure. A global strategy results when a parent has strong institutional pressure, due to subsidiary reliance on parents' resources (Cui \& Jiang, 2012; Yiu \& Makino, 2002). In this situation, full ownership allows the parent to retain control and consistency by 
avoiding reconstruction demands of equity partners (Chan \& Makino, 2007). Whereas, when multi-domestic strategies are implemented, strong institutional pressure from the host market causes MNCs to trade ownership for legitimacy and reduce their ownership stakes (Yiu \& Makino, 2002). The MNC then relies on local goodwill to build an attractive reputation and appeal to legitimating actors. Moreover, greater complexities arise for state owned enterprises (SOEs). SOEs are frowned upon by host markets and therefore face greater obstacles to attain legitimacy. The negative implications of SOE connection with a home country government are perceived by hosts as threatening to their national security and offer the SOE an unfair resource advantage (Meyer, Ding, Li, \& Zhang, 2014).

\subsubsection{Risk and Control}

Ownership levels are also shaped by perceptions of new market risk. Risk has a significant impact on ownership modes (Brouthers, Brouthers \& Nakos, 1998; Davis et al., 2000). Two types of risks for MNCs venturing abroad are investment risk and contractual risk. Investment risk focuses on the environment, concentrating on unstable economic, social or political acts (Brouthers et al., 1998). Contractual risk involves costs relating to formation, control and monitoring of subsidiaries' business activities (Brouthers et al., 1998). Moreover, risk levels are related to the amount of non-re-deployable assets a firm invests, which weaken flexibility, creating a barrier to exit (Pan, 1996). Consequently, acknowledging such risks is imperative to avoid knowledge expropriation.

A mitigator of such risks is institutional distance, which influences MNC strategy and structural decisions (Pinto, Ferreira, Falaster, \& Fleury, 2017). Caution must be taken when assessing institutional distance. Firstly, MNCs must accurately interpret whether the host country prioritizes formal or informal institutions (Eden \& Miller, 2004). OECD countries have strong formal institutions whereas emerging countries are more informally regulated through trust and networks (Eden \& Miller, 2004). Informal regulations shape partial acquisitions, as a local partner will facilitate the comprehension ease of expected normalities in a culturally diverse context. Secondly, the number of prior entries a firm has made will also affect how institutional distance impacts on ownership levels. Differences exist between how a firm combats institutional distance, depending on whether it is the firm's first or subsequent entry (Estrin et al., 2009). 
After host country selection, an MNC must then craft an entry strategy that responds to the institutional distance between their home country and host location, to maximize their competitive advantage (Xu \& Shenkar, 2002). It is widely accepted that institutional distance is an obstacle to transfers and legitimacy (Xu et al., 2004). However, various arguments exist regarding institutional distance's influence on ownership decisions. Firstly, the literature states that high institutional distance results in developed countries opting for full ownership. This facilitates survival through faster decision making with fewer causes of conflict and firms are able to exploit their specific advantages (Gaur \& Lu, 2007). However, Shirodkar and Konara (2017) show that negative institutional distance impacts are reduced when a firm opts for partial ownership. These local partnerships enhance the development of trust in the host environment toward the foreign $\mathrm{MNC}$, improving its capacity to attain legitimacy (Shirodkar \& Konara, 2017). Further benefits for the MNC include trust minimizing LOF and complementary spill-over effects (Yiu \& Makino, 2002).

However, emerging market MNC (EMNC) literature consistently reports that high institutional distance leads to EMNCs partaking in full ownership (Lahiri, Elango, \& Kundu, 2014). The decision of full ownership is founded on the desire to improve and protect their business, in areas where formal institutions are strong (Yang, 2015). Consequently, EMNCs perceive institutional distance as an opportunity to get ahead (Liou et al., 2017). By implementing full ownerships, EMNCs can take advantage of resources, such as skilled labour forces. This reflects the idea that EMNCs and MNCs internationalize for different reasons (Chikhouni et al., 2017). Consequently, EMNCs are portrayed as springing forward due to their late entry, by aggressively acquiring developed resources (Liou et al., 2017; Liou et al., 2016; Malhotra, Lin, \& Farrell, 2016). Therefore, it is necessary to acknowledge an acquirer's home country development when analysing ownership structures.

Moreover, institutional distance therefore pressures MNCs to consider the trade-off between risk and control, when deciding on ownership levels (Delios \& Beamish, 1999; Tihanyi, Griffith, \& Russell, 2005). Different ownership levels reflect diverse levels of control (Davis et al., 2000; Erramilli \& Rao, 1993). Consequently, an MNC must attain a sufficient level of control through an appropriate strategy, to maximize location benefits and legitimacy (Xu et al., 2004). 
MNCs can choose to increase control via full ownership when risk is perceived to be high (Delios \& Beamish, 1999). Full control is beneficial as it facilitates quick decision making without significant scope of conflict, and it provides a smooth platform for the transfer of resources and capabilities (Gaur \& Lu, 2007). This allows a firm to maximize its competitive advantage through exploiting firm specific capabilities. Consequently, full control is also seen as a protection mechanism. Such ownership reduces the threat of relational and opportunistic behaviours, as there is no host partner involved (Gaur \& Lu, 2007; Lu, 2002). Hence, it simplifies the control process (Yang \& Hyland, 2012). Furthermore, full ownership reduces complexity by allowing firms to continue to execute similar routines and behavioural expectations, using expats and young local employees (Peng, 2003). This is especially important when brand value is high (Gatignon \& Anderson, 1988). Consequently, full ownership is beneficial for reducing risk and increasing profit share when a firm has the necessary resources.

However, not all firms desire full ownership (Chang \& Rosenzweig, 2001). Refraining from full ownership can be perceived as an attempt to avoid increasing risks. When the host environment is highly uncertain, it is difficult to manage via full ownership (Davis et al., 2000). Full ownership consists of increased resource commitment to maintain control, which augments risk by reducing an MNC's flexibility to adapt to host environment requirements or exit if necessary (Davis et al., 2000; Tihanyi et al., 2005; Xu \& Shenkar, 2002). Consequently, partial acquisitions appear more appropriate. They permit flexibility due to reduced resource commitment, allowing a firm to position itself competitively in an efficient manner and minimize losses on market exit (Brouthers \& Brouthers, 2001; Meyer \& Tran, 2006). Therefore, joint ventures are suitable when conducting a first entry into a host market, for knowledge learning purposes (Hennart, 1991). 'Going Local' prioritizes local partnerships to enhance in-country networking (Peng, 2003). Hence, partial ownership facilitates local learning, and reduces environmental uncertainty (Agarwal, 1994; Ferreira, da Silva Vicente, Borini, \& de Almeida, 2017). Furthermore, adapting mode of entry to host expectations produces better outcomes than simply choosing an alternative mode of entry (Meyer \& Tran, 2006). The loss of control in partial acquisitions is compensated for by favourable flow-on effects from adapting to host needs, such as legitimacy (Davis et al., 2000). Hence, partnering with locals reduces LOF and enhances firm capacity to gain host legitimacy, as legitimacy is a direct outcome of interest alignment between a foreign partner and a host market (Anand \& Delios, 1997; Eden \& Miller, 2004; Jakobsen \& Meyer, 2008). 


\section{Chapter 3. Hypotheses Development}

\subsection{Hypothesis 1: Imitation}

Institutional theory posits that when a firm enters a new market, its behavior is shaped by the new organizational field (DiMaggio \& Powell, 1983). By a firm adapting its strategy to meet host market expectations, uncertainty is reduced through local acceptance in the form of legitimacy. Newburry and Yakova (2006) identify expected comportment as institutionalized behaviours in the host environment, posing as templates of best practice for foreign entrants. Hence, entry mode imitation is a form of survival assurance when MNCs expand abroad. Such security reduces any uncertainty posed by outcome ambiguity in foreign market environments (Aggarwal \& Goodell, 2010; Qu \& Yang, 2015).

Such imitation reflects the cognitive pillar of institutional theory and is known as mimetic isomorphism, which is an active response to uncertainty in a new market environment (DiMaggio \& Powell, 1983). Environmental uncertainty originates from ambiguous technologies, hazy goals or environmental discrepancies (DiMaggio \& Powell, 1983; Kostova \& Roth, 2002). Henisz and Delios (2001) state specifically that mimetic isomorphism is provoked by uncertainty surrounding a lack of market experience, not doubt attributed to structure of market policy construction. Mimetic isomorphism accounts for social constructions developed during continuous interaction, which become taken-forgranted behaviours, immersing culturally similar firms in conformism (Scott, 1995).

A common method of imitation is frequency-based imitation. Based on the number of firms who have adopted a specific strategy, it involves partaking in 'taken-for-granted' practices (Henisz \& Delios, 2001; Haunschild \& Miner, 1997). Consequently, when entering a new market mimetic isomorphism occurs in the form of frequency-based imitation. In this case, an ownership strategy is chosen based on the volume of current firms partaking in that ownership strategy in the host country. A high volume of participants presents the ownership strategy as legitimate. Therefore, firms spectate and vicariously learn through popularity of ownership levels (Kraatz, 1995). To observe ownership frequency is to observe bandwagons, which consist of numerous firms adopting the same entry mode in a short time period (Xia et al., 2008). Pressure to conform builds through large numbers of adopters, not from strategy results (Abrahamson \& Rosenkopf, 1993). Such social pressure builds fear in non- 
participating firms, leading them to follow (Abrahamson \& Rosenkopf, 1993). Further, partaking in popular practice reinforces the acceptability of a behaviour, increasingly institutionalizing it to therefore continue to offer legitimacy (Tseng \& Chou, 2011; Haunschild \& Miner, 1997; Burns \& Wholey, 1993). Conversely, when entry mode popularity decreases, negative bandwagons appear (Xia et al., 2008). Therefore, imitation demonstrates the power of social justification over economic rationality (Barreto \& BadenFuller, 2006).

In conclusion, if firms in the host country are conducting full acquisitions, the likelihood of a new entrant conducting a full acquisition is higher. This will occur as popularity suggests that full acquisitions are an institutionalized behaviour (Kostova \& Roth, 2002). To host legitimacy donors, compliance signals foreign firm sensitivity to local institutions and enhances their chances of legitimacy attainment (Ang et al., 2015; DiMaggio \& Powell, 1983). Thus, when facing uncertainty in a new market environment, mimetic isomorphism will ensure local legitimacy for long term survival.

H1. There is a positive relationship between full acquisitions conducted by other firms in a host country and a focal firm's adoption of full acquisitions in the host country.

\subsection{Hypothesis 2: Uncertainty Avoidance}

The normative pillar depicts a system of human norms that shape strategies (Kostova \& Roth, 2002; Scott, 1995). However, norms are ingrained in culture so national cultures have different normative institutions. Therefore, cultural analysis acknowledges normative distance risk to enhance the performance of foreign entrants (Brouthers, 2002; Shenkar, 2001; Slangen \& Hennart, 2008). National cultures require proactive managerial acknowledgement to protect against negative externalities. If ignored, cultural differences are a common cause of failure, particularly within acquisitions (Barkema \& Vermeulen, 1998; Rottig, 2013). Therefore, normative isomorphism reduces forecasted uncertainty and enhances local acceptance through legitimacy. Specifically, uncertainty avoidance has an influential presence on international business decisions.

Uncertainty avoidance influences CBA ownership levels (Brouthers et al., 1998; Brouthers \& Hennart, 2007). Highly uncertainty averse cultures perceive ambiguous situations as 
threats (Bhardwaj, Dietz, \& Beamish, 2007; Kedia, Keller \& Julian, 1992; Ko, Seo, \& Jung, 2015). Consequently, when distance exists between home and host environment uncertainty avoidance levels, security threats are perceived. Such differences have negative consequences on cooperation (Barkema et al., 1997). This results from contractual risk, encountering formalization ambiguity and the high costs of implementing and monitoring secure partnerships (Agarwal, 1994). Consequently, when high uncertainty avoidance distance occurs, MNCs are unlikely to work with foreign partners. Such uncertainty motivates firms to mitigate the unknown and resist change. Therefore, uncertainty avoidance is a dominant influencer of acquisition ownership choice and creates an ethnocentric appearance (Contractor, Lahiri, Elango, \& Kundu, 2014; Straughan \& Albers-Miller, 2001).

Furthermore, uncertainty is eradicated with strict regulations and standardization. Firstly, adherence to strict rules is imperative, as rules provide structure and greater structure offers clarity to processes (Aggarwal \& Goodell, 2010; Barr \& Glynn, 2004; Geletkanycz, 1997; Jackofsky, Slocum, \& McQuaid, 1988; Kedia et al., 1992; Kwok \& Tadesse, 2006; Venaik \& Brewer, 2010; Yeniyurt, \& Townsend, 2003). Consequently, with the consistent comfort of known structure, highly uncertainty avoidant cultures favour standardization (Geletkanycz, 1997; Jackofsky et al., 1988). Standardization in MNC strategy means implementing a global strategy, through full ownership. Full ownership imposes strong internal institutions facilitating resource transfer to permit the continuation of standardized practice in foreign locations. Consequently, uncertainty is reduced by avoiding local partner complexities. Instead, full control establishes subsidiary sibling interdependence to facilitate standardization (Newburry \& Yakova, 2006). The benefits of standardization not only include the generic remunerations of cost savings, time efficiency and control, but also security against uncertain results (Newburry \& Yakova, 2006; Tang \& Koveas, 2008).

Therefore, it is evident that uncertainty avoidant cultures desire control. Environments that are uncontrollable pose threats, however, controllable ones offer opportunity (Barr \& Glynn, 2004). Control enforces order and predictability of outcomes, which motivates proactive strategic behaviour (Barr \& Glynn, 2004; Duncan, 1972; Kwok \& Tadesse, 2006; Lin, 2013; Nakata \& Sivakumar, 1996; Podoynitsyna et al., 2013; Schneider, 1989; Schneider \& De Meyer, 1991; Straughan \& Albers-Miller, 2001; Venaik \& Brewer, 2010). MNCs can increase control via full ownership of acquisitions, when risk is perceived to be high (Delios \& Beamish, 1999). High risk originates when uncertainty avoidance differs between 
geographical locations. Distance limits available information, developing uncertainties about decision outcomes (Duncan, 1972). The absence of information is described as information asymmetry and is costly to highly uncertainty avoidant cultures (Aggarwal \& Goodell, 2010). Therefore, as normative distance between the home and host increases, risk assessments are disrupted. Ambiguous assessments pose uncertainty when sourcing a trustworthy local partner (Gaur \& Lu, 2007). Consequently, control is used as a protection mechanism. Full ownership reduces the threat of relational and opportunistic conflict, as there is no host partner involved (Gaur \& Lu, 2007; Lu, 2002).

$\mathrm{H} 2$. There is a positive relationship between uncertainty avoidance distance between host and home country and a focal firm's adoption of full acquisitions in the host country.

\subsection{Hypothesis 3: Collectivism}

Collectivism distance also influences levels of ownership sought in acquisition deals. Partial acquisitions are likely to result from high collectivism distance between home and host environments (Ahammad, Leone, Tarba, Glaister, \& Arlsan, 2017). A highly collectivistic partner is unlikely to willingly share their resources, due to strong in-group loyalties (Ahammad et al., 2017). Thus, to avoid resource transfer disruptions, partial acquisitions should offer a greater ownership stake to the collectivistic partner and management should demonstrate commitment through contributing tacit knowledge (Ahammad et al., 2017). This partial strategy based on quasi-integration will imprint commitment and security on the highly collectivistic partner, enhancing smoothness of operations. Quasi-integration involves an acquirer maintaining only a subset of control (Chi, 1994). This allows firms to protect their highly valuable trade secrets, as partners are permitted to exclusive rights to their own resources without having to fully internalize the resource market, but spillovers can occur (Chi, 1994). Hence, managerial structure within partial ownership structures can proactively mitigate significant losses of firm specific advantage.

Collectivists' lack of desire to share resources with acquisition targets is due to loyalties to their in-group. Collectivists' share information based on the benefits available to fellow ingroup members (Ma, Huang, Wu, Dong, \& Liyun, 2014). However, an acquisition involves sharing resources with an outsider not an in-group member. In this context, knowledge dispersion goes against the expectation of mutual benefits of member behaviour. 
Contrastingly, collaborating with an outsider can be negatively viewed as an attempt to achieve a personal desire. Personal desires acted upon eliminate firms from their in-group, as collectivists reward group cooperation (Chatman \& Barsade, 1995; Hui \& Triandis, 1986; Sawang, Oei, \& Goh, 2006). Hence, collectivists refuse to share resources with outsiders to maintain membership in their in-group, as they believe survival is dependent on in-group inclusion (Hui \& Villareal, 1989). This demonstrates collectivists' prioritization of maintaining group harmony at all costs, to facilitate their long-term success.

Therefore, normative isomorphism highlights the importance of maintaining professional standards when venturing aboard (DiMaggio \& Powell, 1983). Partial acquisitions based on quasi-integration permit such maintenance. By allowing partners exclusive rights to their own resources, professional filtering can still occur. Not integrating resources, filters out the need for disruptive adaptation requirements. Thus, infection of professional methods with foreign concepts is avoided. Therefore, partial acquisitions permit the maintenance of professional orientation and group harmony, when venturing abroad.

H3. There is a negative relationship between collectivism distance between host and home country and a focal firm's adoption of full acquisitions in the host country.

\subsection{Hypothesis 4: Regulatory Distance}

When differences exist between home and host market regulatory environments, complexities augment uncertainty. Regulatory distance is defined as "differences in legal institutions and prevalent rules, laws, and regulations in an MNE's home country and the host country" (Arslan \& Larimo, 2010, p. 182). Such differences impose comprehension and response difficulties for entrants. Therefore, as regulatory distance increases, complexities for foreign entrants rise making this pillar highly relevant to subsidiary ownership strategies (Xu et al., 2004).

There are numerous factors that trigger regulatory distance. Slangen and Beugelsdijk (2010) note that regulatory quality is dependent on the governance system standard in a country. When reduced quality is present, political instability facilitates regulatory distance, simultaneously coinciding with government corruption (Grewal \& Dharwadkar, 2002; Slangen \& Beugelsdijk, 2010). Host government arbitrary standards for foreign entrants may 
result to protect local industries (Arslan \& Larimo, 2010; Slangen \& Beugelsdijk, 2010). Such regulatory factors are exogenous, they cannot be resolved (Modejar \& Zhao, 2013; Slangen \& Beugelsdijk, 2010). Host country NGOs and trade unions can also show hostility. Hence, local governments are not the sole source of regulatory complexities. In transition economies, high regulatory distance results from unclear regulation frameworks, inexperienced bureaucracies and limited court systems (Meyer, 2001). Evidently, the presence of high regulatory distance disrupts comprehension of rules, making professional interactions difficult.

Furthermore, high regulatory distance imposes information asymmetry. Yao and Liang (2017) find that regulatory distance negatively impacts on information disclosure. When institutional distance increases, information asymmetry inflicts opportunity costs (Dikova, Sahib, \& van Witteloostuijn, 2010; Xie, Reddy, \& Liang, 2017). Firstly, local information can be misinterpreted. Ang et al. (2015) state that to comprehensively understand written laws, interpreters need to have an in-depth understanding of the regulatory environment in the host market. Therefore, regulatory distance creates interpretation and application uncertainty. Furthermore, variations of bureaucracy minimize regulation transparency and underdeveloped institutions construct interpretation ambiguity (Kedia \& Bilgili, 2015; Modejar \& Zhao, 2013; Wilson \& Veuger, 2017). Consequently, additional information processing is required to clarify regulation purpose, removing resources from the international expansion. This resource redistribution reduces the viability of business ventures, prolonging entry which may see MNCs missing their window of opportunity (Sambharya \& Musteen, 2014). However, information asymmetry works both ways. The host country has limited information about the incoming MNC, which makes it difficult to carry out the legitimacy assessment (Salomon \& Wu, 2012). Hence, when regulatory distance is high, a foreign MNE's ability to obtain legitimacy is convoluted (Xu \& Shenkar, 2002).

Therefore, the conjoint influence of non-disclosure and information asymmetry along with interpretation uncertainty, establishes LOF for the MNC. LOF results from local market unfamiliarity, which interferes with interpretation (Li et al., 2016; Salomon \& Wu, 2012). Hence, it is the LOF that augments the cost of learning and international expansion (Shirodkar \& Konara, 2017). These costs include consultant fees and time. Costs increase as institutional distance increases, and diminish when similarities exist between regulatory 
environments of the home and host (Gaur \& Lu, 2007; Moore et al., 2015). High costs can override benefits leading to termination of business ventures. Consequently, it is institutions that determine the transaction costs of participating in international expansion (Dikova et al., 2010; Meyer, 2001). Furthermore, non-compliance to regulatory institutions results in costs. Formal institutions have direct and indirect regulatory sanctions, targeted at individuals or firms, imposed by government or alternative authoritative figures (Bruton, Ahlstrom, \& Li, 2010; Grewal \& Dharwadkar, 2002). Sanctions can involve fees, fines and reputation damage.

To avoid withdrawal in locations with high regulatory distance, MNCs strategize ownership formulation. According to Agarwal (1994), when distance increases uncertainty rises, so MNCs prefer to increase their ownership stakes and internalize functions, to avoid the complexities of creating and enforcing contracts. High regulatory distance poses ambiguous law enforcement; hence, partner conflict may be difficult to resolve, leaving opportunistic behaviour to be accepted. Therefore, full ownership facilitates monitoring ease, avoiding relational hazards (Gaur \& Lu, 2007). Ownership is used as a protection mechanism. Full ownership protection permits high control of all processes and decisions which allows efficient decision making absent of partner disagreements, and permits resource transfer enabling MNCs to ensure victory and enforce successful standardized approaches in host markets (Gaur \& Lu, 2007).

However, regulations are country-specific so ownership strategies vary between nations. EMNCs partake in full ownership when regulatory distance is high between home and host countries, for a different reason. EMNCs behaviour varies to that of MNCs, due to their latecomer status (Gaffney, Karst, \& Clampit, 2016). EMNCs prefer full ownership in developed markets to take advantage of the resources present. Hence, they are perceived as using a 'springboard' approach to remain competitive, despite their late entry (Liou et al., 2016; Malhotra et al., 2016). Developed markets have stronger institutional environments, offering EMNCs greater protection, which facilitates high commitment. Consequently, EMNCs aggressively acquire resources to efficiently strengthen their competitive position and compensate the weakness inhibited in the late mover position (Luo \& Tung, 2007). Therefore, EMNCs perceive regulatory distance as an opportunity (Liou et al., 2017). 
In conclusion, the regulatory pillar has an influential position on acquisition ownership (Brouthers \& Hennart, 2007). MNCs prefer full ownership due to their ability to gain control and avoid contractual risk. Moreover, full ownership for EMNCs efficiently advances their competitive position and strengthens their survival capacity when regulatory distance is high.

H4. There is a positive relationship between regulatory distance between host and home country and a focal firm's adoption of full acquisitions in the host country.

\subsection{Hypothesis 5}

The hierarchical effects of institutional pillar influence on acquisition ownership decisions have been neglected in literature. This has led to the over reliance on the cognitive pillar, a traditional strategy research tool, leading to the misinterpretation of behaviour. Evidently, a stereotypical prejudice depicts firms as simply following each other when entering a host market. However, compliance with normative institutions and regulatory institutions is important, as their relevance to strategies analysing subsidiary control is high (Xu et al., 2004). This invites the idea that normative pillar and regulatory pillar compliance is prioritized, making the cognitive pillar relatively redundant in the formulation of ownership strategy. This suggests that firms do not simply follow each other, they indeed acknowledge the institutional environment when formulating ownership strategies.

Regulatory institutions are set by governments and define the political processes of a country, shaping political stability and the potential to predict regulatory changes (Holmes et al., 2013). However, FDI is deterred when host governments inflict tight control on MNC behaviour, especially as democratically produced institutions do not permit government exceptions for certain MNCs (Holmes et al., 2013). Tight control is managed by applying severe penalties if firms disobey regulatory institutions (Ang et al., 2015; Arslan \& Larimo, 2010; Dikova, Sahib, \& van Witteloostuijn, 2010 Grewal \& Dharwadkar, 2002). The lack of flexibility dissuades managers from practicing FDI in such a location. Consequently, host country risk is relatively less important than severe regulatory sanctions that a host's governing body can impose (Delios \& Beamish, 1999). This is amplified by the regulatory pillar basing regulatory penalties on legitimacy attainment (Xu \& Shenkar, 2002). Therefore, 
firms prioritize regulatory institutions to avoid severe sanctions and safeguard legitimacy attainment.

Moreover, regulatory institutions control the value and distribution of a country's financial resources (Holmes et al., 2013). Common belief states that once legitimacy is earned resources are made available. However, this is overly simplified as particular institutionalized behaviours are required for a firm to attain specific resources. Regulatory institutions predominantly influence inward FDI, as host financial support determines the success of entry (Holmes et al., 2013). Such support includes monetary policies and exchange rates, which have a dominant influence on the cost of expansion abroad (Holmes et al., 2013). Therefore, prioritization of regulatory institutions is important to ensure a firm has sufficient resources to successfully carry out the cross-border acquisition. Evidently, firms acknowledge the importance of regulatory institutions when venturing abroad and do not simply follow each other.

Furthermore, normative distance is also relatively more important than cognitive distance. MNCs expand abroad to exploit their firm specific advantage. However, in normatively distant locations MNCs face difficulties transferring strategies from the parent firm to subsidiaries (Eden \& Miller, 2004). Complexities arise because normative institutions are deeply tacit (Kostova \& Zaheer, 1999). When normative distance exists between home and host countries, MNC strategies appear to be appropriate and easily transferred, however, the underlying psychic distance makes the process expensive and convoluted (Xu \& Shenkar, 2002). Therefore, normative distance is relatively more important when MNCs are partaking in a global strategy, which involves full ownership practice (Xu \& Shenkar, 2002). Consequently, when normative distance imposes severe disruptions to strategy transfer within the MNC, firms terminate their entry and choose to locate subsidiaries in alternative host countries that have similar normative institutions (Xu \& Shenkar, 2002). Therefore, normative distance is acknowledged as its tacit nature can complicate strategy implementation.

H5. The effect of regulatory and normative distance on a focal firm's adoption of full acquisitions in a host country is stronger than the effect of full acquisitions conducted by other firms in the host country, on a focal firm's adoption of full acquisitions in the host country. 


\section{Chapter 4. Data and Methodology}

This chapter discusses the data and research method used to investigate the five hypotheses. Firstly, it describes and justifies the data; entry-mode selection, country selection, timeperiod, databases and the sampling process used to acquire the data. Secondly, it presents variables and their measures, followed by the research method of statistical analysis.

A quantitative research design proved appropriate to investigate the research question; how do cognitive, normative and regulatory institutions relatively influence acquisition ownership levels? The specific variables; imitation (I) and ownership (O) form the base relationship, with institutional pillars (IPs) as singular influencers. The purpose of this research is to identify the relative influence of IPs on the relationship between I and O, to describe statistical relationships between institutional pillars and acquisition ownership levels. Consequently, quantitative research is applicable and has several benefits for this study. Firstly, quantitative research is purely scientific, making justifiable conclusions with precision (Jonker \& Pennink, 2010). Hence, adhering to statistical benchmarks allows for increased statistical validity, reinforcing result quality and reliability (Cowan, 1990). Thus, the objectivity of quantitative analysis facilitates cultural stereotype avoidance (Jonker \& Pennink, 2010; Sinkovics, Penz, \& Ghauri, 2008). Also, quantitative data is largely recorded in the public sector, meaning that firms actively provide comparable information for analysis (Wisniewski, 2006). Thus, international business researchers commonly conduct quantitative research, supporting the choice of methodology for my study.

\subsection{Data}

The hypotheses were analyzed using a sample of CBAs, with acquirers from 11 countries choosing between 36 different host nations, during a six-year period commencing in 2009 and ending in 2015. The large variety of home and host nations allowed the research to include a comprehensive range of institutional distances, to maximize result value.

Reputable databases were used to obtain archival data; SDC Platinum, COMPUSTAT, the World Bank Group's Worldwide Governance Indicators (WGIs) and Hofstede's Research Centre. SDC Platinum is provided by Thomson Reuters, offering robust data on global acquisition activity within this study's time-period. This database is highly distinguished and 
used in research included in elite journals (Ang et al., 2015; Beckman \& Haunschild, 2002; Hayward, 2002). Similarly, COMPUSTAT offers significant global business data, fulfilling control variable characteristic requirements. Its fit is portrayed through its common use in research on entry-mode imitation (Ang et al., 2015; Haunschild, 1993; Haunschild \& Miner, 1997; Westphal et al., 2001). WGIs are prominently used in regulatory distance research, resulting from their quality aggregated completeness (Ang et al., 2015; Kaufmann, Kraay \& Mastruzzi, 2004; Lavie \& Miller, 2008; Shirodkar \& Konara, 2017: Siegel \& Laron, 2009; Slangen \& Beugelsdijk, 2010). Lastly, Hofstede's Research Centre is a well-known database commonly used in research that incorporates cultural constructs. Its justification is founded on its extensive use in international business, specifically in the domain of entry mode decisions (Erramilli, 1996).

Archival data permits efficient data collection, overcoming the language and geographical barriers imposed by primary data collection, demonstrating its suitability in international business research (Schultz et al., 2005). Additional benefits include the simplicity of data storage permitting a three-month analysis period and facilitating retrospective longitudinal studies which allow for a larger sample size (Lee \& Peterson, 1997; Schultz et al., 2005). Furthermore, archival data is collected non-obtrusively removing the risk of biased measures, as the collection process is distanced from the researcher (Rabinovich \& Cheon, 2011). It is also possible to attain confidential information under accepted agreements, enhancing research depth (Easterby-Smith, Thorpe, \& Jackson, 2012). Lastly, a larger volume of archival data offers higher statistical power (Rabinovich \& Cheon, 2011). Therefore, archival data removes the threat of bias and provides pertinent data volumes to enhance internal validity. A disadvantage of archival data is the lack of certainty surrounding the data quality (Easterby-Smith et al., 2012). This can be overcome by using a reputable database.

\subsection{Sample}

This research focuses on the manufacturing industry. Long term economic growth is predominantly centered on the manufacturing industry and its technology (United Nations Industrial Development Organization, 2015). Therefore, it is important to comprehend how MNCs within this industry venture abroad, to ensure they continue catalyzing economic growth. Furthermore, the focus on one industry acknowledges practice variation between 
industries (DiMaggio \& Powell, 1983). Each industry has unique internal and external pressures, which include government institutions, customer orientation and public visibility (Griffin \& Mahon, 1997). Hence, by focusing on one industry, research can uncover how similar issues are overcome, to augment the internal validity (Griffin \& Mahon, 1997). Moreover, the choice of industry is also justified by its use in reputable articles (Barkema \& Vermeulen, 1998; Beckman \& Haunschild, 2002; Guillén, 2003; Yang \& Hyland, 2012). Selected industries include; Food and Kindred products (SIC20), Machinery, and Computer and Office Equipment (SIC35), Electronic and Electrical Equipment, and Communication Equipment (SIC36). This selection consists of both high and low technology intensity levels. Food and Kindred products (SIC20) is a low-tech intensity industry whereas Machinery, and Computer and Office Equipment (SIC35) and Electronic and Electrical Equipment, and Communication Equipment (SIC36) are high-tech industries (United Nations Industrial Development Organization, 2015). This differentiation is important because firms react differently to the level of regulatory protection standards, particularly IP standards, in host countries (Fukui, Hammer, \& Jones, 2013). Therefore, institutional distance responses may differ between high-tech industry decisions and low-tech industry decisions.

The time-period of this longitudinal study is 2009 to 2015. Several justifications for this time-period exist. Firstly, it occurs post Asian Financial Crisis of 1997 and Global Financial Crisis of 2008, avoiding analysis discrepancies that a financial crisis would cause to international expansion feasibility (Yang \& Hyland, 2012). This is important as most acquirer countries chosen in this research are situated in Asia. Secondly, a pronounced number of acquisitions occurred during this time-period, explained by the removal of governmental protectionist policies towards foreign market entry and the implementation of acquisition incentives (Tseng \& Chou, 2011). Hence, this time-period is important as academia states that knowledge needs to be updated in the region of Asia-Pacific, due to significant changes to global business (Pan, 1996). Therefore, this time-period is data rich and focuses on a period of change which is in need of research.

Entities are observed CBAs. CBAs were chosen due to their popularity as an imitated international entry mode, making them common subjects of institutional isomorphism studies (Ang et al., 2015; Ang \& Michailova, 2008; Ferreira et al., 2014; Slangen \& Hennart, 2008; Xia et al., 2008). This occurs as literature states that CBAs are not conceived in 
isolation, their surroundings play a role (Lin et al., 2009). The reputability of such studies reinforces mode suitability and demonstrates sufficiency in data availability.

To commence country selection, Xie et al.'s (2017) review paper was acknowledged. This article listed the top 20 acquiring countries between 2005-2014. However, due to data availability, certain countries were added and others removed. Eleven countries are included in this study; Australia, China, Hong Kong, India, Malaysia, New Zealand, Philippines, Singapore, South Korea, Taiwan and Thailand. Predominantly Asia-Pacific based, these countries undertake CBAs and exhibit a variety of uncertainty avoidance and collectivism scores, providing a valid sample for investigation. The mixture of developed and developing markets portrays diverse standards of institution development, as developing countries are known to have less developed institutions and tend to be governed by informal institutions, whereas developed countries have strict institutions and are heavily reliant on formal institutions (Eden \& Miller, 2004). Furthermore, these countries and their host countries were all present in Hofstede's Research Centre, facilitating national culture acknowledgement for all countries included in this study. This consideration offered greater depth to research discussion.

Purposeful sampling was used. Home countries who conduct CBA as a market entry mode were used. They had varying uncertainty avoidance and collectivism scores. The original data set included over 1000 observed acquisitions. However, as SDC data was combined with COMPUSTAT data, approximately 746 observed acquisitions were deleted due to the lack of COMPUSTAT's data availability on SDC's observed acquisitions. Further observed acquisitions were deleted from the sample, due to a lack of host country inclusion in Hofstede's Research Centre. After list-wise deletion of missing data, the final data set consisted of 211 observed acquisitions. This size is suitable, because when sample size increases, random sampling errors decrease, augmenting explanatory power (Ang, 2014).

\subsection{Measurements}

\subsubsection{Dependent Variable}

Ownership was measured by the amount, as a percentage, of equity owned by the acquirer. Data was extracted from SDC Platinum. Ownership was then represented as a dummy 
variable, creating a dichotomous dependent variable. Wholly owned entry, 95\% ownership or greater, was attributed 1 and ownership percentages less than $95 \%$ were classed as international joint ventures receiving a value of 0 (Gaur \& Lu, 2007; Lu, 2002). Such amounts acknowledge common variation in acquisition ownership. The importance of this variable stems from the extensive risk associated with ownership on market entry, making it subject to imitation.

\subsubsection{Independent Variables}

Imitation. The primary independent variable used in this research is imitation. Imitation represents the number of full acquisitions conducted by other firms in a host country. It was measured by summing the number of firms in the same industry and host market that had used the ownership level in the previous three years (Ang et al., 2015; Haunschild \& Miner, 1997; Xie \& Li, 2017). According to Haunschild and Miner (1997), three years is an appropriate waiting period, as firms use recent acquisitions as models. Each year's data was then computed into a single composite variable, to avoid disruption of multicollinearity in the regression analysis (Allen, Bennett, \& Heritage, 2014).

Uncertainty Avoidance Distance. Uncertainty avoidance distance represents the difference in uncertainty avoidance between home and host countries. It was calculated using the uncertainty avoidance cultural value dimension taken from Hofstede (1980). Home country and host country uncertainty avoidance values were taken from Hofstede's Research Centre. Home country uncertainty avoidance scores were then subtracted from host country uncertainty avoidance scores, providing a numerical figure for the distance between home and host uncertainty avoidance levels.

Collectivism Distance. Collectivism distance represents the difference in collectivism between home and host countries. It was calculated using the collectivism cultural value dimension taken from Hofstede (1980). Home country and host country collectivism values were taken from Hofstede's Research Centre. Home country collectivism scores were then subtracted from host country collectivism scores, providing a numerical figure for the distance between home and host collectivism levels. 
Regulatory Distance. Regulatory distance represents the difference in regulatory institutions between home and host countries. It was measured by the WGIs (Ang et al., 2015; Lavie \& Miller, 2008; Shirodkar \& Konara, 2017: Siegel \& Laron, 2009; Slangen \& Beugelsdijk, 2010; Kaufmann et al., 2004). The six indicators include; Voice and Accountability, Government Effectiveness, Political Stability, Regulatory Quality, Rule of Law and Corruption Control (Kaufmann et al., 2004). WGIs offer maximum insight into regulatory distance, as they incorporate aggregated indicators pooled from 35 data sources of 33 organizations. These include information about 199 countries and territories (Kaufmann et al., 2004; Kaufmann, Kraay, \& Mastruzzi, 2009). Furthermore, the time-period of this study matches the WGIs data period. Moreover, subjects of data sources include; the public sector, the private sector, NGO experts, and a multitude of citizens (Kaufmann et al., 2009). This enables a sufficient variety of respondents to offer comprehensive regulatory insight into a large number of countries. Perceptions are measured to portray action foundations, reiterate that governance has no paper trail, and acknowledge differences between written law and practice reality (Kaufmann et al., 2009). Furthermore, Kaufmann et al. (2009) state that WGIs are highly valuable to international business studies as numerous cross-cultural comparisons have statistically significant differences, likely resulting from the reduced margins of error that accompanies their data set. Lavie and Miller's (2008) method is used to calculate regulatory distance. Regulatory distance is computed using the formula $\sum j=1 \mid$ GI $\mathrm{j}$ - GI $\mathrm{h}$, where GI $\mathrm{j}$ indicates host country government indicator sum, and GI $\mathrm{h}$ indicates home country government indicator sum.

\subsubsection{Control Variables}

The following control variables were included in the final research design; firm size, firm performance, firm experience, industry and year.

Firm Size. Firm size is an important control variable influencing acquisition intensity (Collins et al., 2009; Erramilli, 1996). The literature states that larger firms are more likely to partake in foreign expansion, due to their relatively larger amount of resources (Ang et al., 2015). Furthermore, large firms imitate other large firms, due to relatively larger risks involved with sizeable entry efforts (Haveman, 1993). Consequently, by controlling for firm size, the data includes only firms who have the capacity to participate in foreign expansion. It was measured by conducting a natural log of total revenue, for each year up to three years 
prior. Data values were in the millions so the following formula was used, log (value $\mathrm{x}$ $1,000,000)$. To combat the multicollinearity caused by the three separate size variables, only one of the variables was used, current firm size (Allen et al., 2014).

Firm Performance. This control measures performance prior to the acquisition taking place, which indicates a firm's ability to finance acquisitions, facilitating cross-border acquisition imitation potential (Haunschild, 1993; Hayward, 2002). Therefore, controlling for performance refines appropriate sample characteristics. It was measured using Return on Assets (ROA) at t-1 (Ang et al., 2015; Collins et al., 2009; Haunschild, 1993). The following formula was used: (EBITDA/Total Assets).

Firm Experience. This variable is relevant to imitation research, as the level of experience a firm has influences the how firms imitate. Consequently, it must be acknowledged when analyzing imitation behaviours. It is measured by calculating the number of acquisitions a firm has conducted in the previous five years (Ang et al., 2015).

Industry. This control accounts for institutional diversity between industries. This study focuses solely on the manufacturing industry. Three SIC codes were chosen; Food and Kindred products (SIC20), Machinery, and Computer and Office Equipment (SIC 35), and Electronic and Electrical Equipment, and Communication Equipment (SIC36). As previously stated, the manufacturing industry is an appropriate choice given its use in reputable articles and its role in economic development (Barkema \& Vermeulen, 1998; Beckman \& Haunschild, 2002; Guillén, 2003; Yang \& Hyland, 2012).

Year. This was controlled using a series of dummy variables (Hayward M. , 2002). The following years were included as dummy variables; 2009, 2010, 2011, 2012, 2013, 2014, 2015. Representing years as dummies acknowledged any annual changes in environments where acquisitions were completed (Tseng \& Chou, 2011).

\subsection{Analysis}

This research used logistic regression analysis to examine all five hypotheses. STATA, a statistical software for professionals, was used to conduct the logistic regression analyses. 
STATA was the best program to use for the analysis, as it provides the most comprehensive parameter estimate information (Peng, Lee, \& Ingersoll, 2002).

Logistic regression was conducted to test these statistical relationships. Logistic regression is used to estimate the probability of the occurrence of an event, the event being the dependent variable of ownership (Ang, 2014). Logistic regression is highly appropriate for this research, as it contains a dichotomous dependent variable (Kleinbaum \& Klein, 2002). Ownership is a binary, dichotomous and mutually exclusive variable crafted as a dummy variable, with 1 representing full ownership and 0 representing partial ownership. This reinforces the appropriateness of logistic regression, as the logistic function $f(\mathrm{z})$ has a range between 0 and 1 (Kleinbaum \& Klein, 2002). Furthermore, the relationship between the dependent and independent variables is non-linear in logistic regression (Ang, 2014). Logistic regression formulates an elongated S-shape to portray the logistic function, demonstrating the existence of a threshold which aids the formulation of conditions under which ownership types occur (Kleinbaum \& Klein, 2002). This is highly valuable for explaining relationships between ownership modes.

The following logistic regression model was used:

$$
\operatorname{Logit}(\mathrm{Y})=\alpha+\beta 1 \mathrm{X} 1+\beta 2 \mathrm{X} 2 \ldots+\beta \mathrm{kXk}
$$

$\mathrm{X}$ represents an independent variable, $\alpha$ is a constant term portraying an unknown parameter, and $\beta \mathrm{i}$ are parameters calculated using the maximum likelihood model (Ang, 2014; Kleinbaum \& Klein, 2002). The maximum likelihood model is appropriate as it places no restrictions on the type of independent variables used, permitting the use of categorical, ordinal and interval variables (Kleinbaum \& Klein, 2002). Moreover, the maximum likelihood model is preferred over weighted least squares, by several academic researchers (Peng et al., 2002). 


\section{Chapter 5. Results}

\subsection{Descriptive Statistics}

Table 1 reports the descriptive statistics of CBAs conducted by eleven acquirer nations between the years 2009 and 2015. Acquirer nations consisted predominantly of countries located in Asia, where collectivism and uncertainty avoidance varies. The inclusion of Australia and New Zealand, low uncertainty avoidant and collectivistic countries, offered valuable variance to the cultural dimension values. Variance enabled the research to analyze normative distance. Moreover, with both developed and developing nations in this sample, regulatory distance could also be analyzed. Hence, these sample characteristics made the sample suitable for assessing the relative impact of institutions through using distance factors. The sample size included a total of 211 observations in the manufacturing sector. The number of partial acquisitions was slightly greater than the number of full acquisitions, with 107 partial acquisitions and 104 full acquisitions. Moreover, the most acquisitions were conducted from the acquirer home country, Taiwan, who conducted 74 acquisitions. In terms of acquisition target location, Asia (excluding Japan), the BRIC nations, and the European Union were popular. Asia (excluding Japan) was the most common acquisition location with 52 acquisitions occurring there. In contrast, South Africa was the least desirable location receiving 1 acquisition. The greatest number of acquisitions conducted by one home country into one host country, was conducted by Chinese firms who conducted 23 acquisitions in the European Union. 
Table 1. Descriptive statistics of sample acquisitions

\begin{tabular}{|c|c|c|c|c|c|c|}
\hline & Australia & China & Hong Kong & India & Malaysia & New Zealand \\
\hline \multicolumn{7}{|l|}{ Sector } \\
\hline Manufacturing & $\begin{array}{c}6 \\
(2.8)\end{array}$ & $\begin{array}{c}51 \\
(24.2)\end{array}$ & $\begin{array}{c}3 \\
(1.4)\end{array}$ & $\begin{array}{c}4 \\
(1.9)\end{array}$ & $\begin{array}{c}11 \\
(5.2)\end{array}$ & $\begin{array}{c}3 \\
(1.4)\end{array}$ \\
\hline Total & $\begin{array}{c}6 \\
(2.8) \\
\end{array}$ & $\begin{array}{c}51 \\
(24.2)\end{array}$ & $\begin{array}{c}3 \\
(1.4) \\
\end{array}$ & $\begin{array}{c}4 \\
(1.9)\end{array}$ & $\begin{array}{c}11 \\
(5.2) \\
\end{array}$ & $\begin{array}{c}3 \\
(1.4) \\
\end{array}$ \\
\hline \multicolumn{7}{|l|}{ Governance Mode } \\
\hline Partial Acquisition & $\begin{array}{c}4 \\
(3.7)\end{array}$ & $\begin{array}{c}28 \\
(26.2)\end{array}$ & $\begin{array}{c}1 \\
(0.9)\end{array}$ & $\begin{array}{c}1 \\
(0.9)\end{array}$ & $\begin{array}{c}6 \\
(5.6)\end{array}$ & $\begin{array}{c}1 \\
(0.9)\end{array}$ \\
\hline Full Acquisition & $\begin{array}{c}2 \\
(1.9)\end{array}$ & $\begin{array}{c}23 \\
(21.5) \\
\end{array}$ & $\begin{array}{c}2 \\
(1.9)\end{array}$ & $\begin{array}{c}3 \\
(2.8) \\
\end{array}$ & $\begin{array}{c}5 \\
(4.7) \\
\end{array}$ & $\begin{array}{c}2 \\
(1.9)\end{array}$ \\
\hline Total & $\begin{array}{c}6 \\
(2.8) \\
\end{array}$ & $\begin{array}{c}51 \\
(24.2) \\
\end{array}$ & $\begin{array}{c}3 \\
(1.4) \\
\end{array}$ & $\begin{array}{c}4 \\
(1.9) \\
\end{array}$ & $\begin{array}{c}11 \\
(5.2) \\
\end{array}$ & $\begin{array}{c}3 \\
(1.4) \\
\end{array}$ \\
\hline \multicolumn{7}{|l|}{ Acquisition Location } \\
\hline U.S. & $\begin{array}{c}1 \\
(2.9)\end{array}$ & $\begin{array}{c}4 \\
(11.4)\end{array}$ & $\begin{array}{c}0 \\
(0.0)\end{array}$ & $\begin{array}{c}0 \\
(0.0)\end{array}$ & $\begin{array}{c}0 \\
(0.0)\end{array}$ & $\begin{array}{c}1 \\
(2.9)\end{array}$ \\
\hline U. K. & $\begin{array}{c}0 \\
(0.0)\end{array}$ & $\begin{array}{c}1 \\
(8.3)\end{array}$ & $\begin{array}{c}0 \\
(0.0)\end{array}$ & $\begin{array}{c}1 \\
(8.3)\end{array}$ & $\begin{array}{c}0 \\
(0.0)\end{array}$ & $\begin{array}{c}0 \\
(0.0)\end{array}$ \\
\hline European Union & $\begin{array}{c}0 \\
(0.0)\end{array}$ & $\begin{array}{c}23 \\
(57.5)\end{array}$ & $\begin{array}{c}0 \\
(0.0)\end{array}$ & $\begin{array}{c}1 \\
(2.5)\end{array}$ & $\begin{array}{c}0 \\
(0.0)\end{array}$ & $\begin{array}{c}0 \\
(0.0)\end{array}$ \\
\hline Japan & $\begin{array}{c}0 \\
(0.0)\end{array}$ & $\begin{array}{c}1 \\
(9.1)\end{array}$ & $\begin{array}{c}0 \\
(0.0)\end{array}$ & $\begin{array}{c}0 \\
(0.0)\end{array}$ & $\begin{array}{c}0 \\
(0.0)\end{array}$ & $\begin{array}{c}0 \\
(0.0)\end{array}$ \\
\hline BRIC & $\begin{array}{c}0 \\
(0.0)\end{array}$ & $\begin{array}{c}12 \\
(27.9)\end{array}$ & $\begin{array}{c}1 \\
(2.3)\end{array}$ & $\begin{array}{c}1 \\
(2.3)\end{array}$ & $\begin{array}{c}1 \\
(2.3)\end{array}$ & $\begin{array}{c}1 \\
(2.3)\end{array}$ \\
\hline Americas (less U.S.) & $\begin{array}{c}0 \\
(0.0)\end{array}$ & $\begin{array}{c}1 \\
(20.0)\end{array}$ & $\begin{array}{c}0 \\
(0.0)\end{array}$ & $\begin{array}{c}0 \\
(0.0)\end{array}$ & $\begin{array}{c}0 \\
(0.0)\end{array}$ & $\begin{array}{c}0 \\
(0.0)\end{array}$ \\
\hline Asia (less Japan) & $\begin{array}{c}1 \\
(1.9)\end{array}$ & $\begin{array}{c}6 \\
(11.5)\end{array}$ & $\begin{array}{c}2 \\
(3.8)\end{array}$ & $\begin{array}{c}1 \\
(1.9)\end{array}$ & $\begin{array}{c}10 \\
(19.2)\end{array}$ & $\begin{array}{c}0 \\
(0.0)\end{array}$ \\
\hline Australasia \& Pacific & $\begin{array}{c}4 \\
(80.0)\end{array}$ & $\begin{array}{c}0 \\
(0.0)\end{array}$ & $\begin{array}{c}0 \\
(0.0)\end{array}$ & $\begin{array}{c}0 \\
(0.0)\end{array}$ & $\begin{array}{c}0 \\
(0.0)\end{array}$ & $\begin{array}{c}1 \\
(20.0)\end{array}$ \\
\hline Canada & $\begin{array}{c}0 \\
(0.0)\end{array}$ & $\begin{array}{c}2 \\
(50.0)\end{array}$ & $\begin{array}{c}0 \\
(0.0)\end{array}$ & $\begin{array}{c}1 \\
(25.0)\end{array}$ & $\begin{array}{c}0 \\
(0.0)\end{array}$ & $\begin{array}{c}0 \\
(0.0)\end{array}$ \\
\hline Middle East & $\begin{array}{c}0 \\
(0.0)\end{array}$ & $\begin{array}{c}0 \\
(0.0)\end{array}$ & $\begin{array}{c}0 \\
(0.0)\end{array}$ & $\begin{array}{c}0 \\
(0.0)\end{array}$ & $\begin{array}{c}0 \\
(0.0)\end{array}$ & $\begin{array}{c}0 \\
(0.0)\end{array}$ \\
\hline South Africa & $\begin{array}{c}0 \\
(0.0)\end{array}$ & $\begin{array}{c}1 \\
(100.0)\end{array}$ & $\begin{array}{c}0 \\
(0.0)\end{array}$ & $\begin{array}{c}0 \\
(0.0)\end{array}$ & $\begin{array}{c}0 \\
(0.0)\end{array}$ & $\begin{array}{c}0 \\
(0.0)\end{array}$ \\
\hline Switzerland & $\begin{array}{c}0 \\
(0.0) \\
\end{array}$ & $\begin{array}{c}0 \\
(0.0) \\
\end{array}$ & $\begin{array}{c}0 \\
(0.0) \\
\end{array}$ & $\begin{array}{c}0 \\
(0.0) \\
\end{array}$ & $\begin{array}{c}0 \\
(0.0) \\
\end{array}$ & $\begin{array}{c}0 \\
(0.0) \\
\end{array}$ \\
\hline Total & $\begin{array}{c}6 \\
(2.8)\end{array}$ & $\begin{array}{c}51 \\
(23.4)\end{array}$ & $\begin{array}{c}3 \\
(1.4)\end{array}$ & $\begin{array}{c}4 \\
(3.7)\end{array}$ & $\begin{array}{c}11 \\
(5.0)\end{array}$ & $\begin{array}{c}3 \\
(1.4)\end{array}$ \\
\hline
\end{tabular}

Note: Percentages in brackets. 
Table 1 (continued). Descriptive statistics of sample acquisitions (continued).

\begin{tabular}{|c|c|c|c|c|c|c|}
\hline & Philippines & Singapore & South Korea & Taiwan & Thailand & Total \\
\hline \multicolumn{7}{|l|}{ Sector } \\
\hline Manufacturing & $\begin{array}{c}1 \\
(0.5)\end{array}$ & $\begin{array}{c}16 \\
(7.6)\end{array}$ & $\begin{array}{c}41 \\
(19.4)\end{array}$ & $\begin{array}{c}74 \\
(35.1)\end{array}$ & $\begin{array}{c}1 \\
(0.5)\end{array}$ & $\begin{array}{c}211 \\
(100)\end{array}$ \\
\hline Total & $\begin{array}{c}1 \\
(0.5) \\
\end{array}$ & $\begin{array}{c}16 \\
(7.6) \\
\end{array}$ & $\begin{array}{c}41 \\
(19.4) \\
\end{array}$ & $\begin{array}{c}74 \\
(35.1) \\
\end{array}$ & $\begin{array}{c}1 \\
(0.5) \\
\end{array}$ & $\begin{array}{c}211 \\
(100)\end{array}$ \\
\hline \multicolumn{7}{|l|}{ Governance Mode } \\
\hline Partial Acquisition & $\begin{array}{c}0 \\
(0.0)\end{array}$ & $\begin{array}{c}9 \\
(8.4)\end{array}$ & $\begin{array}{c}21 \\
(19.6)\end{array}$ & $\begin{array}{c}35 \\
(32.7)\end{array}$ & $\begin{array}{c}1 \\
(0.9)\end{array}$ & $\begin{array}{c}107 \\
(50.7)\end{array}$ \\
\hline Full Acquisition & $\begin{array}{c}1 \\
(0.9)\end{array}$ & $\begin{array}{c}7 \\
(6.7)\end{array}$ & $\begin{array}{c}20 \\
(19.2)\end{array}$ & $\begin{array}{c}39 \\
(37.5)\end{array}$ & $\begin{array}{c}0 \\
(0.0)\end{array}$ & $\begin{array}{c}104 \\
(49.3)\end{array}$ \\
\hline Total & $\begin{array}{c}1 \\
(0.5)\end{array}$ & $\begin{array}{c}16 \\
(7.6)\end{array}$ & $\begin{array}{c}41 \\
(19.4) \\
\end{array}$ & $\begin{array}{c}74 \\
(35.1) \\
\end{array}$ & $\begin{array}{c}1 \\
(0.5)\end{array}$ & $\begin{array}{c}211 \\
(100)\end{array}$ \\
\hline \multicolumn{7}{|l|}{ Acquisition Location } \\
\hline U.S. & $\begin{array}{c}0 \\
(0.0)\end{array}$ & $\begin{array}{c}2 \\
(5.7)\end{array}$ & $\begin{array}{c}14 \\
(40)\end{array}$ & $\begin{array}{c}13 \\
(37.1)\end{array}$ & $\begin{array}{c}0 \\
(0.0)\end{array}$ & $\begin{array}{c}35 \\
(16.6)\end{array}$ \\
\hline U. K. & $\begin{array}{c}0 \\
(0.0)\end{array}$ & $\begin{array}{c}2 \\
(16.7)\end{array}$ & $\begin{array}{c}3 \\
(25)\end{array}$ & $\begin{array}{c}5 \\
(41.7)\end{array}$ & $\begin{array}{c}0 \\
(0.0)\end{array}$ & $\begin{array}{c}12 \\
(5.7)\end{array}$ \\
\hline European Union & $\begin{array}{c}0 \\
(0.0)\end{array}$ & $\begin{array}{c}1 \\
(2.5)\end{array}$ & $\begin{array}{c}7 \\
(17.5)\end{array}$ & $\begin{array}{c}7 \\
(17.5)\end{array}$ & $\begin{array}{c}1 \\
(2.5)\end{array}$ & $\begin{array}{c}40 \\
(19.0)\end{array}$ \\
\hline Japan & $\begin{array}{c}0 \\
(0.0)\end{array}$ & $\begin{array}{c}0 \\
(0.0)\end{array}$ & $\begin{array}{c}1 \\
(9.1)\end{array}$ & $\begin{array}{c}9 \\
(81.8)\end{array}$ & $\begin{array}{c}0 \\
(0.0)\end{array}$ & $\begin{array}{c}11 \\
(5.2)\end{array}$ \\
\hline BRIC & $\begin{array}{c}0 \\
(0.0)\end{array}$ & $\begin{array}{c}2 \\
(4.7)\end{array}$ & $\begin{array}{c}6 \\
(14.0)\end{array}$ & $\begin{array}{c}19 \\
(44.1)\end{array}$ & $\begin{array}{c}0 \\
(0.0)\end{array}$ & $\begin{array}{c}43 \\
(20.4)\end{array}$ \\
\hline Americas (less U.S.) & $\begin{array}{c}0 \\
(0.0)\end{array}$ & $\begin{array}{c}0 \\
(0.0)\end{array}$ & $\begin{array}{c}0 \\
(0.0)\end{array}$ & $\begin{array}{c}3 \\
(75.0)\end{array}$ & $\begin{array}{c}0 \\
(0.0)\end{array}$ & $\begin{array}{c}4 \\
(1,9)\end{array}$ \\
\hline Asia (less Japan) & $\begin{array}{c}1 \\
(1.9)\end{array}$ & $\begin{array}{c}8 \\
(15.4)\end{array}$ & $\begin{array}{c}9 \\
(15.4)\end{array}$ & $\begin{array}{c}14 \\
(26.9)\end{array}$ & $\begin{array}{c}0 \\
(0.0)\end{array}$ & $\begin{array}{c}52 \\
(24.6)\end{array}$ \\
\hline Australasia \& Pacific & $\begin{array}{c}0 \\
(0.0)\end{array}$ & $\begin{array}{c}0 \\
(0.0)\end{array}$ & $\begin{array}{c}0 \\
(0.0)\end{array}$ & $\begin{array}{c}0 \\
(0.0)\end{array}$ & $\begin{array}{c}0 \\
(0.0)\end{array}$ & $\begin{array}{c}5 \\
(2.4)\end{array}$ \\
\hline Canada & $\begin{array}{c}0 \\
(0.0)\end{array}$ & $\begin{array}{c}0 \\
(0.0)\end{array}$ & $\begin{array}{c}1 \\
(25.0)\end{array}$ & $\begin{array}{c}0 \\
(0.0)\end{array}$ & $\begin{array}{c}0 \\
(0.0)\end{array}$ & $\begin{array}{c}4 \\
(1.9)\end{array}$ \\
\hline Middle East & $\begin{array}{c}0 \\
(0.0)\end{array}$ & $\begin{array}{c}1 \\
(33.3)\end{array}$ & $\begin{array}{c}0 \\
(0.0)\end{array}$ & $\begin{array}{c}2 \\
(66.7)\end{array}$ & $\begin{array}{c}0 \\
(0.0)\end{array}$ & $\begin{array}{c}3 \\
(1.4)\end{array}$ \\
\hline South Africa & $\begin{array}{c}0 \\
(0.0)\end{array}$ & $\begin{array}{c}0 \\
(0.0)\end{array}$ & $\begin{array}{c}0 \\
(0.0)\end{array}$ & $\begin{array}{c}0 \\
(0.0)\end{array}$ & $\begin{array}{c}0 \\
(0.0)\end{array}$ & $\begin{array}{c}1 \\
(0.5)\end{array}$ \\
\hline Switzerland & $\begin{array}{c}0 \\
(0.0)\end{array}$ & $\begin{array}{c}0 \\
(0.0)\end{array}$ & $\begin{array}{c}0 \\
(0.0) \\
\end{array}$ & $\begin{array}{c}2 \\
(100.0)\end{array}$ & $\begin{array}{c}0 \\
(0.0) \\
\end{array}$ & $\begin{array}{c}2 \\
(0.9) \\
\end{array}$ \\
\hline Total & $\begin{array}{c}1 \\
(0.5)\end{array}$ & $\begin{array}{c}16 \\
(7.3)\end{array}$ & $\begin{array}{c}41 \\
(18.8)\end{array}$ & $\begin{array}{c}74 \\
(34.9)\end{array}$ & $\begin{array}{c}1 \\
(0.5)\end{array}$ & $\begin{array}{c}211 \\
(100)\end{array}$ \\
\hline
\end{tabular}

Note: Percentages in brackets. 
Table 2 reports correlations between variables under investigation. Firstly, Table 2 identifies that there are no high correlations between predictor values, as correlation values reside with -0.70 and 0.70 (Bedeian, 2014, p. 130). Therefore, no issues of collinearity can be observed. Moreover, the mean of uncertainty avoidance distance is -5.85 with a standard deviation of 33.39. Evidently the sample consists of sufficient distance of uncertainty avoidance between home and host countries, providing the capacity to measure the impact of institutional change on CBA ownership. Similarly, the mean of collectivism distance is -27.15 with a standard deviation of 33.33 , which also provides appropriate distance diversity to measure the impact on institutional change. Lastly, the mean of regulatory distance is relatively smaller at 0.76 with a standard deviation of 6.69. However, distance is still visible enabling regulatory distance to be measured. Consequently, these values indicate that institutional distance was measured in the sample, highlighting the relative influence of institutions on CBA ownership. 
Table 2. Correlation matrix $(\mathrm{N}=211)$

\begin{tabular}{|c|c|c|c|c|c|c|c|c|c|c|c|c|c|c|c|c|c|c|c|c|c|}
\hline & Variable & Mean & S.D. & (1) & (2) & (3) & (4) & (5) & (6) & (7) & (8) & (9) & $(10)$ & $(11)$ & $(12)$ & (13) & (14) & $(15)$ & (16) & (17) & $(18)$ \\
\hline$(1)$ & Ownership & 0.49 & 0.50 & 1.00 & & & & & & & & & & & & & & & & & \\
\hline$(2)$ & Imitation Full Total & 108.57 & 350.05 & 0.19 & 1.00 & & & & & & & & & & & & & & & & \\
\hline (3) & Uncertainty Avoidance distance & -5.85 & 33.39 & -0.03 & -0.23 & 1.00 & & & & & & & & & & & & & & & \\
\hline (4) & Collectivism distance & -27.15 & 33.33 & -0.29 & -0.36 & -0.04 & 1.00 & & & & & & & & & & & & & & \\
\hline$(5)$ & Regulatory distance & 0.76 & 6.69 & 0.18 & 0.07 & 0.25 & -0.05 & 1.00 & & & & & & & & & & & & & \\
\hline (6) & Firm Size & 23.98 & 4.37 & 0.13 & 0.38 & -0.53 & 0.11 & 0.00 & 1.00 & & & & & & & & & & & & \\
\hline$(7)$ & Firm Performance & 0.07 & 0.12 & 0.11 & 0.17 & 0.05 & -0.13 & 0.08 & 0.25 & 1.00 & & & & & & & & & & & \\
\hline (8) & Experience & 1.29 & 2.27 & -0.07 & 0.18 & -0.18 & 0.07 & -0.16 & 0.46 & 0.15 & 1.00 & & & & & & & & & & \\
\hline$(9)$ & SIC20 & 0.96 & 0.20 & -0.16 & -0.10 & 0.19 & -0.05 & -0.12 & -0.10 & 0.19 & 0.28 & 1.00 & & & & & & & & & \\
\hline (10) & SIC35 & 0.33 & 0.47 & 0.14 & 0.03 & 0.09 & 0.29 & 0.00 & -0.15 & 0.05 & -0.21 & -0.21 & 1.00 & & & & & & & & \\
\hline (11) & SIC36 & 0.57 & 0.50 & -0.02 & 0.04 & -0.21 & -0.05 & 0.08 & 0.20 & -0.17 & 0.01 & -0.47 & -0.76 & 1.00 & & & & & & & \\
\hline (12) & Year 2009 & 0.14 & 0.35 & -0.13 & -0.11 & 0.08 & -0.03 & -0.15 & -0.13 & 0.11 & 0.21 & 0.23 & -0.12 & -0.05 & 1.00 & & & & & & \\
\hline (13) & Year 2010 & 0.14 & 0.35 & -0.14 & -0.06 & -0.06 & -0.06 & -0.13 & 0.06 & -0.06 & -0.02 & -0.01 & 0.18 & -0.15 & -0.17 & 1.00 & & & & & \\
\hline (14) & Year 2011 & 0.14 & 0.35 & -0.14 & 0.04 & -0.04 & -0.04 & -0.09 & 0.09 & 0.15 & -0.03 & -0.15 & 0.06 & 0.05 & -0.18 & -0.17 & 1.00 & & & & \\
\hline (15) & Year 2012 & 0.16 & 0.36 & -0.08 & 0.06 & -0.20 & 0.07 & -0.01 & 0.20 & 0.02 & 0.14 & -0.03 & -0.13 & 0.14 & -0.18 & -0.17 & -0.18 & 1.00 & & & \\
\hline (16) & Year 2013 & 0.10 & 0.31 & 0.10 & 0.08 & 0.06 & 0.04 & 0.09 & -0.07 & -0.08 & -0.10 & 0.03 & 0.06 & -0.08 & -0.14 & -0.13 & -0.14 & -0.14 & 1.00 & & \\
\hline (17) & Year 2014 & 0.11 & 0.32 & -0.07 & 0.07 & 0.01 & -0.03 & 0.10 & -0.07 & -0.11 & -0.11 & -0.13 & -0.04 & 0.12 & -0.15 & -0.14 & -0.15 & -0.15 & -0.12 & 1.00 & \\
\hline (18) & Year 2015 & 0.20 & 0.40 & -0.08 & -0.05 & 0.15 & -0.02 & 0.18 & -0.09 & -0.05 & -0.10 & 0.05 & -0.01 & -0.03 & -0.20 & -0.20 & -0.21 & -0.21 & -0.16 & -0.18 & 1.00 \\
\hline
\end{tabular}

${ }^{+}|\mathrm{r}|>0.066-p<0.10 ; *|\mathrm{r}|>0.078-p<0.05 ; * *|\mathrm{r}|>0.108-p<0.01 ; * * *|\mathrm{r}|>0.127-p<0.001$ 
Table 3. Logistic regression results on institutions' relative influence on acquisition ownership

\begin{tabular}{|c|c|c|c|c|c|c|c|c|}
\hline Variable & Model 1 & & Model 2 & & Model 3 & & Model 4 & \\
\hline Intercept & $\begin{array}{l}-2.210 \\
(1.062)\end{array}$ & * & $\begin{array}{c}-3.293 \\
(1.159)\end{array}$ & $* *$ & $\begin{array}{c}-1.990 \\
(1.068)\end{array}$ & & $\begin{array}{c}-2.636 \\
(1.022)\end{array}$ & $*$ \\
\hline Firm Size & $\begin{array}{c}0.404 \\
(0.045)\end{array}$ & & $\begin{array}{c}0.082 \\
(0.050)\end{array}$ & & $\begin{array}{r}0.032 \\
(0.046)\end{array}$ & & $\begin{array}{c}0.060 \\
(0.044)\end{array}$ & \\
\hline Firm Performance & $\begin{array}{c}2.195 \\
(1.610)\end{array}$ & & $\begin{array}{c}2.491 \\
(1.678)\end{array}$ & & $\begin{array}{c}1.598 \\
(1.620)\end{array}$ & & $\begin{array}{c}1.940 \\
(1.647)\end{array}$ & \\
\hline Experience & $\begin{array}{l}-0.095 \\
(0.089)\end{array}$ & & $\begin{array}{c}-0.088 \\
(0.089)\end{array}$ & & $\begin{array}{c}-0.097 \\
(0.091)\end{array}$ & & $\begin{array}{l}-0.053 \\
(0.089)\end{array}$ & \\
\hline SIC351 & $\begin{array}{c}1.097 \\
(0.603)\end{array}$ & + & $\begin{array}{c}1.282 \\
(0.605)\end{array}$ & $*$ & $\begin{array}{c}0.797 \\
(0.639)\end{array}$ & & $\begin{array}{c}1.174 \\
(0.614)\end{array}$ & + \\
\hline SIC361 & $\begin{array}{c}0.803 \\
(0.562)\end{array}$ & & $\begin{array}{c}0.942 \\
(0.567)\end{array}$ & + & $\begin{array}{c}0.462 \\
(0.598)\end{array}$ & & $\begin{array}{c}0.786 \\
(0.575)\end{array}$ & \\
\hline Year 2010 & $\begin{array}{c}1.115 \\
(0.600)\end{array}$ & + & $\begin{array}{c}1.123 \\
(0.604)\end{array}$ & + & $\begin{array}{c}1.171 \\
(0.620)\end{array}$ & + & $\begin{array}{c}1.195 \\
(0.611)\end{array}$ & + \\
\hline Year 2011 & $\begin{array}{c}0.866 \\
(0.571)\end{array}$ & & $\begin{array}{c}0.877 \\
(0.573)\end{array}$ & & $\begin{array}{c}0.977 \\
(0.593)\end{array}$ & + & $\begin{array}{c}0.972 \\
(0.583)\end{array}$ & + \\
\hline Year 2012 & $\begin{array}{c}-0.064 \\
(0.559)\end{array}$ & & $\begin{array}{c}0.008 \\
(0.556)\end{array}$ & & $\begin{array}{l}-0.229 \\
(0.585)\end{array}$ & & $\begin{array}{l}-0.122 \\
(0.568)\end{array}$ & \\
\hline Year 2013 & $\begin{array}{c}1.053 \\
(0.653)\end{array}$ & & $\begin{array}{c}1.169 \\
(0.652)\end{array}$ & + & $\begin{array}{c}1.004 \\
(0.665)\end{array}$ & & $\begin{array}{c}0.997 \\
(0.668)\end{array}$ & \\
\hline Year 2014 & $\begin{array}{c}-0.186 \\
(0.610)\end{array}$ & & $\begin{array}{l}-0.042 \\
(0.601)\end{array}$ & & $\begin{array}{l}-0.272 \\
(0.624)\end{array}$ & & $\begin{array}{l}-0.227 \\
(0.615)\end{array}$ & \\
\hline Year 2015 & $\begin{array}{l}-0.126 \\
(0.527)\end{array}$ & & $\begin{array}{c}0.153 \\
(0.532)\end{array}$ & & $\begin{array}{l}-0.232 \\
(0.557)\end{array}$ & & $\begin{array}{l}-0.064 \\
(0.541\end{array}$ & \\
\hline Imitation full & $\begin{array}{c}0.001 \\
(0.001)\end{array}$ & + & & & & & & \\
\hline Uncertainty Avoidance distance & & & $\begin{array}{c}0.004 \\
(0.006)\end{array}$ & & & & & \\
\hline Collectivism distance & & & & & $\begin{array}{l}-0.020 \\
(0.006)\end{array}$ & $* * *$ & & \\
\hline Regulatory distance & & & & & & & $\begin{array}{c}0.064 \\
(0.025)\end{array}$ & $* *$ \\
\hline $\begin{array}{l}\text { LR chi2 } \\
\text { d.f. }\end{array}$ & $\begin{array}{c}32.29 \\
12\end{array}$ & $* * *$ & $\begin{array}{c}28.24 \\
12\end{array}$ & $* *$ & $\begin{array}{c}42.09 \\
12\end{array}$ & $* * *$ & $\begin{array}{c}34.79 \\
12\end{array}$ & $* * *$ \\
\hline Model 5 & Coef. & Std. Err. & & Dif mean. & Std. Err. & $\mathrm{Z}$ & & \\
\hline $\mathrm{dxr}$ (imitation) & 0.001 & 0.001 & & -0.003 & 0.000 & -6.949 & & \\
\hline $\mathrm{dxr}(\mathrm{UA})$ & 0.004 & 0.006 & & & & & & \\
\hline $\begin{array}{l}\text { dxr(imitation }) \\
\mathrm{dxr}(\text { COLL })\end{array}$ & $\begin{array}{c}0.001 \\
-0.020\end{array}$ & $\begin{array}{l}0.001 \\
0.006\end{array}$ & & 0.021 & 0.000 & 56.066 & & \\
\hline $\begin{array}{l}\text { dxr(imitation) } \\
\text { Dxr(RD) }\end{array}$ & $\begin{array}{l}0.001 \\
0.064\end{array}$ & $\begin{array}{l}0.001 \\
0.025\end{array}$ & & -0.063 & 0.002 & -36.944 & & \\
\hline Number of alliances & 211 & & 211 & & 211 & & 211 & \\
\hline
\end{tabular}




\subsection{Hypothesis Testing}

Table 3 shows the logistic regression of 211 CBAs that conducted full or partial CBA ownership, between 2009 to 2015 . It tests the five research hypotheses regarding the relative influence of cognitive, normative and regulatory institutions on CBA ownership. The maximum likelihood method was used.

\subsubsection{Hypothesis 1}

Model 1 in Table 3 reports parameters for hypothesis 1 . The LR Chi-square is 32.29 and is significant at 0.0012 confidence level, with 12 degrees of freedom. The small p-value of the Chi-square portrays that there is at least one predictor variable in the model that has an important influence on ownership probability.

Model 1 shows that three variables are significant; SIC35, Year 2010, and Imitation. The log of the odds of SIC35 was positively related to ownership ( $\beta=1.097, P=0.069)$. Consequently, MNCs competing in SIC35 (Machinery, and Computer and Office Equipment) are more likely to engage in full ownership than MNCs in SIC201. Moreover, the log of odds of Year 2010 was positively related to ownership $(\beta=1.115, P=0.063)$. Hence, MNCs in the year 2010 were more likely to partake in full ownership than in 2009. Lastly, the log of odds of imitation was positively related to ownership $(\beta=0.001, P=0.079)$.

Hypothesis 1 predicts that there is a positive relationship between full acquisitions conducted by other firms in a host country and a focal firm's adoption of full acquisitions in the host country. Therefore, this hypothesis was supported with a positive loading of $\beta=0.0013$ ( $P=$ $0.079)$.

\subsubsection{Hypothesis 2}

Model 2 in Table 3 reports parameters for hypothesis 2. The LR Chi-square is 28.24 and is significant at 0.0051 confidence level, with 12 degrees of freedom. The small p-value of the Chi-square portrays that there is at least one predictor variable in the model that has an important influence on ownership probability. 
Model 2 shows that four variables are significant; SIC35 (Machinery, and Computer and Office Equipment), SIC36 (Electronic and Electrical Equipment, and Communication Equipment), Year 2010 and Year 2013. The log of the odds of SIC35 was positively related to ownership ( $\beta=1.282, P=0.035)$. Consequently, MNCs competing in SIC35 are more likely to partake in full ownership than MNCs in SIC201. Similarly, the log of the odds of SIC36 was positively related to ownership $(\beta=0.942, P=0.096)$. MNCs competing in SIC36 are more likely to partake in full CBA ownership than MNCs in SIC201. Moreover, the log of the odds of year 2010 was positively related to ownership $(\beta=1.123, P=0.062)$. Similarly, the log of odds of year 2013 was also positively related to ownership $(\beta=1.1669, P=0.073$ ). Consequently, MNCs in the years 2010 and 2013 were more likely to partake in full ownership than in 2009. However, Model 2 shows that uncertainty avoidance distance has a p-value of 0.476 . Consequently, the relationship between uncertainty avoidance and ownership is not significant.

Hypothesis 2 predicts a positive relationship between uncertainty avoidance distance between host and home country and a focal firm's adoption of full acquisitions in the host country. However, as Model 2 does not contain a significant relationship between uncertainty avoidance distance and ownership, no comment can be made on whether this hypothesis is supported or not.

\subsubsection{Hypothesis 3}

Model 3 in Table 3 reports parameters for hypothesis 3. The LR Chi-square is 42.09 and is significant at 0.000 confidence level, with 12 degrees of freedom. The small p-value of the Chisquare indicates that there is at least one predictor variable in the model that has an important influence on ownership probability.

Model 3 shows that three variables are significant; Year 2010, Year 2011 and Collectivism distance. The $\log$ of odds of Year 2010 was positively related to ownership $(\beta=1.171, P=$ 0.059). Consequently, MNCs in 2010 were more likely to engage in full acquisition ownership than in 2009. Similarly, the log of odds of Year 2011 was also positively related to ownership ( $\beta=0.977, P=0.099)$. Therefore, MNCs in the year 2011 were also more likely to engage in full acquisition ownership than in 2009. Moreover, the log of odds of collectivism distance was negatively related to ownership $(\beta=-0.020, P=0.000)$. 
Hypothesis 3 predicts a negative relationship between collectivism distance between host and home country and a focal firm's adoption of full acquisitions in the host country. This hypothesis was supported with a negative loading of $\beta=-0.020(P=0.000)$. Findings state that when collectivism distance increases, full ownership decreases.

\subsubsection{Hypothesis 4}

Model 4 in Table 3 reports parameters for hypothesis 4 . The LR Chi-square is 34.79 and is significant at 0.000 confidence level, with 12 degrees of freedom. The small p-value of the Chisquare portrays that there is at least one predictor variable in the model that has an important influence on ownership probability.

Model 4 shows that four variables are significant; SIC35, Year 2010, Year 2011 and Regulatory distance. The $\log$ of odds of SIC35 was positively related to ownership $(\beta=1.174, P=0.056)$. Firms competing in SIC35 are more likely to engage in full ownership of acquisitions than MNCs in SIC201. Moreover, the log of odds of Year 2010 was positively related to ownership ( $\beta=0.972, P=0.051)$, as were the log of odds of Year 2011 ( $\beta=0.972, P=0.096)$. Consequently, MNCS in the years 2010 and 2011 were more likely to partake in full acquisition ownership than in 2009. Lastly, the log of odds of regulatory distance was positively related to ownership ( $\beta=-0.064, P=0.009$ ). Therefore, as regulatory distance increases, full ownership of acquisitions increases.

Hypothesis 4 predicts a positive relationship between regulatory distance between host and home country and a focal firm's adoption of full acquisitions in the host country. Model 4 portrays this relationship. Therefore, this hypothesis was supported with a positive loading of $\beta=0.064(P=0.009)$. Consequently, the findings state that when regulatory distance increases full ownership increases.

\subsubsection{Hypothesis 5}

Model 5 in Table 3 uses model 1 as a baseline and then interprets the relative effects of model 2, model 3 and model 4. Appropriate model fit has already been established for these four models, hence, the fit of model 5 is appropriate. 
Model 5 compares model 1, model 2, model 3 and model 4, to demonstrate the interplay of cognitive, normative and regulatory institutions on ownership.

\section{Imitation and Uncertainty Avoidance Distance}

There is a difference in effect between imitation and uncertainty avoidance distance, reflected in the $\mathrm{z}$ score -6.949 . However, only imitation is significant. There is a positive relationship between imitation and ownership $(\beta=0.0013, P=0.079)$. In contrast, uncertainty avoidance distance has a p-value of 0.476 , which is above the 0.10 threshold. Consequently, uncertainty avoidance distance is not significant. Thus, there is not sufficient evidence that a relationship exists between uncertainty avoidance distance and ownership. In conclusion, imitation is argued to have a relatively stronger impact on ownership than uncertainty avoidance distance.

\section{Imitation and Collectivism Distance}

There is a difference in effect between imitation and collectivism distance, reflected in the $\mathrm{z}$ score 56.066. Both variables are significant; imitation and collectivism. There is a positive relationship between imitation and ownership $(\beta=0.0013, P=0.079)$. In contrast, there is a negative relationship between collectivism distance and ownership $(\beta=-0.0201, P=0.000)$. However, collectivism distance has a larger coefficient $(\beta=-0.0201)$, compared to that of imitation $(\beta=0.0013)$. Therefore, collectivism distance is argued to have a relatively stronger impact on ownership, than imitation.

\section{Imitation and Regulatory Distance}

There is a difference in effect between imitation and regulatory distance, reflected in the $\mathrm{z}$ score -36.94. Both variables are significant; imitation and regulatory distance. There is a positive relationship between imitation and ownership $(\beta=0.0013, P=0.0007)$. Moreover, there is a positive relationship between regulatory distance and ownership $(\beta=0.064, P=0.009)$. However, regulatory distance has a larger coefficient $(\beta=0.064)$, compared to that of imitation $(\beta=0.001)$. Therefore, regulatory distance is argued to have a relatively stronger impact on ownership than imitation.

Hypothesis 5 predicted that the effect of distance on a focal firm's adoption of full acquisitions in a host country is stronger than the effect of full acquisitions conducted by other firms in the host country, on a focal firm's adoption of full acquisitions in the host country. This was proven 
by model 3 and model 4, which stated that collectivism distance and regulatory distance both had a relatively greater influence on ownership, than the effect of full acquisitions conducted by other firms in the host country. In model 2, uncertainty avoidance distance was not significant ( $\beta=0.004, P=0.476$ ). Therefore, there is not sufficient evidence that a relationship exists between uncertainty avoidance distance and ownership. Consequently, no judgements can be made on the relative influence of uncertainty avoidance on ownership. However, basing judgement on model 3 and model 4, there is evidence of support for hypothesis 5.

\subsubsection{Control Variables}

Model 1 in Table 3 reported that nine control variables were not significant; Firm Size $(P=$ 0.373), Firm Performance $(P=0.173)$, Experience $(P=0.287)$, SIC36 $(P=0.153)$, Year 2011 $(P=0.129)$, Year $2012(P=0.909)$, Year $2013(P=0.107)$, Year $2014(P=0.760)$, and Year $2015(P=0.811)$. Such $P$-values are greater than the significance level of 0.10 . This suggests that there was not sufficient evidence that a relationship exists between ownership and each of the following variables; Firm Size, Firm Performance, Experience, Year 2011, Year 2012, Year 2013, Year 2014 and Year 2015.

Model 2 in Table 3 reported that seven control variables were not significant; Firm Size $(P=$ 0.103), Firm Performance ( $P=0.138)$, Experience $(P=0.326)$, Year $2011(P=0.126)$, Year 2012 ( $P=0.989)$, Year $2014(P=0.944)$, and Year $2015(P=0.773)$. Such $P$-values are greater than the significance level of 0.10 . This suggests that there was not sufficient evidence to confirm a relationship exists between ownership and each of the following variables; Firm Size, Firm Performance, Experience, Year 2011, Year 2012, Year 2014 and Year 2015.

Model 3 in Table 3 reported that nine control variables were not significant; Firm Size ( $P=$ 0.487), Firm Performance $(P=0.324)$, Experience $(P=0.286)$, SIC35 $(P=0.213)$, SIC36 $(P=$ 0.440), Year $2012(P=0.695)$, Year $2013(\mathrm{P}=0.131)$, Year $2014(P=0.663)$, and Year 2015 $(P=0.677)$. Such $P$-values are greater than the significance level of 0.10 . This suggests that there was not sufficient evidence to confirm a relationship exists between ownership and each of the following variables; Firm Size, Firm Performance, Experience, SIC35, SIC36, Year 2012, Year 2013, Year 2014 and Year 2015. 
Model 4 in Table 3 reported that eight control variables were not significant; Firm Size $(P=$ 0.171), Firm Performance $(P=0.239)$, Experience $(P=0.549)$, SIC36 $(P=0.172)$, Year 2012 $(P=0.829)$, Year $2013(P=0.136)$, Year $2014(P=0.713)$ and Year $2015(P=0.906)$. Such $P-$ values are greater than the significance level of 0.10 . This suggests that there was not sufficient evidence to confirm a relationship exists between ownership and each of the following variables; Firm Size, Firm Performance, Experience, SIC36, Year 2012, Year 2013, Year 2014 and Year 2015.

The results lacked supportive evidence to confirm individual relationships between firm size, firm performance and experience, and ownership. Such explanations can be rationalized through observations of EMNCs engaging in full CBA ownership.

An explanation for the lack of significance of firm size may be linked to EMNC participation in full CBA ownership. The literature states that EMNCs internationalize aggressively, partaking in full acquisitions in developed areas to springboard their competitive position. Hence, their reason for international expansion differs compared to that of MNCs. They desire to 'catch up' to their MNCs counterparts and remain competitive. Therefore, it can be inferred that EMNCs are relatively smaller than MNCs, having entered the market later and desiring to catch up. Size does not constrain the amount of acquisition ownership a firm can conduct. Similarly, the lack of significance of firm performance may also be related to the participation of EMNCs in full CBA ownership. As previously stated, EMNCs partake in full CBA ownership to aggressively catch up to $\mathrm{MNC}$ capacities, having entered late. Therefore, it is likely EMNC performance is relatively lower than that of MNCs from developed markets, yet they still partake in full CBA ownership. Therefore, firm performance may be insignificant to a firm's capacity to partake in full CBA ownership. Lastly, the lack of experience significance to ownership can also be explained by EMNC behaviour. EMNCs enter the market relatively later than MNCs, so they consequently have less experience. However, because they partake in full CBA ownership, experience levels are not significant for the level of acquisition ownership a firm decides to engage in.

Moreover, the insignificance of Years 2012, 2014 and 2015 may be explained the lack of market disruptions during these years. These years are situated the furthest from the Asian Financial Crisis and the Global Financial Crisis, so there may be less market threat/uncertainty pressuring firms to safeguard their firm-specific capabilities 


\section{Chapter 6. Discussions and Conclusions}

\subsection{Discussion of Results of Hypothesis Testing}

\subsubsection{Hypothesis 1}

The results for Hypothesis 1 show that when firms in the host country are conducting fully owned acquisitions, a focal firm is more likely to partake in full ownership. This reflects institutional theory's cognitive pillar which states that mimetic isomorphism is a response to reduce uncertainty in a new market environment. The popularity of full acquisition ownership in the host country portrays it as a taken-for-granted practice. Foreign firms perceive taken-forgranted practices as institutionalized behaviours, presenting such practices as successful behaviours that a new entrant may adopt to attain similar success. This is also known as frequency-based imitation. Through witnessing peers' behaviours, firms can vicariously learn and respond to the expectations of a new host market (Kraatz, 1995). However, when firms stray from socially constructed behaviours, unbearable fear develops, eventually leading firms to succumb to social pressure and practice the popular behaviour (Abrahamson \& Rosenkopf, 1993). Consequently, mimetic isomorphism leads to timely entry that is also cost efficient. In contrast, strategizing a unique entry mode only to succumb to frequency based imitation, results in a loss of resources due to backtracking and re-entry via a different strategy. Therefore, firms who follow each other engage indirectly in resource efficiency (DiMaggio \& Powell, 1983). Yet, this is a secondary effect, as imitation does not prioritize efficiency.

Moreover, partaking the institutionalized behaviour of full acquisition ownership, facilitates attainment of legitimacy (DiMaggio \& Powell, 1983). Legitimacy is given in return for foreign entrants' active respect of host institutions ( $\mathrm{Li}$ et al., 2007). Hence, imitation can be used as a signal to inform the host market of institutional obedience (Ang et al., 2015). Such certification demonstrates to the entrant that the host country accepts their presence (Kostova \& Zaheer, 1999). Evidently, legitimacy is prioritized and provides foreign entrants with various benefits to facilitate their long-term survival. Legitimacy allows firms to prioritize competing for prestigious inputs, and focus less on efficiency due to the strong entry barriers of legitimate status (DiMaggio \& Powell, 1983). Moreover, legitimate firms gain resource access in their host market (Li et al., 2007). This portrays firms who attain host legitimacy are protected from nationalistic based intervention (Li et al., 2007). Therefore, such access facilitates ease of business and improves firm capacity to survive long-term. Consequently, firms who follow 
other firms' entry mode models attain legitimacy which facilitates asset security and enhances their chances of success.

This finding supports the traditional application of cognitive institutions to strategy research. Customarily, strategy researchers apply the cognitive pillar to their research, whereas the normative pillar and the regulatory pillar are researched by international management researchers (Ang et al., 2015). This was noticeable in Lieberman and Asaba's (2006) study that solely focused on environmental uncertainty, analyzing mimetic isomorphism. Such practice follows the identified trend that mimetic isomorphism is the most used pillar construct in empirical studies (Mizruchi \& Fein, 1999).

In conclusion, firms follow each other for the sake of signaling their compliance to host country expectations, in the interest of acquiring legitimacy. Due to the immense opportunities legitimacy status offers, followership is prioritized to secure the capacity to attain such status.

\subsubsection{Hypothesis 2}

The results for Hypothesis 2 show there is not a significant relationship between uncertainty avoidance and acquisition ownership. This is consistent with Ahammad et al.'s (2017) study based on real options theory and transaction cost economics that portrayed uncertainty avoidance as not significant with acquisition ownership. Ahammad et al. (2017) note that uncertainty is a multifaceted variable, hence the broadness of the construct portrays a need to specify a certain type of uncertainty to research. Alternatively, Werner, Brouthers and Brouthers (1996) recognize the importance of including numerous international risk variables. Evidently, a single and broad variable is inadequate for analyzing uncertainty. Caution towards uncertainty avoidance was first introduced by Kogut and Singh (1988) who state that the cultural value dimension is defined in terms of organizational preference, not in terms of cultural attitudes towards risk in wider contexts. Therefore, the complexity of uncertainty avoidance influence on entry mode outcomes must be delicately decoded (Kogut and Singh, 1988). The present study does not specify a type of uncertainty, simply using the broad uncertainty avoidant construct. Consequently, the lack of explicit uncertainty focus may have interfered with the analysis process, leading to failure to find significance between full ownership and uncertainty avoidance. 
However, such results contradict prior research that routinely used uncertainty avoidance as a primary research construct in ownership studies (Brouthers et al., 1998; Contractor et al., 2014; Erramilli, 1996; Hennart \& Larimo, 1998; Pan, 1996). Contractor et al. (2014) state that uncertainty has one of the biggest impacts on MNC acquisition ownership, particularly in emerging markets. Such research portrays the dominant effect the dimension once had. Similarly, Erramilli (1996) states that high anxiety levels present in uncertainty avoidant cultures lead to MNCs implementing full control, due to the risk of working with local partners, whereas low uncertainty avoidant cultures are open to risk taking, willingly cooperating with local partners. Hence, uncertainty avoidance has been proven to influence ownership in both high and low uncertainty avoidant firms. According to Barkema et al., (1997) uncertainty avoidance distance is of great concern, as risk tolerance and formalization disrupt international cooperation efforts. Consequently, prior studies found evidence that supported the importance of uncertainty avoidance in ownership studies. Therefore, theoretical foundations of entry mode decisions and uncertainty avoidance appear interconnected, yet empirical findings do not clearly prove that this connection exists (Brouthers et al., 1998). However, Ahammad et al.'s (2017) study is more recent, and may signal a change in influences of ownership in the present day.

Furthermore, such contradictions in literature have been noted to result from the selection of countries under investigation. Brouthers et al. (1998) hold that empirical finding discrepancies between Kogut and Singh (1988) and Erramilli (1996) may occur as a result of Kogut and Singh's 1988 investigation of the US as a host market, compared with other higher risk markets used in Erramilli's (1996) study. However, the present research includes a variety of high-risk markets and excludes the US, so does not support this argument. Moreover, Ahammad et al (2017) make note of the relatively hands-off approach to business of their study's sole home country, Britain. This may explain the lack of uncertainty avoidance significance, as the British proactively disengage with business, demonstrating a radical approach to their low uncertainty avoidance. Evidently, more studies are needed to investigate whether national culture value dimension significance is country dependent.

Moreover, criticisms of Hofstede's cultural value dimensions are ever present. McSweeney (2002) states that Hofstede's model is problematic and many of his claims fail when tested. Hence, he fails to identify national culture traits. Hofstede claims no part of life is exempt from the grasp of his dimensions; religion, literature, family structures, architecture and social 
stratification are included on his unlimited list (McSweeney, 2002). It is evident that his cultural value dimensions have a broad application, which may disrupt their ability to precisely measure uncertainty within the context of this research. Failing to acknowledge the influence of macroscopic and microscopic cultures, along with cultural and non-cultural stimuli, reinforces this idea that Hofstede's cultural value dimensions are too broad (McSweeney, 2002). Furthermore, his small and single business sample is not believed to be applicable to a country's population (Gollnhofer \& Turkina, 2015). Consequently, as his claims fail to be proven, his theory lacks certification (McSweeney, 2002). Therefore, an alternative measure has been used in literature to measure cultural distance. The Kogut and Singh Index has often been implemented in research on foreign entry (Barkema et al., 1996; Collins et al., 2008; Gollnhofer $\&$ Turkina, 2015). This index offers a convenient measure and permits accurate statistical analysis, which has led to its use in over 200 articles (Yeganeh, 2011). Resulting from the extensive criticism Hofstede's values have encountered, the Kogut and Singh Index is perceived as a reliable informant of cultural distance and has become a widely used tool.

\subsubsection{Hypothesis 3}

The results for Hypothesis 3 show that a negative relationship exists between collectivism distance between host and home country and a focal firm's adoption of full acquisitions in the host country. This supports Ahammad et al's (2017) research that found high collectivism distance leads to partial acquisition ownership, due to collectivistic cultures' unwillingness to share resources with a firm outside their in-group. Collectivists' share information based on the benefits available to fellow in-group members (Ma et al., 2014). Yet, an acquisition involves sharing information with an outsider, a firm that is not an in-group member. In this context, knowledge dispersion goes against the expectation of mutual benefits of member behaviour that governs in-groups. In contrast, knowledge sharing with an outsider can be negatively perceived as an attempt to achieve a personal desire. Personal desires acted upon eliminate firms from their in-group, as collectivists reward group cooperation (Chatman \& Barsade, 1995; Hui \& Triandis, 1986; Sawang et al., 2006). Therefore, collectivists refuse to share resources with outsiders to maintain membership in their in-group, as they believe survival is dependent on ingroup inclusion (Hui \& Villareal, 1989). But to sustain membership trust is vital, so in-group sharing is strictly maintained (Smith et al., 1995). 
Furthermore, collectivistic cultures prioritize group harmony over financial incentives. This is often seen to impair their economic growth (Kyriacou, 2016). However, regardless of its financial expense, members put group loyalties first (Hui \& Triandis, 1986). Literature characterizes the attraction of full acquisitions to involve relatively higher financial returns, compared to partial acquisitions. Fully owned acquisitions avoid coordination costs, portraying such ownership to have strong economic rationale (Davis et al., 2000; Gaur \& Lu, 2007). However, collectivists champion group harmony over financial return, so they are content with partial acquisitions. Moreover, partial acquisitions protect collectivists from losses that could impede their ability to partake in required in-group behaviours when cultural distance is present. Tihanyi et al. (2005) state that high cultural distance requires flexibility to safely respond to risk. Full acquisition ownership encounters high exit costs due to the significant amount of resources a firm must commit. Consequently, reduced resource commitment lessens the cost of market exit. Partial acquisitions permit greater flexibility when cultural distance is present between the home and host country (Davis et al., 2000; Delios \& Beamish, 1999). Therefore, partial acquisitions protect collectivists by allowing them to exit acquisitions more easily and avoid debilitating consequences that could implicate their in-group harmony.

Moreover, Ahammad et al. (2017) maintain that greater attention should be focused on collectivism in ownership studies. As previously stated, uncertainty avoidance is broad in nature, which can negatively influence analysis accuracy. However, collectivism contains a refined focus, being explicit and measurable (Fadil et al., 2005). This facilitates ease of identification and precision in analysis. Moreover, the appropriateness of collectivism as a research construct stems from its title as the most popular dimension used in cross-cultural research (Taras, Kirkman, \& Steel, 2010). This shows a relevance to cross-cultural studies, recognizing it has important implications on international business studies. Therefore, collectivism should be an important focus of ownership research. However, this does contradict prior studies that present uncertainty avoidance and power distance as significant determinants of international entry mode choice, identifying the importance of risk perception and trust on such decisions (Brouthers et al., 1998; Brouthers \& Hennart, 2007). Specifically, uncertainty avoidance has been the construct traditionally used in judgement and decision-making research (Chatterjee, Atav, Min, \& Taylor, 2014). Hence, such application illustrates a gap in literature concerning collectivism and its effect on acquisition ownership decisions. Regardless, cultural distance is an acknowledged factor during the formation of CBA ownership, demonstrating that firms do not simply follow each other. 


\subsubsection{Hypothesis 4}

Results for hypothesis 4 show there is a positive relationship between regulatory distance between host and home country and a focal firm's adoption of full acquisitions in the host country. This illustrates that regulatory distance is acknowledged when firms formulate CBA ownership strategies. However, MNCs and EMNCs engage in full acquisition ownership for different reasons.

Firstly, the results support the literature that states that EMNCs engage in full acquisition ownership when venturing into developed countries, to aggressively compete with MNCs from developed markets (Arslan \& Dikova, 2015; Liou et al., 2016; Luo \& Tung, 2007). EMNCS take advantage of institutional distance, to overcome their poorly developed home country institutions which limit EMNCs growth and delay their market entry. Therefore, fully owned acquisitions and institutional distance offer EMNCs a springboard. EMNCs take advantage of strong institutional environments by aggressively acquiring resources to overcome their home market constraints at an international level (Luo \& Tung, 2007). Consequently, EMNCs are not threatened by regulatory distance, they identify such distance as an opportunity (Liou et al., 2017). Therefore, when regulatory distance is high, EMNCs partake in full CBA ownership due to their latecomer status (Liou et al., 2016; Gaffney et al., 2017).

Moreover, findings also support Agarwal's (1994) research that stated that MNCs who face foreign market uncertainty, maintain internal control through full ownership due to the complexities surrounding creating and administering contracts. Regulatory distance imposes legal differences between home and host markets' contractual formalities, which can be difficult to manage. Ambiguous laws may result in partner conflict causing acquisition failure. This occurs as regulatory distance imposes information asymmetry, thus inflicting investment risk and contractual risk (Dikova et al., 2010; Xie et al., 2017). However, full ownership allows MNCs to respond to comprehensively understood internal institutions and also monitor behaviours (Gaur \& Lu, 2007). Therefore, MNCs prefer to conduct full CBA ownership to simplify regulation obedience by following internal institutions. Furthermore, MNCs partaking in full acquisition ownership when regulatory distance is high augment their survival in two ways; internal system control ameliorates efficient decision making with minimal chance of conflict, and resource transfer within an MNC allows a firm to take advantage of its specific capabilities (Gaur \& Lu, 2007). Sole ownership lessens the threat of conflict, providing efficient 
progress capabilities. Consequently, control that is transposed through full ownership, works as a protection mechanism in regulatory distant markets, to eradicate local opportunistic behaviour and safeguard MNC competitive advantage.

Furthermore, the acknowledgement of regulatory institutions when formulating acquisition ownership strategies supports Arslan and Larimo's (2010) research that shows that regulatory institutions are prioritized to avoid severe penalties of illegal behaviour. Despite the benefits FDI brings, many are still threatened by foreign presence. Consequently, host governments may inflict restrictive policies on MNCs to protect domestic industries (Arslan \& Larimo, 2010). Unfortunately host government pressures are highly complex due to their creation via collaborative efforts of multiple interest groups (Henisz \& Zelner, 2005). This impedes on the ability of foreign entrants to comprehend regulatory institutions and correctly respond. Severe repercussions are imposed when MNCs incorrectly interpret/disobey the host country's regulatory environment, especially when MNCs threaten the greater good of society (Grewal \& Dharwadkar, 2002). Regulatory sanctions can be directly or indirectly imposed (Gatignon \& Anderson, 1988; Grewal \& Dharwadkar, 2002). Direct sanctions involve constraints on foreign equity holdings obliging foreign entrants to share ownership, whereas, indirect sanctions encompass transaction hazards resulting from weaknesses in the host country's institutional environment (Delios \& Beamish, 1999). Therefore, regulatory institutions have a dominant influence on ownership, due to the threat of encountering crippling consequences (Delios \& Beamish, 1999). Consequently, when regulatory distance is present, firms proactively strategize their ownership to avoid illegal behaviours by internalizing their strategy. Internalizing strategy means the subsidiary must adhere to internal institutions. This augments confidence in differentiating between legal and illegal behaviours, as they have sound knowledge of HQ institutions.

Evidently, regulatory distance is acknowledged when firms formulate CBA ownership strategies. Both MNCs and EMNCs strategically respond to regulatory distance to ensure they avoid debilitating regulatory sanctions and take advantage of opportunities that distance can provide. 


\subsubsection{Hypothesis 5}

Results for hypothesis 5 show that the effect of regulatory and normative distance on a focal firm's adoption of full acquisitions in a host country is stronger than the effect of full acquisitions conducted by other firms in the host country on a focal firm's adoption of full acquisitions in the host country. This finding supports Xu et al.'s (2004) research that regulatory institutions and normative institutions are of greater relevance to research concerning subsidiary control strategies. Furthermore, findings also support the increasing researcher belief that the three institutional pillars should be simultaneously analyzed (Ang et al., 2015; Hirsch, 1997). This view is shaped by independent pillar analysis distorting results and leading to the mislabeling of effects (Mizruchi \& Fein, 1999). Consequently, such distortion demonstrates misuse of institutional theory, reducing its value (Hirsch, 1997). Therefore, all three pillars must be simultaneously analyzed to portray a comprehensive illustration of the pillar interplay and its resulting influence (Ang et al., 2015; Gaur et al., 2007). Incorporating all three institutional pillars respects a founding concept of institutional theory; institutions work in unison, not alone (DiMaggio \& Powell, 1983). This contradicts the research trend that studies have taken, solely investigating one institutional pillar. Strategy research tended to focus on the cognitive pillar (Lieberman \& Asaba, 2006). However, the findings of this study reinforce that such research has inaccurately illustrated the strategic explanations of firm behaviour. Also, it would be highly problematic for a firm to consider only one institutional pillar, especially the cognitive pillar, due to the regulatory sanctions and lack of strategy viability firms could encounter.

Regulatory distance is acknowledged by firms when formulating their ownership strategies. As previously stated, regulatory distance increases the threat of being unable to gain legitimacy in a host market. When regulatory distance exists between home and host markets, laws and rules are highly different, which causes institutions to appear ambiguous and disrupts the attempts of foreign firms to understand and adapt to host regulations. Moreover, when host market regulations are incorrectly interpreted, regulatory sanctions pose a significant threat to the new entrants' operations. Being a victim of regulatory sanctions leads to crippling results. Therefore, the fear of severe regulatory repercussions drives firms to prioritize regulatory institutions (Delios \& Beamish, 1999).

Moreover, normative distance is also addressed by firms when formulating their ownership strategies. This supports research that states that cultural distance must be acknowledged as 
having an influence on entry mode ownership (Ahammad et al., 2017; Egelhoff, 1984; Kogut \& Singh, 1988). Each culture has a unique set of political, sociological and psychological mindsets (Hofstede, 1983a). It can therefore be complicated for an acquirer to comprehend a culturally distant firm's idea and communicate that ambiguity exists (Brouthers et al., 1998). Consequently, when two firms from different cultures attempt to integrate their businesses without proactively managing cultural differences, conflict occurs. Conflict can have a fatal influence on acquisitions (Barkema \& Vermeulen, 1998). This highlights that culture is not the cause of conflict within acquisitions, but rather it is a lack of proactive management of cultural differences (Rottig, 2013). Therefore, distress about acquisition failure initiates a firm's prioritization of normative institutions.

Furthermore, results show that a hierarchy exists within the three institutional pillars, reflecting their relative influences on acquisition ownership. This supports Chuang et al.'s (2011) study that illustrated pillar interaction depicts a hierarchy between the three pillars. Results show that the regulatory pillar has a relatively stronger influence than the normative pillar. This supports Yiu and Makino's (2002) research that identified regulatory institutions as imposing a greater influence on entry mode decisions. Two ideas have been chosen to explain the relative importance of regulatory institutions. Firstly, Ang et al.'s (2015) research identified regulatory institutions to have a relatively stronger influence on how MNCs react to institutional pressures, because regulatory institutions are shaped by normative institutions. Consequently, when pursuing regulatory institutions firms simultaneously pursue normative institutions too (Ang et al., 2015). Moreover, prioritizing regulatory institutions over normative institutions is reinforced by regulatory sanctions that threaten firms who disobey host laws and rules. Such consequences support the proactive prioritization of the regulatory pillar, to avoid crippling penalties. Hence, regulatory distance has an important role in entry mode explanations (Brouthers \& Hennart, 2007; Delios \& Beamish, 1999; Meyer, 2001).

However, the normative pillar is also important, as cultural differences affect the implementation of MNC strategies in the host market. Its tacit nature creates complexities for foreign entrants to identify cultural differences, which can lead to discrepancies between a firm's ownership strategy and societal norms and values. Consequently, cultural differences are a common cause of acquisition failure (Barkema and Vermeulen, 1998; Rottig, 2013). Hence, when normative distance is too great, firms are known to pull out of such markets and opt for those who share similar normative institutions. However, as normative institutions do not 
involve threatening regulatory sanctions, they are less important than regulatory institutions. Therefore, proactive management of culture is vital for long term success.

Lastly, the results show that the cognitive pillar has the weakest influence on acquisition ownership. This pillar identifies environment uncertainty exists in new host markets and uses taken-for-granted behaviours to overcome concerns. However, the relative risk of misinterpreting taken-for-granted behaviour is smaller than that of the regulatory pillar and the normative pillar. As previously stated, regulatory institutions impose debilitating sanctions for misconduct, and the tacit nature of normative institutions threatens the viability of strategy implementation. Evidently, the severity of outcomes from these two pillars motivate firms to prioritize them when formulating ownership strategies. However, the LOF is only partially reduced by both regulatory and normative pillar efforts to respond. Therefore, cognitive efforts remain highly important. This ensures that a new entrant comprehends how host players interpret stimuli in their environment, which facilitates their national responsiveness (Kostova $\&$ Zaheer, 1999). Inexperience introduces ambiguous technologies and goals, along with other environmental discrepancies, which could eventually induce failure in the host market if not acted upon (DiMaggio \& Powell, 1983; Kostova \& Roth, 2002). Hence, acknowledging cognitive distance is highly important in order to demonstrate respect of host market expectations and to gain legitimacy. Consequently, following host firms' behaviour is a catalyst for attaining legitimacy.

\subsection{Conclusions}

To conclude, the findings strongly indicate that firms do not simply follow each other when venturing abroad. All three institutional pillars influence CBA ownership decisions, and do so in a hierarchical formation. Thus, institutions work in unison and must all be considered. This has valuable relevance to the realistic context in which firms venture abroad, as it would be problematic for a firm to acknowledge only one institutional pillar. The hierarchical formation shows that the regulatory pillar is prioritized, followed by the normative pillar and then by the cognitive pillar. The regulatory pillar has the strongest influence on ownership decisions due to severe regulatory sanctions that threaten MNC capabilities. The normative pillar has a moderate impact on CBA ownership decisions, as the pillar does not implement severe regulatory sanctions, but tacit cultural differences are a usual cause of acquisition failure. Lastly, the cognitive pillar has the least influence, as the threats of regulatory distance and cultural distance 
are relative stronger than the popularity of actions, because of the crippling repercussions that result. Yet, it is imperative to not discard less influential institutions as irrelevant. Hence, by including all three pillars in research, results increase in value due to their sound theoretical foundation. In contrast, studies that do not include all three institutional pillars mislabel firm behaviour and deplete institutional theory's value. Incorrect use of theory is hazardous. Strategic actions are wrongly explained, readers are erroneously informed and the study is deemed unreliable.

Moreover, when including cultural constructs in research it is important to avoid using broad constructs. Hofstede's cultural value dimensions have encountered significant criticisms, as his claims fail to be proven. Along with the caution posed towards Hofstede's uncertainty avoidance national culture value dimension by reputable researchers, a different measure of uncertainty avoidance distance would be appropriate. The broad characteristic of Hofstede's uncertainty avoidance cultural value dimension, may have interfered with the analysis process, leading it to be found insignificant with acquisition ownership. Specifying a type of uncertainty or including multiple risk provoking variable constructs in studies, could ensure detailed and comprehensive analysis of uncertainty avoidance. Moreover, an alternative method for measuring uncertainty avoidance distance is the Kogut and Singh Index. The popularity of the Kogut and Singh Index in reputable studies researching cultural distance portrays that it is an appropriate measure.

Furthermore, the findings identified a potential shift in which national culture value dimensions influence ownership decisions. Formally, uncertainty avoidance and power distance have been identified as having important influences on decisions of ownership. However, findings from this research support the developing trend that collectivism is a national culture value dimension that should be given greater attention in ownership research. This demonstrates an evolution from remarkable influences, which should be noted for future studies. Such a shift may be explained by the increasing dominance of collectivist cultures in international business, compared to the historic dominance of the U.S., the U.K. and Europe, which are stand out locations of research on ownership. This idea is reinforced by Pan (1996) who stated ownership literature needs to be revised due to significant changes in the Asia Pacific region, caused by the global market. Therefore, this change supports a revision of national culture value dimensions, as Eastern countries have noteworthy cultural differences compared to those in the West. 
It is also evident that MNCs and EMNCs have different motivations when responding to regulatory distance. This portrays the importance of distinguishing between the two when researching regulatory distance and ownership. MNCs implement full acquisition ownership to avoid encountering crippling regulatory sanctions, which are highly threatening in regulatory diverse environments. Hence, full ownership is used as a mechanism of protection. In contrast, EMNCs perceive regulatory distance as an opportunity. Therefore, they conduct full acquisitions to take advantage of the strength of the institutional environment, to aggressively acquire resources, to overcome the disadvantages of their less developed home environment and compete against MNCs. This study did not specifically distinguish between EMNCs and MNCs. However, from the country selection it was evident that both were present, which encouraged the literature to cover MNC and EMNC ownership behaviours.

\subsection{Implications}

\subsubsection{Theoretical implications}

This study contributes to research on the influence of institutions on CBA ownership. To the best of my knowledge, no research has previously investigated the relative influence of all three institutional pillars on CBA ownership. Therefore, this research embodies an effort to introduce the importance of including three institutional pillars in research to understand their relative influence on CBA ownership.

Institutional theory was founded on the concept that its three institutional pillars interplay to influence firm strategies. However, researchers have not been including three pillars in their research. Specifically, strategy researchers have used only the cognitive pillar. Such practice has been criticized as a misuse of institutional theory. As previously stated, incorrect use of theory is hazardous; strategic actions are wrongly explained, readers are erroneously informed and the study is deemed unreliable. Consequently, researchers are now calling for more studies analyzing the collective influence of all three pillars on firm strategy. This study responds to this need, explaining the influence of regulatory institutions, normative institutions and cognitive institutions, on CBA ownership.

This study advances our knowledge of the relative influence of the three institutional pillars on CBA ownership and introduces a hierarchical pattern of institution authority on CBA ownership 
decisions. Previous literature failed to include all three institutional pillars, which reduced the value of institutional theory. Evidently, prior studies failed to identify the extent to which all three pillars influence the formulation of ownership decisions for CBAs. Ownership decisions are influenced by a hierarchical institutional pillar weight configuration of all three institutional pillars. Regulatory institutions have the strongest influence on ownership decisions for CBAs. Severe repercussions of regulatory sanctions threaten foreign entrants with costly, and at times, crippling consequences. Thus, firms proactively manage regulatory obedience to avoid punitive consequences, to enhance their long-term survival. Normative institutions have the second greatest influence on the construction of CBA ownership decisions. Normative institutions are tacit in nature and inform the extent of cultural distance between the home and host market. Hence, host market suitability can be deceiving, as the market may portray that a firm's strategy would be successfully implemented, however, underlying tacit normative differences disrupt strategy realization and can cause an acquisition to fail. Therefore, cultural differences are a common cause of acquisition catastrophe; hence prioritized acknowledgement of normative institutions' is important. Lastly, cognitive institutions have relatively less influence than both regulatory institutions and normative institutions. This is explained by the absence of severe repercussions involved with cognitive institutions. Cognitive institutions portray how host market participants interpret stimuli in their environment, which informs foreign firms of appropriate national responsive behaviour. Adhering to host market expectations permits the attainment of legitimacy. Consequently, it is necessary to acknowledge cognitive institutions when devising CBA ownership plans. However, their explicit nature and lack of regulatory sanctions reduces their prioritized position to third place.

In addition, it is worth mentioning a recent theoretical claim that this research supports. Findings of this research support the recent declaration made by Ahammad et al. (2017) that the national cultural value dimension, collectivism, should be given more attention in ownership research. Its influence on resource sharing, governed by in-group behavioural expectations, influences ownership strategies. Furthermore, its precise quantifiable nature augments analysis accuracy. Therefore, its relevance and measurability portray the appropriateness of collectivism as a research construct on ownership studies. This contrasts with former research that tended to opt for uncertainty avoidance and power distance constructs. Evidently, researchers are asked to partake in cultural construct decisions with an open mind, to avoid the reoccurring focus on uncertainty avoidance and power distance that presents a narrow evaluation of cultural influences on ownership. 
Moreover, this research identifies the importance of selecting measures that offer precision to quantitative analysis. After analysis, uncertainty avoidance was deemed insignificant to CBA ownership. This is not to say that such a finding was incorrect, however, due to negative criticisms of Hofstede's work, it may be more appropriate to implement the Kogut and Singh Index to measure cultural distance. Its relatively recent popularity depicts collective researcher support for such a measure, and reinforces its use. Such use may enhance the comprehensive assessment of cultural constructs on CBA ownership. Thus, leading to greater result certainty.

\subsubsection{Managerial implications}

This study provides certain practical implications for firm managers planning international expansion via CBAs. It is vital for managers to consider all three institutional pillars when forming CBA ownership decisions. Regulatory distance, normative distance and cognitive distance all impose pressures on foreign entrants to conform to notably different expectations in host markets. Indeed, current research fails to inform the importance of three pillar acknowledgement when crafting CBA ownership decisions. However, this research presents managers with three-pillar criteria they should consider when structuring CBA ownership decisions. Managers should strongly avoid the assessment of only one or two pillars. As previously stated, regulatory institutions, normative institutions and cognitive institutions work in unison. Thus, they all influence CBA ownership. Therefore, when managers fail to acknowledge all institutional pillars, they are at risk of inadequately assessing host country expectations and exhibiting punishable behaviours. If managers were to solely assess cognitive institutions, regulatory sanctions could debilitate their firm, along with tacit normative institutions deceivingly presenting host market suitability but actually consisting of tacit and disruptive cultural differences. Further, focusing solely on regulatory institutions similarly jeopardies CBA success, as again tacit normative institutions camouflage disruptive cultural differences, and failure to acknowledge cognitive institutions immobilizes firms' capacity to comprehend how host participants interpret stimuli from their environment, threatening legitimacy attainment.

Furthermore, this research illustrates how institutional theory's three pillars have a hierarchical influence on CBA ownership. Managers must acknowledge the pillar hierarchy towards ownership, to avoid damaging penalties. However, this should not be confused with only assessing one pillar. Acknowledging the hierarchical process involves a firm considering one 
pillar at a time, which on completion leads to correct comprehensive use of institutional theory. Consequently, managers should firstly prioritize regulatory institutions, followed by normative institutions and lastly assess cognitive institutions. Management must be aware that regulatory institutions impose the most severe repercussions for misbehaviour, through regulatory sanctions. Usually enforced by host governments, regulatory sanctions restrict the choices of foreign entrants, potentially paralyzing their operations. This particularly occurs if the greater good of society is threatened. Evidently, management negligence towards regulatory institutions is detrimental to CBA success. Secondly, managers must prioritize conformity to normative pillar expectations. Normative institutions are tacit in nature, which requires management effort to interpret cultural differences. Hence, a location may appear appropriate however, underlying implicit cultural differences can cause overwhelming strategy disruptions. Normative institutions' importance is reinforced by cultural differences being a common cause of acquisition failure. Consequently, proactive management of cultural differences is imperative, reiterating the importance of prioritizing normative institutions. Lastly, managers must acknowledge cognitive institutions. The cognitive pillar demands that foreign firms analyze how host market participants interpret information from their environment. Evidently, such skill allows foreign entrants to respond to taken-for-granted behaviours, eagerly illustrating their respect for day-to-day host behaviours, in return for legitimacy.

\subsection{Limitations and Suggestions for Future Research}

The limitations of this study inform future research suggestions. Firstly, a limitation of this study is that it did not differentiate between developing economies and developed economies. The chosen countries were a mix of developing and developed economies, but they were all analyzed in one experiment. Consequently, when discussing results, it was simply implied that both EMNCs and MNCs partook in full CBA ownership in the presence of regulatory distance, for different reasons. MNCs used full ownership as a protection mechanism where regulatory distance was present, whereas, EMNCs partook in full acquisition ownership to take advantage the opportunities regulatory distance imposed. However, as firms were not classified as EMNCs or MNCs and were not analyzed separately, this research cannot soundly inform that EMNCs and MNCs partook in full acquisition ownership when faced with regulatory distance for different reasons. A country's level of development is reflected in terms of resource availability, which alters the motivation of EMNCs and MNCs. Therefore, future research investigating regulatory distance and CBA ownership, should distinguish between EMNCs and MNCs, and 
test institutions' influence separately. This will strengthen support of the motivational differences between EMNCs and MNCs ownership strategies, enhancing internal validity.

Moreover, a limitation of this study involves the exclusion of strong acquirer countries which disrupts the extent of generalizability the results of this study can provide. The excluded top acquiring countries included Japan, USA, UK and Germany. The inclusion of more countries in this study would have resulted in an overwhelming volume of data that was beyond the requirements of this thesis. However, a consequence of such exclusion is that the applicability of the findings is limited. It would be irresponsible to assume the findings of this research would be applicable to all top acquiring countries, due to unique characteristics of firms from such locations. Also, experience, trade agreements and proactive corruption avoidance differ between countries. Consequently, future research should distinguish between top acquiring countries and countries that acquire relatively less, and separately test the influence of institutions on the two groups. These groups may demonstrate different institution hierarchies' due to unique characteristics such as experience, which is known to influence how firms imitate.

An additional limitation was the lack of time and availability of data on minor markets that disrupted the capacity to measure cultural distance using the Kogut and Singh Index. The isolated use of Hofstede's national culture value dimensions has been negatively critiqued. However, necessary data requirements for the Kogut and Singh Index measure, were beyond those collated for this research. Time was a highly constricting factor of data collection. Therefore, future studies should take the time to investigate data availability to guarantee the use of Kogut and Singh's cultural distance measure and maximize the value of the research findings. The Kogut and Singh Index has become a reputable measure of cultural distance as it offers a statistical measure of increased accuracy. Moreover, the specific use of Hofstede's cultural value dimension, uncertainty avoidance, has also been negatively critiqued due to its broadness. Alternatively, future research analyzing the influence of uncertainty avoidance could include a number of specific international risk variables, to comprehensively analyze relevant uncertainties, rather than utilizing a broad construct. The potential of misinterpreting the influence of uncertainty avoidance, is high. Consequently, choosing multiple relevant and focused risk constructs would improve the capacity to correctly interpret findings, increasing internal validity. 
Furthermore, this research also offers certain guidance for future research direction. Firstly, future ownership studies should incorporate collectivism as a national culture construct. The recent identification of its importance calls for research to develop a more comprehensive understanding about how collectivism impacts on entry mode decisions. This will broaden understandings of cultural influences, venturing beyond the habitual use of uncertainty avoidance and power distance. The current narrow cultural focus may restrict research of valuable insight. Secondly, future research can gain further insight by investigating institutions' influence on ownership by introducing moderators to the relationship. Moderators introduce boundary conditions to relationships. Hence, analyzing moderator influence on the hierarchical influence of all three institutional pillars on ownership decisions, may illustrate additional contextual factors that interact with the strength of such a relationship. This may uncover conditions under which the hierarchical order of institutional influences changes. 


\section{Reference List}

Abrahamson, E., \& Rosenkopf, L. (1993). Institutional and competitive bandwagons: Using mathematical modeling as a tool to explore innovation diffusion. The Academy of Management Review, 487-517.

Agarwal, S. (1994). Socio-Cultural Distance and the Choice of Joint Ventures: A Contingency Perspective. Journal of International Marketing, 2(2), 63-80.

Agarwal, S., \& Ramaswami, S. (1992). Choice of Foreign Market Entry Mode: Impact of Ownership, Location and Internalization Factors. Journal of International Business Studies, 23(1), 1-27.

Aggarwal, R., \& Goodell, J. W. (2010). Financial markets versus institutions in European countries: Influence of culture and other national characteristics. International Business Review, 19(5), 502-520.

Aguinis, H. (2004). Regression Analysis for Categorical Moderators. New York: Guilford Press.

Ahammad, M., Leone, V., Tarba, S., Glaister, K., \& Arlsan, A. (2017). Equity Ownership in Cross-border Mergers and Acquisitions by British Firms: An Analysis of Real Options and Transaction Cost Factors. British Journal of Management, 28, 180-196.

Allen, P., Bennett, K., \& Heritage, B. (2014). SPSS Statistics Version 22: A Practical Guide. Victoria, Australia: CENGAGE Learning.

Anand, J., \& Delios, A. (1997). Location Specificity and the Trasnferability of Downstream Assets to Foreign Subsidiaries. Journal of International Business Studies, 28(3), 579603.

Ang, S. H. (2014). Research Design for Business and Management. London, United Kingdom: SAGE Publications Ltd.

Ang, S. H., \& Michailova, S. (2008). Institutional explanations of cross-border alliance modes: the case of emerging economies firms. Management International Review, $48(5), 551-576$.

Ang, S. H., Benishke, M., \& Doh, J. (2015). The Interactions of Institutions on Foreign Market Entry Mode. Strategic Management Journal, 36(10), 1536-1553.

Argote, L. (2013). Organizational Learning: Creating, Retaining and Transferring Knowledge. New York: Springer.

Arslan, A., \& Dikova, D. (2015). Influences of Institutional Distance and MNEs' Host country Experience on the Ownership Strategy in Cross-Border M\&As in Emerging Economies. Journal of Transnational Management, 20(4), 231-256.

Arslan, A., \& Larimo, J. (2010). Ownership Strategy of Multinational Enterprises and the Impacts of Regulative and Normative Institutional Distance: Evidence from Finnish 
Foreign Direct Investments in Central and Eastern Europe. Journal of East-West Business, 16(3), 179-200.

Baik, Y., \& Park, Y.-R. (2015). Toward a better understanding of MNE's Local Staffing Decision: a multilevel analysis. Management Decision, 53(10), 2321-2338.

Ball, R. (2001, January 1). Individualism, Collectivism, and Economic Development. The ANNALS of the American Academy of Political and Social Science, 573(1), 57-84.

Barkema, H., \& Vermeulen, F. (1998). International Expansion through Start up or Acquisition: A Learning Perspective. The Academy of Management Journal, 41(1), 726.

Barkema, H., Bell, J., \& Johannes, P. (1996). Foreign Entry, Cultural Barriers, And Learning. Strategic Management Journal, 17(2), 151-166.

Barkema, H., Shenkar, O., Vermeulen, F., \& Bell, J. (1997). Working Abroad, Working with Others: How Firms Learn to Operate International Joint Ventures. The Academy of Management Journal, 40(2), 426-442.

Baron, R., \& Kenny, D. (1986). The Moderator-Mediator Variable Distinction in Social Psychological Research: Conceptual, Strategic, and Statistical Considerations. Journal of Personality and Social Psychology, 51(6), 1173-1182.

Barr, P. S., \& Glynn, M. A. (2004). Cultural Variations in Strategic Issue Interpretation : relating cultural uncertainty avoidance to controlability in discriminating threat and opportunity. Strategic Management Journal, 25, 59-67.

Barreto, I., \& Baden-Fuller, C. (2006). To Conform or To Perform? Mimetic Behaviour, Legitimacy-Based Groups and Performance Consequences. Journal of Management Studies, 43(7), 1559-1581.

Baum, J., Li, S., \& Usher, J. (2000). Making the next move: how experiential and vicarious learning shape the locations of chains' acquisitions. Administrative Science Quarterly, 45(4), 766-801.

Beckman, C. M., \& Haunschild, P. R. (2002). Network Learning: The effects of Partners' Heterogeneity of Experience on Corporate Acquisitions. Administrative Science Quarterly, 47(1), 92-124.

Bedeian, A. G. (2014). "More Than Meets the Eye": A Guide to Interpreting the Descrptive Statistics and Correlation Matrices Reported in Management Research. Academy of Management Learning \& Education, 13(1), 121-135.

Belderbos, R., van Olffen, W., \& Zou, J. (2011). Generic and specific learning mechanisms in foreign entry location choice. Strategic Management Journal, 32(12), 1309-1330.

Benito, G. (1996). Ownership Structures of Norwegian Foreign Subsidiaries in Manufacturing. The International Trade Journal, 10(2), 157-198. 
Bernerth, J. B., \& Aguinis, H. (2016). A Critical Review and Best-Practice Recommendations For Control Variable Usage. Personnel Psychology, 69(1), 229-283.

Beronne, P., Cruz, C., Gomez-Mejia, L. R., \& Larraza-Kintana, M. (2010). Socioemotional Wealth and Corporate Responses to Institutional Pressures: Do Family-Controlled Firms Pollute Less? Administrative Science Quarterly, 55, 82-113.

Bhardwaj, A., Dietz, J., \& Beamish, P. W. (2007). Host country cultural influences on foreign direct investment. Management International Review, 47(1), 29-50.

Brewer, M., \& Chen, Y.-R. (2007). Where (Who) Are Collectives in Collectivism? Psychological Review, 114(1) 133-151.

Brouthers, K. (2002). Institutional, cultural and transaction cost influences on entry mode choice and performance. Journal of International Business Studies, 33(2), 203-221.

Brouthers, K. (2013). A retrospective on: Institutional, cultural and transaction cost influences on entry choice and performance. Journal of International Business Studies, 44(1), 1422.

Brouthers, K. D., \& Brouthers, L. E. (2001, March 1). Explaining the National Cultural Distance Paradox. Journal of International Business Studies, 32(1), 177-189.

Brouthers, K., \& Hennart, J. F. (2007). Boundaries of the Firm: Insights From International Entry Mode Research. Journal of Management, 33(3), 395-425.

Brouthers, K., Brouthers, L., \& Nakos, G. (1998). Entering Central \& Eastern Europe: Risks and Cultural Barriers. Thunderbird International Business Review, 40(5), 485-504.

Bruton, G. D., Ahlstrom, D., \& Li, H.-L. (2010). Institutional Theory and Entrepreneurship : Where are we now and where do we need to move in the future? Entrepreneurship Theory and Practice, 34(3), 421-440.

Burns, L., \& Wholey, D. (1993). Adoption and abandonment of matrix management programs. Academy of Management Journal, 36(1), 106-138.

Cantwell, J., Dunning, J., \& Lundan, S. (2010). An evolutionary approach to understanding international business activity: The co-evolution of MNEs and the institutional environment. Journal of International Business Studies, 41(4), 567-596.

Chan, C., \& Makino, S. (2007). Legitimacy and Multi-Level Institutional Environments: Implications for Foreign Subsidiary Ownership Structure. Journal of International Business Studies, 38(4), 621-638.

Chang, S.-J., \& Rosenzweig, P. (2001). The choice of entry mode in sequential foreign direct investment. Strategic Management Journal, 22(8), 747-776.

Chatman, J. A., \& Barsade, S. G. (1995). Personality, Organizational Culture, and Cooperation : Evidence from a business simulation. Administrative Science Quarterly, 423-443. 
Chatman, J., Polzer, J., Barsade, S., \& Neale, M. (1998). Being different yet feeling similar : The influence of demographic composition and organizational culture on work processes and outcomes. Administrative Science Quarterly, 43(4), 749-780.

Chatterjee, S., Atav, G., Min, J., \& Taylor, D. (2014). Choosing the sure gain and the sure less: uncertainty avoidance and the reflection effect. Journal of Consumer Marketing, 31(5), 351-359.

Chen, C. C., Chen, X. P., \& Meindl, J. R. (1998). How Can Cooperation Be Fostered? The Cultural Effects of Individualism-Collectivism. Academy of Management Review, 23(2), 285-304.

Chi, T. (1994). Trading in Strategic Resources: Necessary Conditions, Transaction Cost Problems, And Choice Of Exchange Structure. Strategic Management Journal, 15(4), 271-290.

Chiara DiGuardo, M., Marrocu, E., \& Paci, R. (2016). The effect of local corruption on ownership strategy in cross-border mergers and acquisitions. Journal of International Business Studies, 69(10), 4225-4241.

Chikhouni, A., Edwards, G., \& Farashahi, M. (2017). Psychic distance and ownership in acquisitions: Direction matters. Journal of International Management, 23(1), 32-42.

Chuang, Y.-T., Church, R., \& Ophir, R. (2011). Taking Sides: The Interactive Influences of Institutional Mechanisms on the Adoption of Same-Sex Partner Health Benefits by Fortune 500 Corporations, 1990-2003. Organization Science, 22(1), 190-209.

Collins, J., Holcomb, T., Certo, S. T., Hitt, M., \& Lester, R. (2009). Learning by doing: Cross-border mergers and acquisitions. Journal of Business Research, 62(12), 13291334.

Contractor, F., Lahiri, S., Elango, B., \& Kundu, S. K. (2014). Insitutional, cultural and industry related determinants of ownership choices in emerging market FDI acquisitions. International Business Review, 23(5), 931-941.

Cousins, S. D. (1989). Culture and self perception in Japan and the United States. Journal of Personality and Social Psychology : Personality Processes and Individual Differences, 56(1), 124-131.

Cowan, C. D. (1990). Why statisticians need their probabilities - getting into regression. Marketing Research, 65-68.

Cui, L., \& Jiang, F. (2012). State owwnership effect on firm's FDI ownership decisions under institutional pressure: a study of Chinese outward-investing firms. Journal of International Business Studies, 43(3), 264-284.

Davidson, W. (1980). The Location of Foreign Direct Investment Activity: Country Characteristics and Experience Effects. Journal of International Business Studies, 11(2), 9-22. 
Davis, P., Desia, A., \& Francis, J. (2000). Mode of international entry: An isomorphism perspective. Journal of International Business Studies, 31(2), 239-258.

Dawar, N., Parker, P. M., \& Price, L. J. (1996). A cross-cultural study of interpersonal information exchange. Journal of International Business Studies, 13(6), 43-57.

Deephouse, D. L. (1996). Does Isomorphism Legitimate? Academy of Management Journal, 39(4), 1024-1039.

Delios, A., \& Beamish, P. W. (1999). Ownership Strategy of Japanese Firms: Transactional Institutions and Experience Influences. Strategic Management Journal, 20(10), 915933.

Delios, A., \& Henisz, W. (2000). Japanese firms' Investment Strategies in Emerging Economies. The Academy of Management Journal, 43(3), 305-323.

Dikova, D., \& van Witteloostuijn, A. (2007). Foreign Direct Investment Mode Choice: Entry and Establishment Modes in Transition Economies. Journal of International Business Studies, 38(6), 1013-1033.

Dikova, D., Sahib, P. R., \& van Witteloostuijn, A. (2010, February). Cross-border acquisition abandonment and completion: The effect of institutional differences and organisational learning in the international business service industry, 1981-2001. Journal of International Business Studies, 41(2), 223-245.

DiMaggio, P. J., \& Powell, W. W. (1983). The Iron Cage Revisited: Institutional Isomorphism and Collective Rationality in Organizational Fields. American Sociological Review, 147-160.

Duncan, R. B. (1972). Charateristics of Oranizational Environments and Perceived Environmental Uncertainty. Administrative Science Quarterly, 17(3), 313-327.

Dunning, J. H., \& Lundan, S. M. (2008, December). Institutions and the OLI paradigm of multinational enterprise. Asia Pacific Journal of Management, 25(4), 573-593.

Earley, P. C. (1993). East meets West meets Mideast: Further Explorations of Collectivistic and Individualistic Work Groups. Academy of Management Journal, 36(2), 319-348.

Easterby-Smith, M., Thorpe, R., \& Jackson, P. R. (2012). Managment \& Business Research (Vol. 5). London, England: SAGE .

Eden, L., \& Miller, S. R. (2004). Distance Matters: Liability of Foreigness, Institutional Distance and Ownership Strategy (Vol. 16). New York: Emerald Publishing Group Limited.

Egelhoff, W. (1984). Patterns of Control in U.S., U.K., and European Multinational Corporations. Journal of International Business Studies, 15(2), 73-83. 
Elango, B., Lahiri, S., \& Kundu, S. K. (2013). How does firm experience and institutional distance impact ownership choice in high-tech acquisitions? R\&D Management, 44(5), 501-516.

Erdem, T., Swait, J., \& Valenzuela, A. (2006). Brands as Signals: A Cross-country Validation Study. Journal of Marketing, 70(1), 34-48.

Erramilli, K. (1996). Nationality and Subsidiary Ownership Patterns in Multinational Corporates. Journal of International Business Studies, 27(2), 225-248.

Erramilli, K., Agarwal, S., \& Kim, S.-S. (1997). Are Firm-Specific Advantages Location Specific Too? Journal of International Business Studies, 28(4), 735-757.

Erramilli, M. K., \& Rao, C. (1993). Service Firms' International Entry Mode Choice: A Modified Transaction-Cost Analysis Approach. Journal of Marketing, 557(3), 19-38.

Estrin, S., Baghdasaryan, D., \& Meyer, K. (2009). The Impact of Institutional and Human Resource Distance on International Entry Strategies. Journal of Management Studies, 46(7), 1172-1196.

Fadil, P., Williams, R., Limpaphayom, W., \& Smatt, C. (2005). Equity or Equality? A Conceptual Examination of the Influence of Individualism/Collectivism on the CrossCultural Application of Equity Theory. Cross Cultural Management, 12(4), 17-35.

Ferreira, M. A., da Silva Vicente, S. C., Borini, F. M., \& de Almeida, M. I. (2017). Degree of equity ownership in cross-border acquisitions of Brazilian firms by multinationals: a strategic response to international distance. Revista de Administrção, 52(1), 59-69.

Ferreira, M. P., Santos, J. C., de Almeida, M. I., \& Reis, N. R. (2014). Mergers \& acquisitions research: A bibliometric study of top strategy and international business journals, 1980-2010. Journal of Business Research, 67(12), 2550-2558.

Field, A. (2013). Discovering Statistics Using IBM SPSS Statistics. London: Sage Publishing Ltd.

Fligstein, N. (1985). The Spread of the Multidivisional Form among Large Firms, 1919-1979. American Sociological Review, 50(3), 377-391.

Frijns, B., Gilbert, A., Lehnert, T., \& Tourani-Rad, A. (2013). Uncertainty avoidance, risk tolerance and corporate takeover decisions. Journal of Banking and Finance, 37(7), 2457-2471.

Fukui, E. T., Hammer, A. B., \& Jones, L. Z. (2013). Are U.S. exports influenced by stronger IPR protection measures in recipient markets? Business Horizons, 56(2), 179-188.

Gaffney, N., Karst, R., \& Clampit, J. (2016). Emerging Market MNE Cross-border Acquisitions Equity Participation: The Role of Economic and Knowledge Distance. International Business Review, 25(1), 267-275. 
Gatignon, H., \& Anderson, E. (1988). The Multinational Corporation's Degree of Control over Foreign Subsidiaries : An Empirical Test of a Transaction Cost Explanation. Journal of Law, Economics, and, Organization, 4(2), 305-336.

Gaur, A., Delios, A., \& Singh, K. (2007). Institutional Environments, Staffing Strategies, and Subsidiary Performance. Journal of Management, 33(4), 611-636.

Gaur, A. S., \& Lu, J. W. (2007). Ownership Strategies and Survival of Foreign Subsidiaries: Impacts of Institutional Distance and Experience. Journal of Management, 33(1), 84110.

Geletkanycz, M. A. (1997). The Salience of 'Cultures Consequences': the effects of cultural values on top executive commitment to the status quo. Strategic Management Journal, $18(8), 615-634$.

Gollnhofer, J. F., \& Turkina, E. (2015). Cultural distance and entry modes: implications for global expansion strategy. Cross Cultural Management, 22(1), 21-41.

Gomes-Casseres, B. (1989). Ownership Structures of Foreign Subsidiaries: Theory and Evidence. Journal of Economic Behavior and Organization, 11(1), 1-25.

Greenwood, R., \& Meyer, R. (2008). Influencing ideas: a celebration of DiMaggio and Powell (1983). Journal of Management Inquiry, 17(4), 258-264.

Grewal, R., \& Dharwadkar, R. (2002). The Role of the Institutional Environment in Marketing Channels. Journal of Marketing, 66(3), 82-97.

Griffin, J., \& Mahon, J. (1997). The Corporate Social Performance and Corporate Financial Performance Debate. Business \& Society, 36(1), 5-31.

Guillén, M. (2003). Experience, Imitation, \& the Sequence of Foreign Entry: Wholly Owned and Joint-Venture Manufacturing by South Korean Firms and Business Groups in China, 1987-1995. Journal of International Business Studies, 34(2), 185-198.

Guillén, M. F. (2002). Structural Inertia, Imitation, And Foreign Expansion: South Korean Firms And Business Groups in China, 1987-95. Academy of Management Journal, $45(3), 509-525$.

Hair, J., Sarstedt, M., Hopkins, L., \& Kuppelwieser, V. (2014). Partial least squares structural equation modeling (PLS-SEM): An emerging tool in business research. European Business Review, 26(2), 106-121.

Haleblian, J., McNamara, G., Kolev, K., \& Dykes, B. J. (2012). Exploring firm characteristics that differentiate leaders from followers in industry merger waves: a competitive dynamics perspective. Strategic Management Journal, 33(9), 1037-1052.

Harzing, A.-W. (2002). Acquisitions versus Greenfield Investments: International Strategy and Management of Entry Modes. Strategic Management Journal, 23(3), 211-227. 
Hasan, M. M., Ibrahim, Y., \& Uddin, M. M. (2016). Institutional Distance Factors Influencing Firm Performance: A Hypothetical Framework from Cross-Border Mergers and Acquisitions. The Journal of Developing Areas, 50(6), 378-386.

Haunschild, P. (1993). Interorganizational Imitation: The Impact of Interlocks on Corporate Acquisition Activity. Administrative Science Quarterly, 38(4), 562-592.

Haunschild, P. R., \& Miner, A. S. (1997). Modes of Interorganizational Imitation: The Effects of Outcome Salience and Uncertainty. Administrative Science Quarterly, 42(3), 472500 .

Haveman, H. (1993). Follow the Leader: Mimetic Isomorphism and Entry into New Markets. Administrative Science Quarterly, 38(4), 593-627.

Hayes, A. (2014). Introduction to Mediation, Moderation, and Conditional Process Analysis. New York: The Guilford Press.

Hayward, M. L. (2002). When do firms learn from their acquisition experience? Evidence from 1990-1995. Strategic Management Journal, 23(1), 21-39.

Henisz, W., \& Delios, A. (2001). Uncertainty, Imitation, and Plant Location: Japanese Multinational Corporations, 1990-1996. Administrative Science Quarterly, 46(3), 443475.

Henisz, W., \& Zelner, B. (2005). Legitimacy, Interest Group Pressures, and Change in Emergent Institutions: The Case of Foreign Investors and Host Country Governments. Academy of Management Review, 30(2), 361-382.

Hennart, J.-F. (1991). The Transaction Costs Theory of Joint Ventures: An Empirical Study of Japanese Subsidiaries in the United States. Management Science, 37(4), 483-497.

Hennart, J.-F., \& Slangen, A. H. (2015). Yes, we really do need more entry mode studies! A commentary on Shaver. Journal of International Business Studies, 46(1), 114-122.

Hill, C., Hwang, P., \& Chan, K. (1990). An Eclectic Theory of the Choice of International Entry Mode. Strategic Management Journal, 1(2), 117-128.

Hirsch, P. (1997). Sociology Without Social Structure: Neoinstitutional Theory Meets Brave New World. American Journal of Sociology, 102(6), 1702-1723.

Hoffman, A. (1999). Institutional Evolution and Change: Environmentalism and the U.S. Chemical Industry. Academy of Management Journal, 42(4), 351-371.

Hofstede, G. (1980). Culture and Organizations. International Studies of Management and Organization, 10(4), 15-41.

Hofstede, G. (1983a). National Cultures in Four Dimensions: A Research-Based Theory of Cultural Differences among Nations. International Studies of Management \& Organization, 13(1-2), 46-74. 
Hofstede, G. (1983b). The Cultural Relativity of Organizational Practices and Theories. Journal of International Business Studies, 14(2), 75-89.

Hofstede, G. (2001). Culture's Consequences: Comparing Values, Behaviors, Institutions, and Organizations Accross Nations. Thousand Oaks, CA: Sage Publications.

Hofstede, G., \& Bond, M. H. (1984). Hofstede's Culture Dimensions: An Independent Validation Using Rokeach's Value Survey. Journal of Cross-Cultural Psychology, 15(4), 417-433.

Holmes, R. M., Miller, T., Hitt, M. A., \& Salmador, M. P. (2013). The Interrelationships Among Informal Institutions, Formal Institution, and Inward Foreign Direct Investment. Journal of Management, 39(2), 531-566.

Hui, C. H., \& Villareal, M. J. (1989). Individualism-Collectivism and Psychological Needs : Their Relationships in Two Cultures. Journal of Cross-Cultural Psychology, 20(3), 310-323.

Hui, C., \& Triandis, H. C. (1986). Individualism-Collectivism A Study of Cross-Cultural Researchers. Journal of Cross-Cultural Psychology, 17(2), 225-248.

Husted, B. W. (1999). Wealth, Culture, and Corruption. Journal of International Business Studies, 30(2), 339-359.

Jackofsky, E. F., Slocum Jr, J. W., \& McQuaid, S. J. (1988). Cultural Values and the CEO : Alluring Companions? Academy of Management Executive, 11(1), 39-49.

Jakobsen, K., \& Meyer, K. (2008). Partial Acquisition: The Overlooked Entry Mode. Foreign Direct Investment, Location and Competitiveness, 2, 203-226.

Jin, B., Park, J. Y., \& Kim, J. (2008). Cross-cultural examination of the relationships among firm rep, e-satisfaction, e-trust, and e-loyalty. International Marketing Review, 25(3), 324-337.

Jonker, J., \& Pennink, B. (2010). The Essence of Research Methodology. Berlin, Germany: Springer-Verlag.

Kaufmann, D., Kraay, A., \& Mastruzzi, M. (2004). Governance Matters III: Governance Indicators for 1996, 1998, 2000, 2002. The World Bank Economic Review, 18(2), 253287.

Kaufmann, D., Kraay, A., \& Mastruzzi, M. (2009). Governance Matters VIII: Aggregate and Individual Governance Indicators, 1996-2008. World Bank Policy Research Working Paper 4978.

Kedia, B. L., \& Bilgili, T. V. (2015). When history matters: The effect of historical ties on the relationship between institutional distance and shares acquired. International Business Review, 24(6), 921-934. 
Kedia, B. L., Keller, R. T., \& Julian, S. D. (1992). Dimensions of national culture and the productivity of R\&D units. The Journal of High Technology Management Research, $3(1), 1-18$.

Kim, W. C., \& Hwang, P. (1992). Global Strategy and Multinationals' Entry Mode Choice. Journal of International Business Studies, 23(1), 29-53.

Kirkman, B., Lowe, K., \& Gibson, C. (2006). A Quarter Century of "Culture's Consequences": A Review of Empirical Research Incorporating Hofstede's Cultural Values Framework. Journal of International Business Studies, 37(3), 285-320.

Kleinbaum, D., \& Klein, M. (2002). Logistic Regression: A Self-Learning Text. New York, United States of America: Springer.

Ko, D., Seo, Y., \& Jung, S.-U. (2015). Examining the effect of cultural convergence, processing fluency, and uncertainty avoidance in online purchase decisions in the U.S. and Korea. Marketing Letters, 26(3), 377-390.

Kogut, B., \& Singh, H. (1988). The Effect of National Culture on the Choice of Entry Mode. Journal of International Business Studies, 19(3), 411-430.

Kostova, T., \& Roth, K. (2002). Adoption of an Organizational Practice by Subsidaries of Multinational Corporations: Institutional and Relational Effects. Academy of Management Journal, 45(1), 215-233.

Kostova, T., \& Zaheer, S. (1999). Organizational Legitimacy Under Conditions of Complexity: The Case of Multinational Enterprise. Academy of Management Review, 24(1), 64-81.

Kraatz, M. (1995). The role of interorganizational networks in shaping strategic adaptation: Evidence from liberal arts colleges. Academy of Management Journal, 1995(1), 246250.

Kwok, C. C., \& Tadesse, S. (2006). National Culture and Financial Systems. Journal of International Business Studies, 37(2), 227-247.

Kyriacou, A. P. (2016). Individulism-collectivism, governance and economic development. European Journal of Political Economy, 42, 91-104.

Lahiri, S., Elango, B., \& Kundu, S. K. (2014). Cross-border acquisition in services: comparing ownership choice of developed and emerging economy MNEs in India. Journal of World Business, 49(3), 409-420.

Lai, K. K. Y., \& Zaichkowsky, J. L. (1999). Brand imitation: Do the Chinese have different views? Asia Pacific Journal of Management, 16(2), 179-192.

Lavie, D., \& Miller, S. (2008). Alliance Portfolio Internationalization and Firm Performance. Organization Science, 19(4), 623-646. 
Lazer, D., Arrow, H., \& Contractor, N. (2004). Network Theory And Small Groups. Small Group Research, 35(3), 307-332.

Lee, F., \& Peterson, C. (1997, December). Content analysis of archival data. Journal of Consulting and Clinical Psychology, 65(6), 959-969.

Lee, J. A., Garbarino, E., \& Lerman, D. (2007). How cultural differences in uncertainty avoidance affect product perceptions. International Marketing Review, 24(3), 330349.

Lee, Y., Hemmert, M., \& Kim, J. (2014). What drives the international ownership strategies of Chinese firms? The role of distance and home country institutional factors in outward acquisitions. Asian Business and Management, 197-225.

Li, J., Jiang, F., \& Shen, J. (2016). Institutional distance and the quality of the headquarterssubsidiary relationship: The moderating role of the institutionalization of headquarters practices in subsidiaries. International Business Review, 25(2), 589-603.

Li, J., Yang, J. Y., \& Yue, D. R. (2007). Identity, Community, And Audience: How Wholly Owned Foreign Subsidaries Gain Legitimacy In China. Academy of Management Journal, 50(1), 175-190.

Lieberman, M., \& Asaba, S. (2006). Why Do Firms Imitate Each Other? Academy of Management Review, 31(2), 366-385.

Lin, J. (2013). Why are Chinese partners passive innovators? National culture, organisation processes and innovation propensity in cross-border alliances. International Journal of Entrepreneurship and Innovation Management, 17(4), 271-283.

Lin, K.-W., \& Huang, K.-P. (2014). Moral Judgement and Ethical Leadership in Chinese Management: the role of confucianism and collectivism. Quality and Quantity, 48(1), $37-47$.

Lin, Z., Peng, M., Yang, H., \& Sun, S. L. (2009). How Do Networks And Learning Drive M\&As? An Institutional Comparison Between China and the United States. Strategic Management Journal, 30(10), 1113-1132.

Liou, R. S., Chao, M. C.-H., \& Yang, M. (2016). Emerging economies and institutional quality: Assessing the differential effects of institutional distances on ownership strategy. Journal of World Business, 51(4), 600-611.

Liou, R. S., Chao, M. C.-h., \& Ellstrand, A. (2017). Unpacking Institutional Distance: Addressing Human Capital Development and Emerging-Market Firms' Ownership Strategy in an Advanced Economy. Thunderbird International Business Review, 59(3), 281-295.

Lu, J. W. (2002). Intra- and Inter-organizational Imitative Behavior: Institutional Influences on Japanese Firms' Entry Mode Choice. Journal of International Business Studies, 33(1), 19-37. 
Luo, Y., \& Tung, R. (2007). International Expansion of Emerging Market Enterprises: A Springboard Perspective. Journal of International Business Studies, 38(4), 481-498.

Lynn, M., \& Gelb, B. D. (1996). Identifying innovative national markets for technical consumer goods. International Marketing Review, 13(6), 43-57.

Ma, Z., Huang, Y., Wu, J., Dong, W., \& Liyun, Q. (2014). What matters for knowledge sharing in collectivistic cultures? Empirical evidence from China. Journal of Knowledge Management, 18(5), 1004-1019.

Makino, S., \& Delios, A. (1996). Local Knowledge Transfer and Performance: Implications for Alliance Formation in Asia. Journal of International Business Studies, 27(5), 905927.

Malhotra, S., Lin, Z., \& Farrell, C. (2016). Cross-national uncertainty and level of control in cross-boarder acquisitions: A comparison of Latin American and U.S. multinationals. Journal of International Business studies, 69(6), 1993-2004.

Malhotra, S., \& Zhu, P. (2013). Paying for cross-border acquisitions: The impact of prior acquirers' decisions. Journal of World Business, 48(2), 271-281.

Malhotra, S., Zhu, P. C., \& Reus, T. H. (2015, December). Anchoring on the acquisition premium decisions of others. Strategic Management Journal, 36(12), 1866-1876.

Markus, H. R., \& Kitayama, S. (1991). Culture adn The Self : Implications for Cognition, Emotion, and Motivation. Psychological Review, 98(2), 224-253.

Martinez, J., \& Jarillo, J. C. (1991). Coordination Demands of International Strategies. Journal of International Business Studies, 22(3), 429-444.

Mattoo, A., Olarreaga, M., \& Saggi, K. (2004). Mode of foreign entry, technology transfer, and FDI policy. Journal of Development Economics, 75(1), 95-111.

McNamara, G. M., Haleblian, J., \& Dykes, B. J. (2008). The Performance Implications of Participating in an Acquisition Wave: Early Mover Advantages, Bandwagon Effects, and The Moderating Influence of Industry Characteristics and Acquirer Tactics. Academy of Management Journal, 51(1), 113-130.

McSweeney, B. (2002). Hofstede's model of national cultural differences and their consequences: A triumph of faith - a failure of analysis. Human Relations, 55(1), 89118.

Meyer, J., \& Rowan, B. (1977). Institutionalized Oranizations: Formal Structure as Myth and Ceremony. American Journal of Sociology, 83(2), 340-363.

Meyer, K. E. (2001). Institutions, Transaction Costs, and Entry Mode Choice in Eastern Europe. Journal of International Business Studies, 32(2), 357-367.

Meyer, K., \& Tran, Y. T. (2006). Market Prenetration and Acquisition Strategies for Emerging Economies. Long Range Planning, 39(2), 177-197. 
Meyer, K., Ding, Y., Li, J., \& Zhang, H. (2014). Overcoming distrust: How state-owned enterprises adapt their foreign entries to institutional pressures abroad. Journal of International Business Studies, 45(8), 1005-1028.

Mizruchi, M., \& Fein, L. (1999). The Social Construction of Organizational Knowledge: A Study of the Uses of Coercive, Mimetic, and Normative Isomorphism. Administrative Science Quarterly, 44(4), 653-683.

Moatti, V. (2009). Learning to expand or expanding to learn? The role of imitation and experience in the choice among several expansion modes. European Management Journal, 27(1), 36-46.

Modejar, R., \& Zhao, H. (2013). Antecedents to Government Relationship Building and the Institutional Contingencies in a Transition Economy. Management International Review, 53(4), 579-605.

Moore, C. B., Payne, G. T., Bell, R. G., \& Davis, J. L. (2015). Institutional Distance and Cross-Border Venture Capital Investment Flows. Journal of Small Business Management, 53(2), 482-500.

Morosini, P., Shane, S., \& Singh, H. (1998). Cultural Distance and Cross-Border Acquisition Performance. Journal of International Business Studies, 29(1), 137-158.

Morris, M. W., \& Peng, K. (1994). Culture and Cause : American and Chinese Attributions for Social and Physical Events. Journal of Personality and Social Psychology, 67(6), 949-971.

Nakata, C., \& Sivakumar, K. (1996). National Culture and New Product Development : An Integrative Review. Journal of Marketing, 60(1), 61-72.

Newburry, W., \& Yakova, N. (2006). Standardization preferences : a function of national culture, work interdependence and local embeddedness. Journal of International Business Studies, 37(1), 44-60.

Newman, K. L., \& Nollen, S. D. (1996). Culture and Congruence: The Fit between Management Practices and National Culture. Journal of International Business Studies, 27(4), 753-779.

North, D. (1990). Institutions, Institutional Change and Economic Performance. Cambridge, UK: Cambridge University Press.

Oehme, M., \& Bort, S. (2015). SME internationalization modes in the German biotechnology industry: the influence of imitation, network position, and international experience. Journal of International Business Studies, 46(6), 629-655.

Oliver, C. (1991). Strategic responses to institutional processes. Academy of Management Review, 16(1), 145-179. 
Ouchi, W. (1977). The Relationship betweeen Organization Structure and Organization Control. Administrative Science Quarterly, 22(1), 95-113.

Oxley, J. E. (1999). Institutional environment and the mechanisms of governance: the impact of instellectual property protection on the structure of inter-firm alliances. Journal of Economic Behavior and organization, 38(3), 283-309.

Padmanabhan, P., \& Cho, K. R. (1996). Ownership Strategy for a Foreign Affiliate: An Empirical Investigation of Japanese Firms. Management International Review, 36(1), 45-65.

Pan, Y. (1996). Influences on Foreign Equity Ownership Level in Joint Ventures in China. Journal of International Business Studies, 27(1), 1-26.

Peng, C. Y. J., Lee, K. L., \& Ingersoll, G. M. (2002). An Introduction to Logistic Regression Analysis and Reporting. The Journal of Educational Research, 96(1), 3-14.

Peng, M. (2003). Institutional Transitions and Strategic Choices. The Academy of Management Review, 28(2), 275-296.

Peng, M. W., Sun, S. L., Pinkham, B., \& Chen, H. (2009). The Institution-Based View as a Third Leg for a Strategy Tripod. Academy of Management Perspectives, 23(3), 63-78.

Peng, M. W., Wang, D. Y., \& Jiang, Y. (2008). An institution-based view of internaitonal business strategy: a focus on emerging economies. Journal of International Business Studies, 39(5), 920-936.

Pfeffer, J., Salancik, G., \& Leblebici, H. (1976, June 1). The Effect of Uncertainty on the Use of Social Influence in Organizational Decision Making. Administrative Science Quarterly, 21(2), 227-245.

Piaskowska, D., \& Trojanowski, G. (2014). Twice as Smart? The Importance of Managers' Formative-Years' International Experience for their International Orientation and Foreign Acquisition Decisions. British Journal of Management, 25(1), 40-57.

Pinto, C. F., Ferreira, M. P., Falaster, C., \& Fleury, M. T. (2017). Ownership in cross-border acquisitions and the role of government support. Journal of World Business, 52(4), 533-545.

Podoynitsyna, K., Song, M., van der Bij, H., \& Weggeman, M. (2013). Improving new technology venture performance under direct and indirect network externality conditions. Journal of Business Venturing, 28(2), 195-210.

Qu, W. G., \& Yang, Z. (2015). The effect of uncertainty avoidance and social trust on supply chain collaboration. Journal of Business Research, 68(5), 911-918.

Quintal, V. A., Lee, J. A., \& Soutar, G. N. (2010). Tourists' Information Search: the Differential Impact of Risk and Uncertainty Avoidance. International Journal of Tourism Research, 12(4), 321-333. 
Rabinovich, E., \& Cheon, S. (2011). Expanding Horizons and Deepening Understanding via the Use of Secondary Data Sources. Journal of Business Logistics, 32(4), 303-316.

Robinson, R. (1969). Ownership Across National Frontiers. International Executive, 14-16.

Rottig, D. (2013). A Marriage Metaphor Model for sociocultural Integration in International Mergers and Acquisitions. Thunderbird Intenational Business Review, 55(4), 439-451.

Saad, G. (2015). Individualism-collectivism and the quantity versus quality dimensions of individual and group creative performance. Journal of Business research, 68(3), 578586.

Salomon, R., \& Wu, Z. (2012). Institutional distance and local isomorphism strategy. Journal of International Business Studies, 43(4), 343-367.

Sambharya, R., \& Musteen, M. (2014). Institutional environment and entrepreneurship: An empirical study accross countries. Journal of International Entrepreneurship, 12(4), 314-330.

Sawang, S., Oei, T., \& Goh, Y. W. (2006). Are Country and Culture Values Interchangeable? A Case Example Using Occupational Stress and Coping. International Journal of Cross Cultural Management, 6(2), 205-219.

Schneider, S. C. (1989). Strategy Formulation : The Impact of National Culture. Organization Studies, 10(2), 149-168.

Schneider, S. C., \& De Meyer, A. (1991). Interpreting and responding to strategic issues : The impact of national culture. Strategic Management Journal, 12(4), 307-320.

Schultz, K., Hoffman, C., \& Reiter-Palmon, R. (2005). Using Archival Data for I-O Research: Advantages, Pitfalls, Sources, and Examples. Psychology Faculty Publications, 42(3) 31-37.

Scott, W. R. (1995). Institutions and Organizations. California, United States of America: SAGE publications, Inc.

Shane, S. (1995). Uncertainty Avoidance and the Preference for Innovation Championing Roles. Journal of International Business Studies, 26(1), 47-68.

Sharma, S., Durand, R. M., \& Gur-Arie, O. (1981). Identification and Analysis of Moderator Variables. Journal of Marketing Research, 291-300.

Shenkar, O. (2001). Cultural distance revisited: Towards a more rigorous conceptualization and measurement of cultural differences. Journal of International Business Studies, $32(3), 1-11$.

Shenkar, O. (2012). Beyond cultural distance: Switching to a friction lens in the study of cultural differences. Journal of International Business Studies, 43(1), 12-17. 
Shenkar, O., \& Zeira, Y. (1992). Role Conflict and Role Ambiguity of Chief Executive Officers in International Joint Ventures. Journal of International Business Studies, 23(1), 55-75.

Shirodkar, V., \& Konara, P. (2017). Institutional Distance and Foreign Subsidiary Performance in Emergin Markets: Moderating Effects of Ownership Strategy and Host Country Experience. Management International Review, 57(2), 179-207.

Siegel, J. I., \& Larson, B. Z. (2009, September). Labor Market Institutions and Global Strategic Adaptation: Evidence from Lincoln Electric. Management Science, 55(9), 1527-1546.

Singh, S. (2006). Cultural differences in, and influences on, consumers' propensity to adopt innovations. International Marketing Review, 23(2), 173-191.

Sinkovics, R. R., Penz, E., \& Ghauri, P. N. (2008). Enhancing the Trustworthiness of Qualitative Research in International Business. Management International Review, 48(6), 689-714.

Slangen, A. H., \& Hennart, J. F. (2008). Do multinationals really prefer to enter culturally distant countries through greenfeilds rather than through acquisitions? The role of parent experience and subsidiary autonomy. Journal of International Business, 39(3), 472-490.

Slangen, A., \& Beugelsdijk, S. (2010). The impact of institutional hazards on foreign multinational activity: A contengency perspective. Journal of International Business Studies, 41(6), 980-995.

Smith, P. C., Budzeika, K. A., Edwards, N. A., Johnson, S. M., \& Bearse, L. N. (1986). Guidelines for Clean Data: Detection of Common Mistakes. Journal of Applied Psychology, 71(3), 457-460.

Smith, K. G., Carroll, S. J., \& Ashford, S. J. (1995). Intra- And Interorganizational Cooperation : Toward A Research Agenda. Academy of Management Journal, 38(1), 7-23.

Straughan, R. D., \& Albers-Miller, N. (2001). An international investigation of cultural and demographic effects on domestic retail loyalty. International Marketing Review, $18(5), 521-541$.

Tan, D. (2009). Foreign market entry strategies and post-entry growth: Acquisitions vs greenfield investments. Journal of International Business, 40(6), 1046-1063.

Tang, L., \& Koveas, P. (2008). A framework to update Hofstede's cultural value indices: economic dynamics and institutional stability. Journal of International Business Studies, 39(6), 1045-1063. 
Taras, V., Kirkman, B., \& Steel, P. (2010). Examining the Impact of Culture's Consequences: A Three-Decade, Multilevel, Meta-Analytic Review of Hofstede's Cultural Value Dimensions. Journal of Applied Psychology, 95(5), 1-35.

Taylor, S. E., Sherman, D. K., Kim, H. S., Jarcho, J., Takagi, K., \& Dunagan, M. S. (2004). Culture and Social Support: Who Seeks It and Why? Journal of Personality and Social Psychology, 87(3), 354-362.

Thomson Reuters. (n.d). Overview. Retrieved from the answer company Thomson Reuters: financial.thomsonreuters.com.

Tihanyi, L., Griffith, D. A., \& Russell, C. J. (2005). The Effect of Cultural Distance on Entry Mode Choice, International Diversification, and MNE performance: A Meta-Analysis. Journal of International Business Studies, 36(3), 270-283.

Triandis, H. C. (1989). The Self and Social Behavior in Differing Cultural Contexts. Psychological Review, 96(3), 506-520.

Triandis, H. C., Bontempo, R., Villareal, M. J., Asai, M., \& Lucca, N. (1988). Individualism and Collectivism : Cross-Cultural Perspectives on Self-Ingroup Relationships. Journal of Personality and Social Psychology, 54(2), 323-338.

Tseng, J.-J., \& Chou, P.-H. (2011). Mimetic isomorphism and its effect on merger and acquisition activities in Taiwanese financial industries. The Service Industries Journal, 31(9), 1451-1469.

Ueno, S., \& Sekaran, U. (1992). The Influence of Culture on Budget Control Practices in the USA and Japan : A Empirical Study. Journal of International Business Studies, 23(4), 659-674.

United Nations Industrial Development Organization. (2015). Industrial Development Report 2016: The Role of Technology and Innovation in Inclusive and Sustainable Development. Vienna.

Venaik, S., \& Brewer, P. (2010). Avoiding uncertainty in Hofstede and GLOBE. Journal of International Business Studies, 41(8), 1294-1315.

Wagner, J. A. (1995, February). Studies of Individualism-Collectivism : Effects on Cooperation in Groups. Academy of Management Journal, 38(1), 152-172.

Weber, Y., Oded, S., \& Raveh, A. (1996). Natioanl and corporate cultural fit in mergers/acquisitions: An exploratory study. Management Science, 1215-1228.

Werner, S., Brouthers, L. E., \& Brouthers, K. D. (1996). International Risk and Perceived Environmental Uncertainty: The Dimensionality and Internal Consistency of Miller's Measure. Journal of International Business Studies, 27(3), 571-587.

Westphal, J. D., Seidel, M.-D. L., \& Stewart, K. J. (2001). Second-order Imitation: Uncovering Latent Effects of Board Network Ties. Administrative Science Quarterly, 46(4), 717-747. 
Wilson, K., \& Veuger, S. (2017). Information Frictions in Uncertain Regulatory Environments : Evidence From U.S. Commercial Banks. Oxford Bulletin of Economics and Statistics, 79(2), 205-233.

Wisniewski, M. (2006). Quantitative Methods for Decision Makers. London: Pearson Education Ltd.

Xia, J., Tan, J., \& Tan, D. (2008). Mimetic Entry and Bandwagon Effect: The Rise and Decline Of International Equity Joint Venture in China. Strategic Management Journal, 29(2), 195-217.

Xie, E., Reddy, K., \& Liang, J. (2017). Country-specific determinants of cross-border mergers and acquisitions: A comprehensive review and future research directions. Journal of World Business, 52(2), 127-183.

Xie, W., \& White, S. (2006). From imitation to creation: the critical yet uncertain transition for Chinese firms. Journal of Technology Management in China, 1(3), 229-242.

Xie, Z., \& Li, J. (2017). Selective imitation of compatriot firms: Entry mode decisions of emerging market multinationals in cross-border acquisitions. Asia Pacific Management Journal, 34(1), 47-68.

Xu, D., \& Shenkar, O. (2002). Institutional Distance and the Multinational Enterprise. The Academy of Management Review, 27(4), 608-618.

Xu, D., Pan, Y., \& Beamish, P. W. (2004). The Effect of Regulative and Normative Distances on MNE Ownership and Expatriate Strategies. Management International Review, 44(3), 285-307.

Yang, M. (2015). Ownership participation of cross-border mergers and acquisitions by emerging market firms: Antecedents and performance. Management Decision, 53(1), 221-246.

Yang, M., \& Hyland, M. (2006). Who do Firms Imitate? A Multilevel Approach to Examining Sources of Imitation in the Choice of Mergers and Acquisitions. Journal of Management, 32(3), 381-399.

Yang, M., \& Hyland, M. (2012). Similarity in Cross-border Mergers \& Acquisitions: Imitation, Uncertainty and Experience among Chinese Firms, 1985-2006. Journal of International Management, 18(4), 352-365.

Yao, S., \& Liang, H. (2017). Firm location, political geography and environmental information disclosure. Journal of Applied Economics, 49(3), 251-262.

Yeganeh, H. (2011). A generic conceptualization of the cultural distance index: Application to Schwartz's and Hofstede's frameworks. Journal of Strategy and Management, 4(4), 325-346. 
Yeniyurt, S., \& Townsend, J. D. (2003). Does culture explain of new products in a country? : An empirical investigation. Internatioanl Marketing Review, 20(4), 377-396.

Yiu, D., \& Makino, S. (2002). The Choice between Joint Venture and Wholly Owned Subsidiary: An Insitutional Perspective. Organization Science, 13(6), 667-683.

Zaheer, S. (2004). Overcoming the Liability of Foreigness. The Academy of Management Journal, 44(3), 285-307. 